The Canadian Mineralogist

Vol. 43, pp. 1921-1958 (2005)

\title{
THE STRUCTURE OF SILICATE MELTS: A GLASS PERSPECTIVE
}

\author{
GRANT S. HENDERSON ${ }^{\S}$ \\ Department of Geology, The University of Toronto, 22 Russell Street, Toronto, Ontario M5S 3B1, Canada
}

\begin{abstract}
Glasses are widely used as analogues for the study of silicate melts. Although they are solid materials, their structure is inherently complex and difficult to study. However, progress has been made in elucidating this structure, its relationship to composition, and how it behaves at high temperatures and pressures. Recent research has brought to light some new findings with important implications for natural melts. These include the observation that the structure is dependent upon the type and size of alkali or alkaline-earth cations incorporated into the glass network, with Li behaving very differently than other alkali cations. In addition, the presence of more than one type of alkali cation can cause non-linear physical behavior. Elements such as $\mathrm{Al}, \mathrm{Ti}$ and $\mathrm{Fe}$, which play important roles in petrological phenomena, can exhibit coordination environments (e.g., 5-fold) or polyhedral arrangements (e.g., triclusters) that are not common in crystalline phases. Furthermore, polyamorphic phase-transitions may occur at high temperature and pressures; the application of new theoretical models like mean field-constraint hypothesis suggests that several glass phenomena, and probably melt phenomena as well, may be related to stress-rigid to floppy transitions. The state of understanding of glass structure, although still rudimentary relative to crystalline materials, has grown exponentially over the last few decades, often with geological researchers at the forefront.
\end{abstract}

Keywords: melts, structure, glasses, petrology, spectroscopy, behavior, model.

\section{SOMMAIRE}

On se sert couramment des verres pour étudier les bains fondus silicatés. Quoiqu'ils sont des matériaux solides, leur structure est naturellement complexe et difficile à étudier. Toutefois, des progrès ont été faits dans l'étude de cette structure, sa relation à la composition, et son comportement à températures et pressions élevées. Les projets de recherche récents font ressortir les implications importantes aux bains fondus naturels. A titre d'exemple, la structure dépendrait de la sorte et la taille d'ion alcalin ou alcalino-terreux qui se trouve incorporé dans le réseau du verre. Le Li se comporte de façon très différente des autres alcalins. De plus, la présence de plus d'une sorte d'alcalin peut causer des comportements physiques non-linéaires. Les élements tels Al, $\mathrm{Ti}$ et $\mathrm{Fe}$, dont l'importance pétrologique est évidente, peuvent adopter une coordinence inhabituelle, cinq par exemple, et un arrangement polyédrique, des groupements par trois, par exemple, qui ne sont pas communs dans les phases cristallines. De plus, des transitions de phases polyamorphiques pourraient avoir lieu à températures et à pressions élevées. L'application de nouveaux modèles théoriques, par exemple le modèle de contrainte moyenne du champ, fait penser que plusieurs phénomènes impliquant les verres, et tout probablement les bains fondus, pourraient résulter de transitions de matériau rigide face aux contraintes à matériau déformable. Quoique les connaissances de la structure du verre sont rudimentaires en comparaison de celles des matériaux cristallins, les connaissances ont augmenté exponentiellement au cours des dernières décennies, souvent grâce aux découvertes de chercheurs oeuvrant dans le domaine des sciences de la Terre.

Mots-clés: bains fondus, structure, verres, pétrologie, spectroscopie, comportement, modèle.

\section{INTRODUCTION}

Magmas are generally considered to be mixtures of silicate melt, crystalline products and evolved fluids and gases. The melt phase is widely acknowledged to play an important role in igneous processes ( $c f$. Stebbins et al. 1995, and references therein, Mysen 2003) because the physical and chemical behavior of natural magmas is related to melt structure. Thus, styles of volcanic eruption are dependent upon the viscosity of the erupting magma, and the viscosity is directly related to the structure of the melt within the magma.

Over the last 25 years, investigators have predominantly used glasses as proxies for silicate melts. Whereas in situ studies of melts are most desirable, it is easier to use quenched melts or glasses as analogues. This is because glasses are considered to have structures that resemble the liquid state, and as glasses are solid,

$\S \quad$ E-mail address: granth@geology.utoronto.ca 
experimental data can be extracted more easily (e.g., at room temperature) than from molten analogues. As a benefit from this approach, not only has the understanding of melt structure improved, but so has understanding of the structure of glasses. Conversely, there has also been a tendency in the geological sciences (1) to interpret experimental data obtained from glasses in terms of concepts more typical of ordered materials, and (2) to probe the structure of glasses that have geologically relevant compositions, but for which the structure is complex. This has occurred because geological researchers are generally more familiar with crystalline materials, such as minerals, than amorphous materials like glasses. Despite these misgivings, research on melt structure using glasses has come a long way, but one should always remember that after $\sim 75$ years of intensive research, there remains no consensus on the structure of $\mathrm{SiO}_{2}$ glass, a compositionally simple material.

Here, I review some simple concepts about melt structure from a glass perspective, rather than from a geological one, and bring to the attention of the geological community some recent results based on glass-structure studies that have important implications for geological melts.

\section{Glass AND the Glass Transition}

Glasses are solid amorphous materials that lack long-range order and are non-crystalline (the term "solid" refers to a rigid material that does not flow when subjected to a moderate applied stress). Glasses have been cooled to the solid state, have not crystallized and are said to exhibit the glass transition, which is essential for any amorphous material to be defined as a "glass"; without the glass transition, the material is amorphous but not a glass. The glass transition is characterized by a sudden change in thermodynamic properties (e.g., heat capacity) from crystal-like to liquid-like values, with changing temperature. The temperature of the transition is called the glass (transition) temperature (Wong \& Angell 1976). However, a single temperature, as suggested by the above definition, does not necessarily denote the glass transition. It is more accurate to refer to a temperature region or interval in which the transition between liquid-like and solid-like behavior takes place. This region, however, is narrow and generally represented by a single "glass-transition temperature" $\left(\mathrm{T}_{\mathrm{g}}\right)$. Figure 1 is a plot of enthalpy and heat capacity $\mathrm{C}_{\mathrm{p}}$ (the derivative of the enthalpy; $\mathrm{C}_{\mathrm{p}}=\mathrm{dH} / \mathrm{dT}$ ) versus temperature for two different heating and cooling rates. $T_{g}$ is defined as some characteristic point on the heating or cooling curve. In Figure 1b, it is the point extrapolated from the rapid increase in $\mathrm{C}_{\mathrm{p}}$. Alternatively, it could also be defined as the extrapolated point of intersection in the enthalpy versus $\mathrm{T}$ plot. The precise temperature at which $\mathrm{T}_{\mathrm{g}}$ occurs depends on many factors, such as cooling rate and glass composition. Different authors may use different criteria for defining $\mathrm{T}_{\mathrm{g}}$. For example, Stevenson et al. (1995) defined $\mathrm{T}_{\mathrm{g}}$ as the maximum in the $\mathrm{C}_{\mathrm{p}}$ versus $\mathrm{T}$ curves. Consequently, it is generally convenient to define the glass transition as the point at which the viscosity of the glass reaches $10^{13}$ poise. A complete overview of the glass transition is well beyond the scope of this paper; a more in-depth discussion of $\mathrm{T}_{\mathrm{g}}$ is given in Moynihan (1995).

\section{ORDER IN GLASSES}

The forces linking atoms in a glass or vitreous material are the same as those in crystalline materials (Zachariasen 1932). Therefore, glasses must also form extended three-dimensional structures, but lack the periodicity and symmetry of crystalline materials and consequently are disordered (cf. Fig. 2). The structure of a crystalline material can be defined by its unit cell, lattice type, symmetry and atom positions. For a glass, this is not the case. There is no lattice, no translational symmetry, and the "unit cell" can be considered as infinite in size. Consequently, the structure of a glass must be defined using an approach other than that employed for crystalline materials.

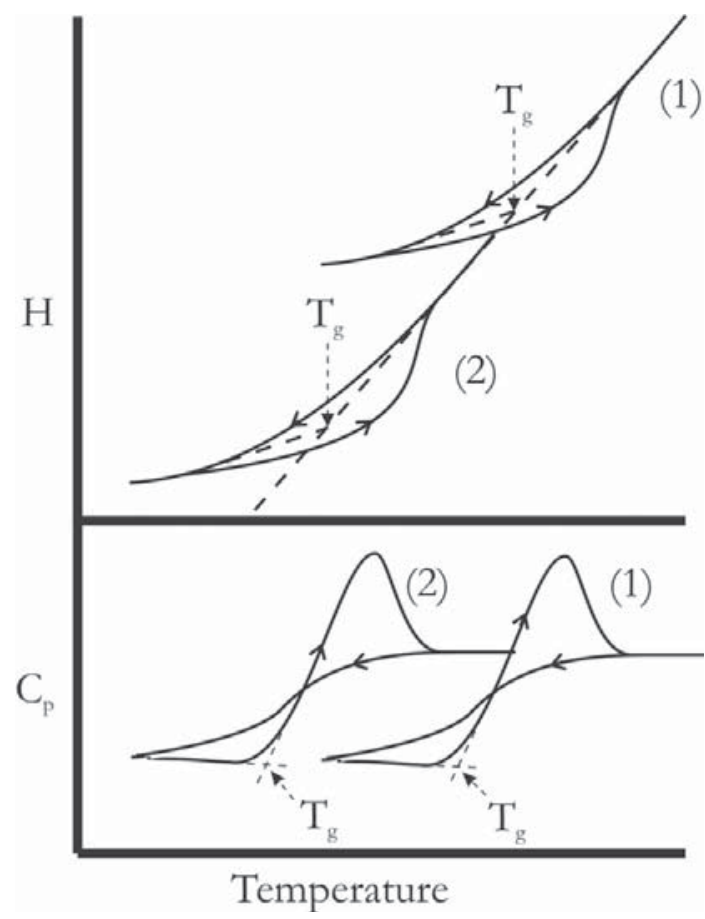

Fig. 1. Plot of the enthalpy $(\mathrm{H})$ and the heat capacity $\left(\mathrm{C}_{\mathrm{p}}\right)$ versus temperature during cooling and reheating at two different rates ( 1 and 2$)$. The glass transition $\left(\mathrm{T}_{\mathrm{g}}\right)$ is indicated on both sets of curves (after Moynihan 1995). 


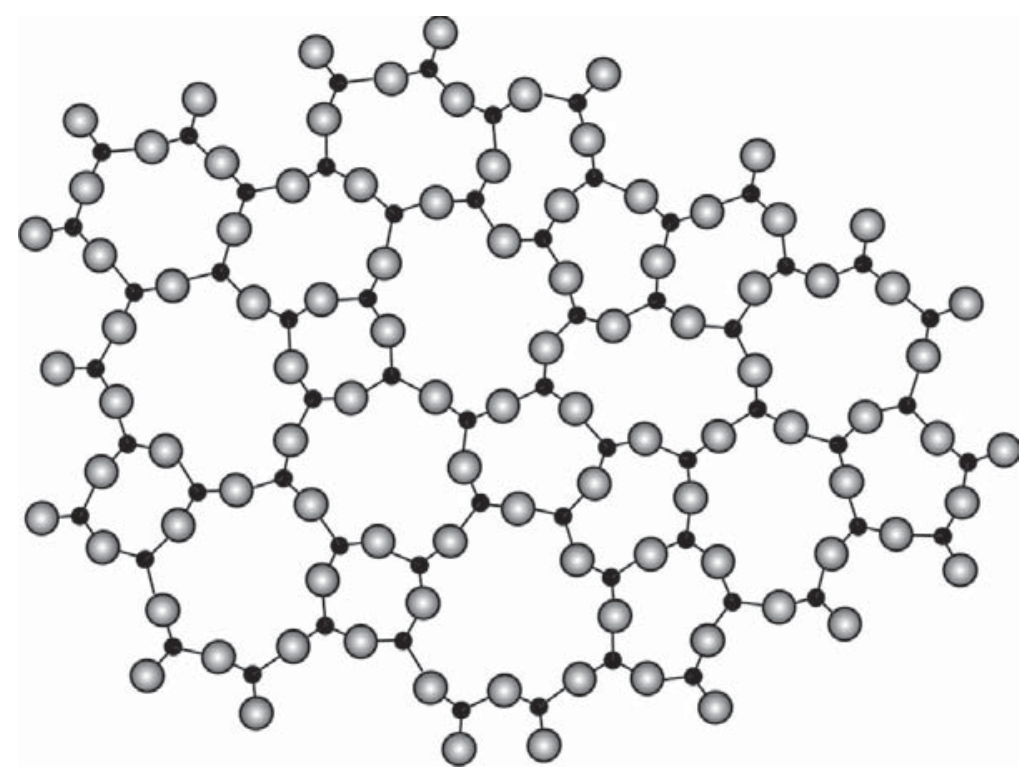

FIG. 2. A two-dimensional glass network of composition $A_{2} \mathrm{O}_{3}$ (after Zachariasen 1932). Dark circles are $A$ atoms and light circles are $\mathrm{O}$ atoms. Note that the network is fully connected with all $\mathrm{O}$ atoms being shared between $2 A$ atoms. In addition, different sized rings can be observed.

One of the most common ways of defining the structure of glasses is to use concepts of order. However, unlike crystalline materials, the presence of order in glasses cannot be precisely defined. As will be evident later, this is a common "limitation" when dealing with these materials. The limited structural information that one can extract from a glass is commonly not well defined and open to multiple interpretations. Glass structure is usually described in terms of the amount of order that can be observed using experimental techniques, and by characterization of the structural units responsible for the order. In $\mathrm{SiO}_{2}$ glass [or vitreous $\left.\mathrm{SiO}_{2}\left(\mathrm{v}-\mathrm{SiO}_{2}\right)\right]$, the basic structural building block is the same as that of crystalline silicates: the $\mathrm{SiO}_{4}$ tetrahedron (Mozzi \& Warren 1969). The degree of order is usually interpreted in terms of three structural ranges: short, intermediate or median (medium), and long-range order ( $c f$. Fig. 3). The definition of each of these types of order is somewhat arbitrary, with different authors using different criteria to define them. Wright (1994) defined four ranges of order: (I) the structural unit, (II) the interconnection of adjacent structural units, (III) the network topology (medium-range order), and (IV) long-range fluctuations in density (long-range order). The parameters that define the first two ranges of order defined by Wright (1994) are generally grouped under short-range order. However, subdivision of short-range order more clearly defines the boundary between the levels of order that differentiate a crystal from a glass.

\section{Short-range order (Range I and II)}

Short-range order (SRO) encompasses the region of the first coordination sphere and nearest neighbors (Wright 1990). This is generally represented by a structural building block that commonly has a radial distance up to $2 \AA$. Glasses definitely experience some degree of short-range order. As will be seen later, the structural unit of $\mathrm{v}-\mathrm{SiO}_{2}$ and silicate glasses is the $\mathrm{SiO}_{4}$ tetrahedron (Mozzi \& Warren 1969, Bell \& Dean 1972, Gerber \& Himmel 1986). Having determined that this is the basic building block for $\mathrm{Si}$-containing oxide glasses, short-range order can be characterized further by several parameters (Wright 1990). These are: $d$, the bond length, $\phi$, the tetrahedral bond-angle, $\alpha$, the intertetrahedral or dihedral bond-angle (bridging oxygen bond-angle), $\delta_{1}$ and $\delta_{2}$, the bond-torsion angles, and $\mathrm{N}$, the coordination number. Here, the bond length (d), tetrahedron angle $(\phi)$, and the coordination number (n) define the tetrahedron (range I), and the intertetrahedron bond-angle $(\alpha)$, the dihedral angle, and the bond-torsion angles $\left(\delta_{1}, \delta_{2}\right)$ define the linkage between individual tetrahedra (range II).

For silicate glasses, the parameters defining the tetrahedron are highly constrained and show little variation from glass to glass. Consequently, there is little difference between $\mathrm{a} \mathrm{SiO}_{4}$ tetrahedron in a glass and a crystal. However, the parameters that define the way in which individual tetrahedra are linked together are highly vari- 
able (Mozzi \& Warren 1969). The wide variation in $\alpha$, $\delta_{1}$ and $\delta_{2}$ distinguishes a glass from its corresponding crystalline analogue. It is with the interconnection of adjacent tetrahedra that disorder begins.

\section{Intermediate-range order}

Intermediate- or median-range order (IRO) generally extends beyond adjacent tetrahedra to a radial distance of 10-20 $\AA$ (Wright 1990). The maximum limit of IRO coincides with the maximum range of order that is observed by direct structural probes such as neutron and X-ray scattering. Structural features that can be recognized in this region, like rings, involve the way in which the tetrahedra are linked together. The majority of investigations of glass structure today are directed toward determination of the structure in this range, as well as its spatial relationship with surrounding structure.

\section{Topology}

The structure defined by the short- and intermediate-range order can also be described in terms of topological concepts, where the topology describes the interconnections between atoms (see later) making up the structure of the glass. Topology is defined in terms of the following parameters: connectivity $(\mathrm{C})$, connection mode $(\gamma)$, and decoration (i). Decoration is the

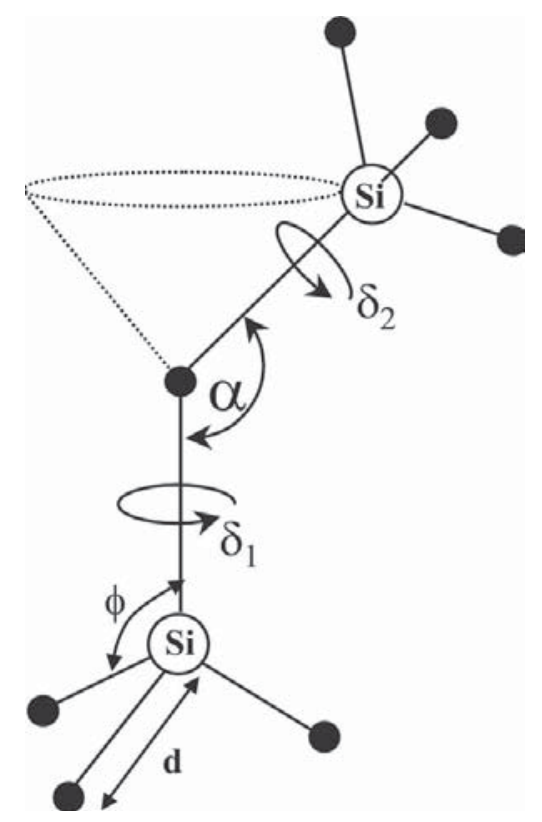

FIG. 3. A schematic representation of the parameters that define short and intermediate- or median-range structure in a glass. concept of using a basic topological structure that can then be decorated to represent a number of different glasses (Wright et al. 1991a). A two-dimensional structure is defined in Figure 4a and shown with two types of possible decorations in $4 b$ and $4 c$. In Figure $4 b$ the decoration is monatomic, where the centers of the triangles are replaced by single atoms, whereas Figure $4 \mathrm{c}$ has diatomic decorations where the centers of the triangles are replaced with two-dimensional analogs of tetrahedra.

Connection mode is the number of atoms that two adjacent structural units share between one another (Wright et al. 1991a). In Figure 4c, it can be seen that each pair of adjacent triangles shares only one corner atom. Therefore, this structure has $\gamma=1$. In three dimensions, any two tetrahedra will also share only one corner atom with each other, and $\gamma$ will remain 1 .

Connectivity is the number of atoms in each structural unit that are shared with other units. In Figure 4c, the basic structural unit is a two-dimensional analogue of the tetrahedron, i.e., a triangle. It is obvious that for each triangle, all three atoms at the corners are shared by another triangle. Thus for the two-dimensional structure, $\mathrm{C}=3$. A similar arrangement in three dimensions with tetrahedra would give $\mathrm{C}=4$.

One of the most common intermediate-range structures observed in silicate glasses, as will be seen later, is a ring of $\mathrm{SiO}_{4}$ tetrahedra (Figs. 4, 5). They are seen in both crystalline and random structures. In two dimensions, rings are a sequence of triangles connected at their vertices. A primitive (minimal) ring is one that is not divided by another path; i.e., any two vertices in a ring cannot be joined through a shorter path (Marians \& Hobbs 1990). In Figure 5, minimal path rings clearly stand out as the white spaces that are surrounded by black triangles. It is these primitive rings that must be counted in analyzing the ring statistics of an amorphous structure (Guttman 1990).

In Figure 5, there are 5-, 6-, and 7-membered rings, which appear as 5-, 6-, and 7-sided white polygons. It can be shown geometrically that any random twodimensional network of corner-sharing triangles will have an average ring-size of 6 (Marians \& Hobbs 1990). However, in three-dimensional structures, rings become more complex and are more difficult to visualize.

\section{Long-range order}

In long-range order (LRO), one considers larger groupings of structural units than those observed in intermediate-range order, particularly the periodic and symmetric arrangements of these groupings. Features of long-range order occur at scales greater than 10-20 $\AA$ and essentially imply a definite crystalline structure. Consequently, glasses do not exhibit long-range structural order or periodicity (Narten 1972, Bell \& Dean 1972). However, it is possible to recognize long-range fluctuations in density in a glass if it becomes phase- 
separated into two glasses that have slightly different structures. Consequently, care must be taken to recognize cases where authors are referring to long-range periodicity or structural variations versus fluctuations in physical properties induced by the formation of structurally different phases.

\section{Hypotheses on Glass Structure}

Having outlined the degree of order that can be recognized in a glass, one must now apply some sort of structural hypothesis in interpreting how the various degrees of order are linked spatially, as well as how they respond to changes where different types of atoms are present. Hypotheses of glass structure have traditionally been divided into the continuous randomnetwork model (Zachariasen 1932, Warren 1934), and the crystallite model (Lebedev 1921, Randall et al.

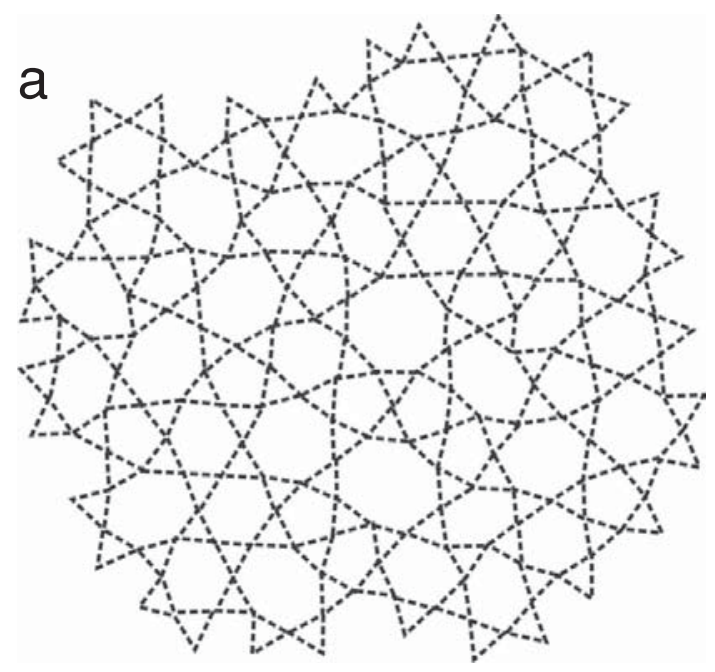

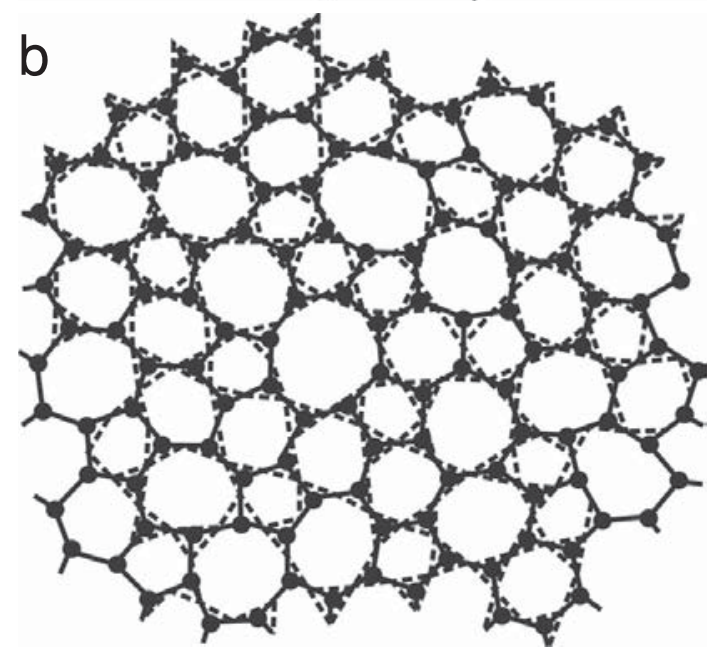

1930), or some variation on one or the other, or both. In the random-network hypothesis, one considers glasses to be formed of a continuous, randomly linked threedimensional network (Zachariasen 1932). With the crystallite model, one considers glasses to consist of discrete regions of crystalline-like structure separated by regions of disorder (Randall et al. 1930). Differences between the continuous random-network and the crystallite hypotheses have become somewhat blurred, the two hypotheses differing only in their degree of local order (Wright et al. 1982). Authors of studies on most recent glass structure do not invoke the crystallite model, but use instead some type of random-network model (see below).

\section{Crystallite model}

The crystallite model was first proposed by Lebedev (1921) and later supported by the experiments of Randall et al. (1930). According to Porai-Koshits (1990), in the original hypothesis, Lebedev claimed that the structure of glass consists of an accumulation of microcrystallites in a disordered medium. However, the results of Randall et al. (1930) revealed that the range of atomic order must be limited to approximately 10 $\AA$, and consequently the term crystallite was proposed (Porai-Koshits 1990). These crystallites have the same structure as a normal crystalline lattice, but are only 8-15 $\AA$ in diameter, corresponding to only a few unit cells (Vogel 1971). The crystallites have sharp boundaries and are considered to make up $80 \%$ of the glass

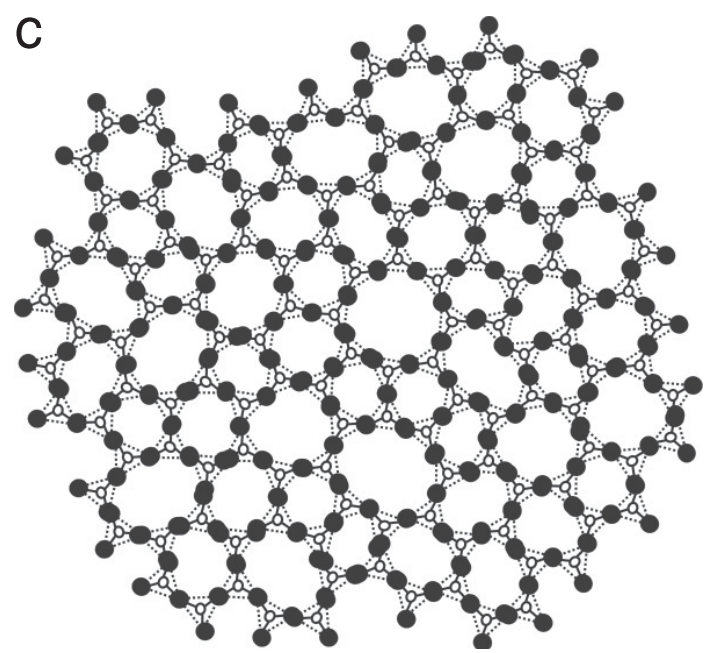

FIG. 4. Fully connected networks exhibiting different decoration (after Wright et al. 1991a). 


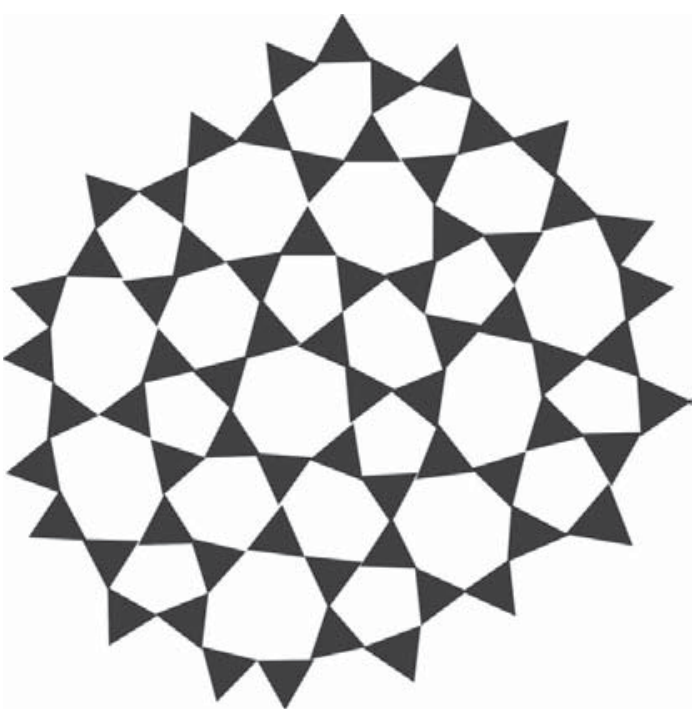

FIG. 5. A two-dimensional network showing different sized rings with minimal ring paths appearing as white space (after Marians \& Hobbs 1990).

structure, with the remainder being totally random (Porai-Koshits 1958).

Over time, it was recognized that the original crystallite model no longer applied (Evstropyev \& Porai-Koshits 1972), and it was modified to incorporate various amorphous cluster and packing models, such as cubic close-packed polyhedral structures (Gaskell 1975), pentagonal dodecahedra (Robinson 1965, Herms \& Steill 1980), cluster models (Phillips 1982), and strained mixed cluster hypothesis (Goodman 1975, 1985). Such amorphous cluster models appear to correlate with the structure of some metallic glasses (Gaskell 1975), but have shortcomings when applied to oxide glasses. In addition, it is very important that care be taken in interpreting the term "cluster", as used in the context of the structure of a glass. In many recent papers, the term is used correctly, to mean a "close group" or "bunch of smaller things". However, implicit in the use of the term is that the glass structure can be described by one of the cluster hypotheses noted above, but in most cases, this is not what had been intended by authors using this term. It is important that the intended connotation of the term "cluster" be explicitly explained by authors, particularly given that if "clusters" are present in a glass, they must consist of only a few atoms.

This situation exists because Porai-Koshits (1958) observed that silica gels, which consist of discrete $10 \AA$ particles within a homogeneous medium and can therefore be considered a model for the crystallite hypothesis, show small-angle X-ray scattering (SAXS). Indeed, it can be shown both theoretically and experimentally that a material that has clusters of ordered regions on the scale of 8-15 ̊ should exhibit SAXS. However, no such scattering has ever been observed in oxide glasses. Currently, adherents to the crystallite hypothesis for glass structure view the crystallites as regions of order, where the center of the region is the most regular and is very much like that of crystals. The regularity of the crystal-like lattice then decreases away from the center to produce highly disordered intermediate regions (Vogel 1971, Goodman 1985).

As noted above, this glass-structure hypothesis has generally been superseded in recent years by some type of random-network hypothesis. However, it should be noted that comparison of glass structures and crystal structures remains highly valuable for interpreting experimentally derived data on glass, as the short- and intermediate-range structure of many glasses can be shown to be similar to compositionally equivalent crystalline phases (Gaskell 1995).

\section{The continuous random-network (CRN) model}

The continuous random-network (CRN) model was proposed by Zachariasen (1932) and was experimentally supported by Warren (1934). Zachariasen postulated that oxide glasses are formed by an extended three-dimensional interconnected network that lacks symmetry and periodicity ( $c f$. Fig. 2). Further, certain conditions must be met in order to form such a network. For an oxide glass of composition $\left.\mathrm{A}_{m} \mathrm{O}_{n}, 1\right)$ Each $\mathrm{O}$ atom must be linked to no more than two $A$ atoms; the coordination number (n) of $\mathrm{O}$ must be less or equal to 2. 2) The number of $O$ atoms surrounding an $A$ atom must be small; the coordination number of $A$ must be low. 3) The polyhedra so formed must share corners, not edges or faces; $\gamma$ equals 1. 4) For three-dimensional networks, at least three corners in each polyhedron must be shared; $\mathrm{C}$ must be greater or equal to 3 .

This does not mean that materials that fail to meet the above criteria cannot form glasses. If the above criteria are met, however, the conditions for glass formation are favorable.

Under Zachariasen's conditions, the basic structural units of a $\mathrm{SiO}_{2}$ glass network are tetrahedra that are linked by sharing corner oxygen atoms. Shared corner oxygen atoms are called bridging oxygen (BO) atoms and are shared between two adjacent atoms of silicon. Oxygen atoms that are bonded to only one tetrahedrally coordinated cation are termed non-bridging oxygen (NBO) atoms. Non-bridging oxygen atoms disrupt the connectivity of the network of $\mathrm{SiO}_{2}$ tetrahedra. A glass made up of tetrahedra with no NBO has the general formula $\mathrm{TO}_{2}$. Zachariasen (1932) also realized that glasses rarely have pure diatomic compositions. The three-dimensional network may be modified by the addition of other cations, such as alkalis and alkaline earths. The effect of these cations of general composi- 
tion $B_{n} \mathrm{O}$ is to disrupt the continuous three-dimensional network by breaking bridging oxygen bonds. The chemical formula then becomes $A_{m} B_{n} \mathrm{O}$, where $m$ and $n$ represent the average number of $A$ and $B$ atoms per $\mathrm{O}$, respectively. Glasses of $A_{m} B_{n} \mathrm{O}$ compositions will form if the repulsive forces between the $A$ and $B$ atoms are small, that is, if the distances between the $A$ and $B$ atoms are large and the charge on atom $B$ is small. The $\mathrm{O}$ atoms introduced with the network modifiers attach themselves to only one network former, creating non-bridging oxygen atoms within the structure (Vogel 1971). These non-bridging oxygen atoms produce holes, which the $B$ cations then occupy.

Cations that are tetrahedrally coordinated (i.e., Si, $\mathrm{B}, \mathrm{P}, \mathrm{Ge}$ and As) make up the network and are termed network formers. In higher coordinations, cations are network modifiers. These cations (i.e., $\mathrm{Na}, \mathrm{K}, \mathrm{Ca}$ and $\mathrm{Ba}$ ) modify the network by interrupting the connectivity of the network of tetrahedra and creating non-bridging oxygen atoms. Interstitial atoms occupy holes within the framework of tetrahedra without modifying its connectivity (Hawthorne 1992). Some cations (i.e., $\mathrm{Na}$ and $\mathrm{Ca}$ ) may be network modifiers or interstitial atoms, and both the network modifiers and interstitial cations can also be referred to as charge-compensating cations. According to Zachariasen's rules, network formers generally have coordination numbers of 3 or 4 , whereas modifiers have $\mathrm{n}$ greater or equal to 6 . Some cations, such as $\mathrm{Al}, \mathrm{Fe}$ and $\mathrm{Ti}$, that may have coordination numbers of 4 or 6 , act as either network formers or network modifiers and are termed intermediate oxides. However, more recent studies have indicated that cations such as $\mathrm{Al}$ and $\mathrm{Fe}$ prefer to act as network formers (see later).

The Zachariasen-Warren model for $\mathrm{SiO}_{2}$ glass can be summarized as follows. The structure consists of an interconnected network of $\mathrm{Si}$ atoms bonded to oxygen atoms in a tetrahedral configuration, with individual tetrahedra linked together through sharing of the corner bridging oxygen atoms. There are narrow unimodal distributions of the $\mathrm{Si}-\mathrm{O}$ bond length and the $\mathrm{O}-\mathrm{Si}-\mathrm{O}$ bond angles, which peak at $1.61 \AA$ and $109.5^{\circ}$, respectively. The model has a broad unimodal distribution of Si-O-Si angles $(\alpha)$ that peaks at $144 \AA$ (see below). There is no correlation among $\mathrm{Si}-\mathrm{O}$ bond lengths, $\alpha$, and $\phi$. The torsion angles $\left(\delta_{1}, \delta_{2}\right)$, are randomly distributed and uncorrelated with each other and with the $\mathrm{Si}-\mathrm{O}$ bond length, $\alpha$ and $\phi$. The model contains no morphological or crystalline long-range order, and the network has a connectivity of 4 , is continuous and chemically ordered. Furthermore, the structural parameters are statistically homogeneous (Galeener 1990).

Galeener (1988) highlighted some advantages and shortcomings of the Zachariasen-Warren model. Advantages are that some assumptions made over the entire model (i.e., statistical homogeneity) lead to mathematical simplifications, and the model fits diffraction data relatively well. Shortcomings include an inability to explain the existence of point defects observed in experimental $\mathrm{SiO}_{2}$ glass data; furthermore, some correlation among $\delta$, the $\mathrm{Si}-\mathrm{O}$ bond length, $\alpha$ and $\phi$ must exist for all rings of $T-\mathrm{O}$ bonds to close; dihedral angles are probably not randomly distributed, as regular rings are believed to exist (Galeener 1982).

The Zachariasen-Warren model of glass structure is a competent one in that the arrangement of atoms described is in agreement with the characteristic properties of glass. Although it was originally devised to explain oxide glasses, it has proven to be a comprehensive model and has been successfully applied to various non-oxide glasses such as $\mathrm{GeS}_{2}$ and $\mathrm{BeF}_{2}$ (Wright et al. 1982).

\section{Modified random-network (MRN) model}

This model has been developed from Zachariasen's CRN model in order to explain some experimental results obtained on alkali silicate glasses. The initial work by Warren \& Biscoe (1938) on sodium silicate glasses (see later) proved to be unsuccessful using the CRN model, in determining the relationship between the bridging and non-bridging oxygen atoms where modifying cations are present. Since then, there have been many studies and structural models designed to explain the structural role of a network modifier (such as $\mathrm{Na}$ ). Presently, the most widely accepted model was developed by Greaves and coworkers (Greaves et al. 1981, Greaves 1985). Greaves et et al. (1981) conducted an extended X-ray absorption fine structure (EXAFS) analysis to study the local structure of sodium silicate glasses with varying molar compositions. The data on Si EXAFS revealed that the structures of sodium silicate glasses remain relatively similar owing to the presence of common rigid $\mathrm{SiO}_{4}$ tetrahedra within the alkali silicate glass. Minor differences were observed in the EXAFS data and were attributed to the addition of network modifiers and the distribution of $\mathrm{Q}^{\mathrm{n}}$ species (see later). The Na EXAFS spectra showed a higher frequency of oscillations than the Si EXAFS, indicating that the $\mathrm{Na}-\mathrm{O}$ bond is longer than the $\mathrm{Si}-\mathrm{O}$ bond and that different bonding interactions are taking place.

Greaves (1985) developed a modified random network (MRN) glass structure to incorporate both the covalent bonding nature of the silicon network and the ionic interactions of the sodium atoms. The structure of sodium silicate glass was proposed to be a natural extension of the structure of crystalline silicates, with the interpenetration of two sublattices. This involves a random continuous covalent $\mathrm{SiO}_{2}$ network intercalated by an ionic fraction of the modifying cation component $\left(\mathrm{Na}_{2} \mathrm{O}\right)$. The non-bridging oxygen (NBO) atoms provide the structural link between the two sublattices by coordinating with the modifying cations. This results in local structural order of sodium around the non-bridging oxygen atoms. Figure 6 shows this partly covalent and partly ionic modified random-network model (MRN). The figure shows the clustering of sodium ions with 
the non-bridging oxygen atoms, thus resulting in the formation of percolation channels. Such percolation channels are supported by ionic and channel-diffusion measurements, such as those by Ingram (1987). However, molecular dynamic simulations by Sunyer $e t$ al. (2002) contradict the popular perception that these channels are static and are a result of the microsegregation of alkali ions (e.g., Vessal et al. 1992). Instead, they reported that the channels are of a more dynamic nature. However, care should be taken in interpreting their data, as their results are strongly dependent on the time parameter used in their calculations.

The CRN, MRN and crystallite hypotheses have all proven at one time or another to be successful to varying degrees in explaining how atoms may be linked together to form a glass network. The hypotheses differ mainly in the magnitude of fluctuations in the degree of local order. At the present time, the most widely accepted hypothesis is the MRN, as it agrees with most recent experimental studies. However, none of them address whether or not regions of crystalline topology occur

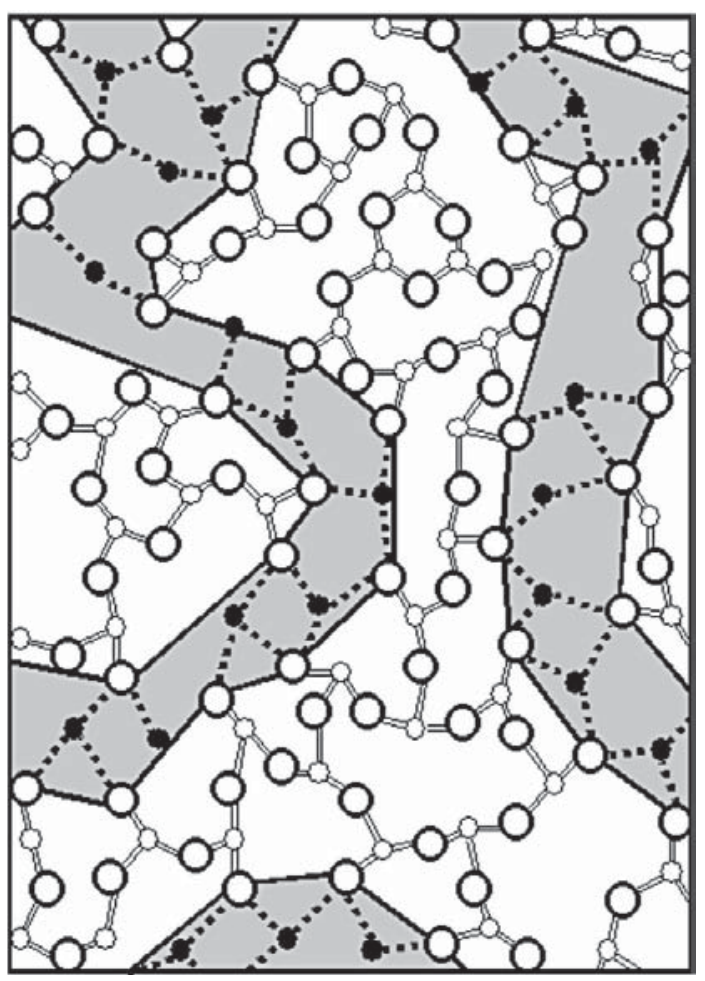

FIG. 6. A modified random network (MRN) for a "twodimensional" oxide glass. Covalent bonds are shown by solid lines, and ionic bonds, by dotted lines. Dark grey channels are the percolation channels that run through the network. Alkali: black atoms, silicon: small white atoms, oxygen: large white atoms (after Greaves 1985). more frequently than would be predicted by random statistics.

\section{Mean field-constraint model}

This is a topological model first proposed by Phillips (1979) and applied to chalcogenide glasses (containing Se and S: Boolchand et al. 2001a, b), then later expanded and modified by Thorpe (1983) for networks in general. It considers only the bond-force interactions as described by valence-force-fields (VFF) (two-body central forces associated with bond stretching and three-body non-central forces associated with bond bending) and Van der Waals interactions, and assumes that these interactions act as mechanical constraints on the glass network. One can then calculate the number of constraints as a function of average coordination number for an atom, as well as relate the number of constraints in interatomic force-field space with the number of degrees of freedom in real space.

In general, one can consider a glass network to be "constrained" to varying degrees. This leads to a description of the glass network in terms of the degree of connectivity based on the mean average coordination-number $(\overline{\mathrm{r}})$ and, from this, a description of the network in terms of degree of stiffness or rigidity. A random network will go from being easily deformable ("floppy") to a mechanical stiff ("rigid") state as the mean coordination number or network connectivity increases to a value of $\sim 2.40$. Glasses will essentially be polymeric in nature where $\overline{\mathrm{r}}$ is less than 2.4 and consist of extensive floppy regions with "islands" of more rigid regions. However, as $\overline{\mathrm{r}}$ increases, the rigid regions increase in volume to generate a rigid network with floppy islands and the network can be described as an amorphous solid (Thorpe 1983). The transition from floppy to rigid is continuous, with the rigid regions said to "percolate" through the network. The value of $\bar{r}$ at which the network undergoes the transition from floppy to rigid is termed $\bar{r}_{p}$ (its value is around 2.4, as above) and the network is said to undergo a rigidity percolation. To date, no relationship has been shown between percolation of the rigid regions and the percolation channels of the MRN.

This hypothesis has proven to be fairly robust in describing the physical behavior and glass-forming ability of chalcogenide glasses, and is now being applied to oxide glasses (Trachenko et al. 2004, Vaills et al. 2005). Furthermore, experimental data utilizing modulated differential scanning calorimetry (MDSC) and Raman optical elasticity support the theoretical basis for a floppy-to-rigid transition, and have shown that there is more than one transition ( $c f$. Feng et al. 1997, Selvanathan et al. 2000). For example, in ternary $\mathrm{Ge}_{x} \mathrm{As}_{x} \mathrm{Se}_{1-2 x}$ glasses at $\overline{\mathrm{r}}=2.40$, a second-order transition is observed from a floppy to unstressed rigid state, whereas at $\overline{\mathrm{r}}=2.52$, there is a further first-order transition from unstressed rigid to stressed rigid phase 
(Wang et al. 2000). The unstressed rigid phase is an intermediate phase ( $c f$. Thorpe et al. 2000), and the width $(\Delta \overline{\mathrm{r}})$ of the intermediate phase and order of the transition are related to the median-range order of the network (Micoulaut \& Phillips 2003). The identification of an intermediate phase provides new theoretical and experimental challenges for understanding the explicit nature of the behavior of glasses and offers exciting possibilities for explaining a number of phenomena such as phase separation and the behavior of density and viscosity.

The model is based on relatively simple theoretical concepts and clearly appears to have supportive experimental data for its application to real glasses. An interesting point to note is that the concept of a strained network and the need for such a network to relax as network modifiers are added to a glass had been suggested previously for germanate glasses from a purely experimental approach $(c f$. Henderson \& Wang 2002).

\section{The Structure of $\mathrm{SiO}_{2}$ Glass}

A number of experimental techniques are used to study the structure of glasses. Diffraction techniques are by far the most common to date, but in recent years, nuclear magnetic resonance (NMR), vibrational and $\mathrm{X}$-ray absorption spectroscopies are becoming widely used. A combination of all these techniques offers the best approach to obtaining information about the structure of a glass.

Traditionally, X-ray and neutron scattering (the term diffraction also is used although neither $\mathrm{X}$-rays nor neutrons coherently diffract from an amorphous material) have been the most widely used direct structural probes of glass structure. A glass sample is bombarded with X-rays or neutrons, and the manner in which they are scattered is monitored. The scattering gives information about the position of the atoms relative to each other. For crystalline samples, this usually leads to the identification of a unit cell, lattice type, and the positions of the atoms in the lattice, from which the extended structure can be solved. However, the nature of glasses does not allow such a structure solution. For amorphous materials, the lack of periodicity and symmetry would require that every atom in the structure be identified and their positions known with respect to the other atoms, in order to accurately determine the structure as a whole. However, useful structural information can be extracted from the scattering data. In particular, information about the short-range structure can be determined fairly easily, whereas insight into the intermediate-range order can be obtained by comparing the data on experimental scattering to theoretical or experimental data obtained from crystalline model compounds. It is somewhat of a trial-and-error method; if the data from the model compound do not correlate with those obtained from the experimental scattering, then the model must be wrong.
If the model fits the experimental data, then the model may, but not necessarily, describe the structure or parts of the structure accurately.

The data on experimental scattering are given in the form of a radial distribution function (RDF), $G(r)$, or a correlation function, $T(r)$, which is derived from the experimental interference-function, $Q i(Q)$. An alternative approach for multicomponent systems, which is favored in more recent studies, is to use the X-ray weighted Faber-Ziman or total structure-factor $S(k)$ (Faber \& Ziman 1965) (TSF). A more detailed review of this approach is given in Henderson (2002). These functions are one-dimensional representations of the three-dimensional structure of the glass. The experimental interference-function depends on the scattering vector, $Q$ (s or $k$ also are used), which is a function of the X-ray or neutron wavelength and the scattering angle. The radial distribution and the correlation functions can be thought of as probability functions that give the chances that the surface of a sphere of radius $(r)$ from some central atom will intersect other atoms. These functions are averages over the entire system. This is analogous to choosing every atom in the system as the central atom and calculating a radial distribution function (RDF) for each. Taking the average of the calculated RDF of every atom in the system would give the radial distribution function derived by experiment. Therefore, scattering experiments give information about the average structure of glasses and not the absolute structure. For this reason, it is possible that many different models can duplicate fairly accurately the results obtained by experiment. A successful model must reproduce all features of the experimental data, and if this is not the case, then only part of the model structure is correct.

Since radial distribution functions and correlation functions are one-dimensional, an interpretation must be made in order to extract three-dimensional information. The positions of the peaks indicate interatomic distances (Wong \& Angell 1976). For example, it is clear that the first two peaks in Figure 7 have maxima at approximately 1.6 and $2.6 \AA$, respectively. So one can conclude that the nearest-neighbor atoms have mean bond-distances of 1.6 and $2.6 \AA$, respectively. From the peak widths, bond-distance variations can be determined. Areas under the peaks are related to average coordination number (Zarzycki 1982). Generally, RDFs have tall sharp peaks at small radial distances and weak broad peaks at large radial distances. The structure at small radius (short range) thus is less variable than that at larger radial distances (intermediate range). From this type of experimental data, interatomic distances for different pairs of atoms can be determined for the short-range structure.

Silica $\left(\mathrm{SiO}_{2}\right)$ glass is the most extensively studied to date, its composition is simple, and its structure provides a useful basis against which the structure of other glasses can be compared. However, as noted in the 
introduction, one must remember that there remains no consensus concerning the exact nature of the structure of $\mathrm{SiO}_{2}$ glass. Whereas one group of researchers may prefer one structural model to another, there is by no means agreement as to the explicit structure of this glass. Having said this, researchers are in agreement with respect to some structural features.

\section{The $\mathrm{SiO}_{4}$ tetrahedron (short-range order)}

On the basis of experimental evidence, it is generally agreed that the tetrahedron is the basic structural unit of $\mathrm{SiO}_{2}$ glasses. Each $\mathrm{Si}$ atom is bonded to four $\mathrm{O}$ atoms, and each $\mathrm{O}$ atom is bonded to two $\mathrm{Si}$ atoms. This is determined from the fact that the ratio of bond distances of the three nearest peaks in the RDF of $\mathrm{SiO}_{2}$ glass is similar to that of crystalline silicates (Mozzi \& Warren 1969, Konnert \& Karle 1972). These tetrahedra generally have a well-defined tetrahedral angle $(\phi)$ of $109.5^{\circ}$ (Narten 1972), which is very close to the angle of a perfect tetrahedron at $109.47^{\circ}$ (Wright et al. 1982). It is also agreed that the tetrahedra are linked to each other through their corners in a manner similar to the connection between tetrahedra in crystalline $\mathrm{SiO}_{2}$ (Cartz 1964).

Whereas it is agreed that the tetrahedra share corners, there remains disagreement with regard to the intertetrahedral angle $(\alpha)$. This angle is an important parameter simply because it can be determined from the scattering data and gives some indication as to how the $\mathrm{SiO}_{4}$ tetrahedra are linked. This angle $\alpha$ exhibits a broad range of values from $\sim 120^{\circ}$ to $180^{\circ}$ (Henderson et al. 1984); Mozzi \& Warren (1969) determined a mean value around $144^{\circ}$. This value is the one commonly quoted in the geological literature on melts, partly because it is close to that found in most silicate minerals $\left(\sim 143^{\circ}\right)$. However, its value continues to be in dispute. Other values being suggested lie between $143^{\circ}$ to $\sim 153^{\circ}$ (Gladden 1990a). The average value $\alpha$ is usually calculated from the first and third peak of the RDF. Some authors assume that the average value of the intertetrahedral angle coincides with the peak value of the $\mathrm{Si}-\mathrm{Si}$ distribution, and since the $\mathrm{Si}-\mathrm{O}$ peak is relatively narrow and well defined, the $\mathrm{Si}-\mathrm{O}$ value is assumed to be constant. These authors simply calculate $\alpha$ through a simple trigonometric relation:

$$
\sin \frac{\alpha}{2}=\frac{r_{\mathrm{Si}-\mathrm{Si}}}{2 r_{\mathrm{Si}-\mathrm{O}}}
$$

with the calculated value being relatively high (da Silva et al. 1975, Konnert \& Karle 1973b).

Mozzi \& Warren (1969), however, felt that the average intertetrahedron angle must be extracted from a bond-angle distribution, $\mathrm{V}(\alpha)$, because the $\mathrm{Si}-\mathrm{Si}$ peak is partially overlapped on both sides by the adjacent peaks and also the Si-Si peak is ultimately dependent on strain energy (Galeener 1982). These authors therefore

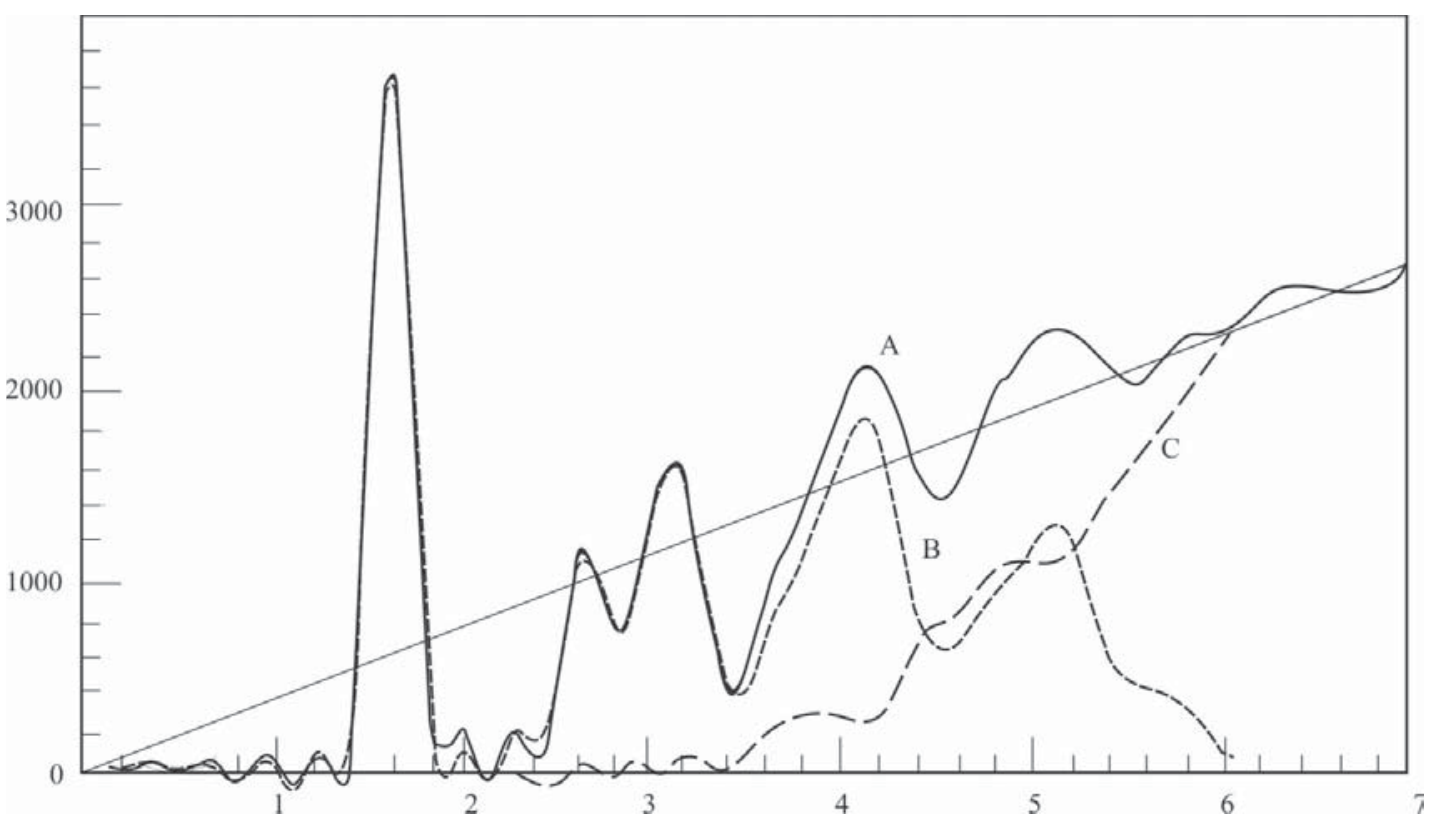

Fig. 7. Radial distribution function for $\mathrm{SiO}_{2}$ glass (curve A). The first peak represents $\mathrm{Si}-\mathrm{O}$ distances, the second, the $\mathrm{O}-\mathrm{O}$ distances, and the third, the Si-Si distances (after Mozzi \& Warren 1969). 
converted the $\mathrm{Si}-\mathrm{Si}$ peak into a probability distribution, $\mathrm{G}\left(\mathrm{r}_{\mathrm{Si}-\mathrm{Si}}\right)$, from which the $\mathrm{Si}-\mathrm{O}-\mathrm{Si}$ bond-angle distribution, $\mathrm{V}(\alpha)$, can be calculated. The value of the $\mathrm{r}_{\mathrm{Si}-\mathrm{O}}$ is again taken to be constant, and the distributions have the following relation:

$$
V(\alpha) \mathrm{d} \alpha \mathrm{G}\left(\mathrm{r}_{\mathrm{Si}-\mathrm{Si}}\right) \mathrm{dr}_{\mathrm{Si}-\mathrm{Si}}
$$

where

$$
\frac{\mathrm{dr}_{\mathrm{Si}-\mathrm{Si}}}{\mathrm{d} \alpha}=\mathrm{r}_{\mathrm{Si}-\mathrm{O}} \cos \left(\frac{\alpha}{2}\right)
$$

This method results in relatively low values of $\alpha$ (e.g., Mozzi \& Warren 1969). The problem arises over whether or not $\mathrm{G}(\mathrm{rSi}-\mathrm{Si})$ follows a simple Gaussian distribution (e.g., Leko 1993, Wright 1994), as well as whether or not the torsional angles $\mathrm{d}_{1}$ and $\mathrm{d}_{2}$ contribute to the shape of the distribution function.

It can probably be said that there is no dispute over the average intertetrahedral bond-angle, but rather over the methods used in its calculation. For example, da Silva et al. (1975) recalculated the data of Mozzi \& Warren (1969) using equation 1 . They also changed the $\mathrm{Si}-\mathrm{Si}$ peak distribution used by Mozzi \& Warren (1969) so that it would show a Gaussian distribution (Fig. 8a). However, Coombs et al. (1985) recalculated the data of da Silva et al. (1975) using equation 3 and showed that the change in the Si-Si peak distribution did not change the average value of $\alpha$, but the Gaussian distribution of $\mathrm{G}\left(\mathrm{r}_{\mathrm{Si}-\mathrm{Si}}\right)$ did give unrealistically low values of $\alpha(<$ $120)$, and $\mathrm{Si}-\mathrm{Si}$ distances greater than twice the $\mathrm{Si}-\mathrm{O}$ distance, $>3.2 \AA$ (Fig. 8b). Most recently, Tucker et al. (2005) obtained a Si-O-Si angle centered around $151^{\circ}$ based on reverse Monte Carlo modeling of neutronscattering data.

Nuclear magnetic resonance (NMR) spectroscopy has also been used to determine the $\mathrm{Si}-\mathrm{O}-\mathrm{Si}$ bondangle distribution. Smith \& Blackwell (1983) showed a good linear correlation between chemical shift and the secant of the $\mathrm{Si}-\mathrm{O}-\mathrm{Si}$ bond angle using different polymorphs of silica. A correlation between chemical shift and $\mathrm{Si}-\mathrm{Si}$ distance also was shown. Using this linear correlation, data from magic angle spinning NMR give a distribution function, $W(\bar{\beta})$, of the mean secant per Si tetrahedron. This can be converted to a distribution function, $X(\bar{\beta})$, of the secants of all $\mathrm{Si}-\mathrm{O}-\mathrm{Si}$ bond angles, where $\beta=\sec \alpha$. This distribution is then used to calculate $V(\alpha)$ via

$$
X(\beta)=V(\alpha) \frac{\mathrm{d} \alpha}{\mathrm{d} \beta}
$$

Dupree \& Pettifer (1984) and Farnan et al. (1992) used this method to determine the $\mathrm{Si}-\mathrm{O}-\mathrm{Si}$ bond-angle distribution. The model of Dupree \& Pettifer (1984) that gave the best agreement with experiment has a broad, symmetric $V(\alpha)$ distribution with nearly constant prob- ability over $140-155^{\circ}$, whereas Farnan et al. (1992) obtained a $V(\alpha)$ distribution from $\sim 130$ to $180^{\circ}$ for glass of $\mathrm{K}_{2} \mathrm{Si}_{4} \mathrm{O}_{9}$ composition, with a maximum at $143^{\circ}$ consistent with the data obtained by Mozzi \& Warren (1969) for $\mathrm{SiO}_{2}$ glass. However, Mauri et al. (2000) showed that the average $\mathrm{Si}-\mathrm{O}-\mathrm{Si}$ angle calculated from NMR spectra is not consistent with the distribution of Mozzi \& Warren (1969), but closer to a mean of $151^{\circ}$.

\section{Ring structures (intermediate-range order)}

For correlations beyond adjacent tetrahedra in silicate glasses, the tetrahedra make up ring structures (Cartz 1964, Bell \& Dean 1972, Gerber \& Himmel 1986) and it is these ring structures that constitute the medium- or intermediate-range structure. However, the exact nature of these ring structures is not well understood. Bell \& Dean (1972) considered glass structure to be composed of 4- and 5-membered rings, and to contain no rings of other sizes. Gerber \&
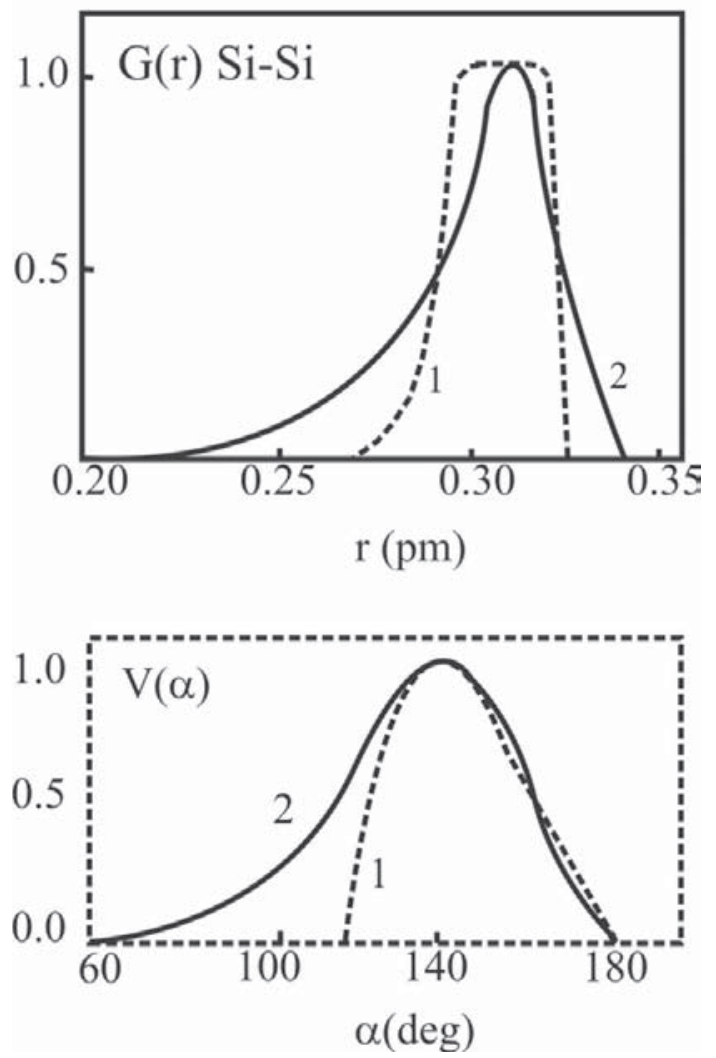

FIG. 8. a) Probability-distribution functions $\mathrm{Gr}(\mathrm{Si}-\mathrm{Si})$ and the corresponding intertetrahedral bond-distributions $[\mathrm{V}(\alpha)]$ calculated by (1) Mozzi \& Warren (1969), and that of da Silva (1975) calculated by (2) Coombs et al. (1985) (after Leko 1993). 
Himmel (1986) considered glasses to consist only of 6-membered rings. The model of Cartz (1964) included 5-, 6-, and 7-membered rings, with occasional 8membered rings present. All these models agree reasonably well with data on experimental scattering. In fact, almost any continuous network of corner-linked tetrahedra reproduces the first three major peaks in an RDF reasonably well (Bell \& Dean 1972).

Even the radial distance, over which some degree of intermediate-range order exists, is not well defined. Some investigators believe that experimental RDFs show no structure beyond the range of $\sim 8 \AA$ (Henderson et al. 1984). Others claim that peaks are observed in experimental RDFs well beyond the $7 \AA$ range (Gerber $\&$ Himmel 1986), and order persists to $10 \AA$ (Gaskell et al. 1991), whereas others, such as Konnert \& Karle (1973a), claim to have observed deviations from a uniform distribution of atoms out to $15-20 \AA$. It is not at all clear to what radial extent order can be recognized in silica glass. However, it is generally agreed that no order exists beyond $20 \AA$, as beyond this distance, the structure would approach the dimensions of crystallites capable of coherent diffraction or capable of producing discrete vibrational bands in Raman spectra.

\section{Structural models}

Glass structure is generally studied by comparing the experimentally derived data with some sort of model structure. The first of these were manually constructed ball and stick models. Presently, these model structures are generated numerically. Constraints such as density, temperature and interatomic potentials are provided, and the computer generates allowable configurations such that the more probable structures appear more often (Zarzycki 1982). This approach allows for a more systematic variation of parameters (Wright 1990). However, the models must address the entire range of order observed in glasses. Short-, intermediate-, and long-range order are all correlated and affect each other. Consequently, if a model fails over one range of order, it must be wrong (Wright et al. 1991b).

\section{Models based on a random network}

Bell \& Dean (1972) built a physically continuous random-network model of corner-linked tetrahedra using polystyrene spheres and steel wires. This is the best-known model based on the continuous randomnetwork hypothesis. It contains about 1000 atoms and was intended to approximate the Zachariasen-Warren $(\mathrm{Z}-\mathrm{W})$ model. However, as the model contains complete rings of bonds, there exist correlations among the $\mathrm{Si}-\mathrm{O}$ bond length, $\alpha, \phi, \delta$ that are not specified by the $\mathrm{Z}-\mathrm{W}$ model. In this respect, the Bell \& Dean model is more realistic than the Z-W model. Bell \& Dean revised their model until they had good agreement with experimental results. The best fit was found where $\alpha$ is equal to $153^{\circ}$ and the tetrahedra are arranged in 4- and 5-membered rings. The model was later refined by Gaskell \& Tarrant (1980), who found better agreement with experimental data if the Bell \& Dean model is "relaxed", with a value for $\alpha$ about $10^{\circ}$ lower than the original model. No 3membered rings were incorporated into the original Bell \& Dean model. Some authors believe that the model is too small, and not an accurate representation of a real system. Its small size implies that large proportions of the atoms are at the surface and are not properly bonded (Galeener 1988, Wright et al. 1991a).

Thorpe \& de Leeuw (1986) constructed $\mathrm{a} \mathrm{SiO}_{2}$ random network with periodic boundary conditions. A "supercell" was created that contains over 1500 atoms, and it was extended periodically in three dimensions. The model was then used to calculate the physical properties of the glass, and these were found to agree with experimental data. The model specifies elements of short- and intermediate-range order, such as rings, as well as correlations between angles. The long-range order of the model, however, is unrealistic owing to the periodicity of the supercell.

Sen \& Thorpe (1977) developed a central force model to study the vibrational excitations of $A X_{2}$ glasses such as $\mathrm{SiO}_{2}$. The model does not deal with surface atoms because it is infinite. It contains constant $\mathrm{Si}-\mathrm{O}$ bond lengths, $\phi$ and $\alpha$ (i.e., these parameters are the same throughout the model). This is unrealistic in real $\mathrm{SiO}_{2}$ glass since these parameters can have wide distributions (e.g., Mozzi \& Warren 1969). The central force model also does not specify dihedral angles and rings, and so cannot give information about intermediaterange order. However, the mean field-constraint model described previously is a more advanced variety of the original Sen \& Thorpe model.

Computer models of glasses involve specifying the initial position and parameters of a given number of atoms. Information is entered about the coordinates of each particle as well as parameters such as their size and charge and interatomic potentials. A structural simulation is then conducted to determine the most likely structure of the glass. Two common techniques for structural determination are the Monte Carlo (MC) and the molecular dynamics methods.

Using the Monte Carlo method, various configurations are tried by randomly moving atoms. All possible configurations are compared to a random number until the most energetically favorable structure is found. This can be done for any given temperature. Using the molecular dynamics method, the system is initially studied at high temperatures. The Newtonian equations of motion are integrated for different species, giving information about thermal motion and thermodynamic properties. The system is then cooled at a given rate to some temperature below the glass transition (Soules 1990).

These types of computer simulations give detailed information about the resulting theoretical structure. 
The position of every atom is known and can easily be used to calculate a radial distribution function that can be used for comparison to experiment. However, molecular dynamics methods use cooling rates that are much higher than realistically attainable, forming a glass at a higher $T_{g}$, and the structure of the resulting glass may not necessarily be comparable to real glasses, formed at lower $\mathrm{T}_{\mathrm{g}}$ (Leko 1993).

Gladden (1990a) developed a computer algorithm that simulated the building of random networks similar to that of Bell \& Dean (1972). The algorithm adds individual $\mathrm{SiO}_{4}$ (or any $A X_{4}$ ) tetrahedron to the structure, specifying elements of short-range order such as $\mathrm{Si}-\mathrm{O}$ bond distance and the $\mathrm{O}-\mathrm{Si}-\mathrm{O}$ bond angle. A tetrahedron that is being introduced is rotated about $\delta_{1}$ and $\delta_{2}$ until the position that will introduce the least strain is found. New tetrahedra are permitted to bond at more than one vertex, allowing rings to be formed, but only where this adds a minimum amount of strain. The resulting model is then energy relaxed. Correlation and interference functions are calculated in order to compare to experiment. Gladden (1990a) compared a number of models taking into consideration mediumrange parameters such as a minimum ring-size and equilibrium $\mathrm{Si}-\mathrm{O}-\mathrm{Si}$ angle. The best agreement with experiment was found from a model with a minimum ring-size of 5 and a mean $\mathrm{Si}-\mathrm{O}-\mathrm{Si}$ angle $(\alpha)$ of $146^{\circ}$. Another model gave a mean $\alpha=143^{\circ}$ (Gladden 1990b). It was also shown that the $\mathrm{Si}-\mathrm{O}-\mathrm{Si}$ bond-angle distribution, $V(\alpha)$, changes if the minimum ring-size also changes: small rings (3- and 4-membered) form skewed $V(\alpha)$ distributions.

\section{Quartz-based models}

According to some researchers, the best correlation between experiment and model occurs for quartz-based structures. Narten (1972) showed that the silica glass RDF is in good agreement with the RDFs calculated from an $\alpha$-quartz model. However, the density of quartz is too high for silica glass. This can be corrected by having $12 \%$ of the atom positions normally occupied in quartz left randomly vacant in the glass. Such a correction would also account for the coordination number $\mathrm{n}$ of 3.5, which is less than the ideal value of 4 for $\mathrm{SiO}_{2}$ tetrahedra. Randomly varied vacancies would also account for a loss of structure beyond $8 \AA$.

Henninger et al. (1967) also provided evidence for a structure of silica glass based on quartz. They reached their conclusions based on two independently obtained RDFs, one from X-ray-scattering data and one from neutron-scattering data. Both of the RDFs showed good agreement with fused quartz. However, Wright (1994) rejected models based on quartz because he claimed that the higher density of quartz shifts the first peak of the diffraction profile to higher values of $Q$ than that of the glass.

\section{Cristobalite-based models}

Hicks (1967) considered cristobalite to be the most likely model based on configurational entropy and the fact that silica glass devitrifies to cristobalite. Roy (1974) had similar arguments and pointed out that cristobalite is easier to form. He believed that glass cannot have a tridymite structure because of the difficulty in forming tridymite.

Gerber \& Himmel (1986) found that the structure of silica glass most resembles that of high cristobalite. They obtained correlation functions for glass that exhibit low-intensity periodic oscillations at small radial distances. Of all the $\mathrm{SiO}_{2}$ polymorphs, only cristobalite has the same period for these oscillations. Thus, Gerber \& Himmel (1986) concluded that silica glass generally consists of six-membered rings like those found in high cristobalite.

Based on his own experiments and the results of others, Phillips (1982) concluded that the structure of $\mathrm{SiO}_{2}$ glass resembles that of $\alpha$-cristobalite. However, the Phillips model was rejected by Galeener \& Wright (1986) for several reasons. They calculated a neutrondiffraction intensity function for silica glass based on cristobalite and compared it with that derived from experiment. Unfortunately, their calculated cristobalitebased model had three peaks in the region below $5.3 \AA$, as opposed to two peaks observed in the experimental scattering pattern of $\mathrm{SiO}_{2}$ glass. For this reason, they concluded that it was improbable that silica glass can be represented by a cristobalite-based model. Furthermore, the Phillips model allowed ordered regions to be as large as $66 \AA$, but the correlation between the experimentally derived scattering profile of $\mathrm{SiO}_{2}$ glass and that calculated from a cristobalite model decreased at longer length-scales (Galeener \& Wright 1986). Therefore, ordered regions greater than 15-20 Å across probably do not exist. On this basis, the Phillips model can be rejected.

LeBail (1995) modeled the structure of $v-\mathrm{SiO}_{2}$ using the Rietveld method. A crystalline model was chosen and then mathematically distorted by the application of isotropic microstrain. This approach produces "amorphous" diffraction-patterns due to line broadening. LeBail (1995) used small models of several polymorphs of crystalline silica with periodic boundary-conditions and refined their cell parameters and atom coordinates until a best fit was achieved with the X-ray diffraction data of Konnert \& Karle (1973b) and the neutron data of Johnson et al. (1983). LeBail's $\beta$-cristobalite model gives the expected values for $\mathrm{Si}-\mathrm{O}$ and $\mathrm{O}-\mathrm{O}$ distances and $\mathrm{O}-\mathrm{Si}-\mathrm{O}$ angles. However, the model gives values that are too large for the mean $\mathrm{Si}-\mathrm{O}-\mathrm{Si}$ angle and the mean $\mathrm{Si}-\mathrm{Si}$ distance. The model is small, made up of only 24 atoms, and is also made up exclusively of sixmembered rings. 


\section{Tridymite-based models}

Konnert \& Karle (1972, 1973a) and Konnert et al. (1974) found the structure of silica glass to be most like tridymite. They compared the RDFs of quartz, cristobalite, and tridymite to that of silica glass and found the best agreement to be with the tridymite data (Fig. 9). They concluded that $90 \%$ of the glass is composed of tridymite-like regions with six-membered rings about 12 to $20 \AA$ across. The tridymite-like regions joined together in a manner analogous to twinning in crystalline structures, but with a wide variation of twin orientations and occasional small distortions. Discrepancies between silica glass and tridymite RDFs were attributed to perturbations at the boundaries between ordered and disordered regions in the glass.

Wright (1994) rejected this tridymite model for $\mathrm{v}-\mathrm{SiO}_{2}$ because the shape and height of the peaks at 4.1 and $5.0 \AA$ of amorphous silica and tridymite differ (indicated by arrows in Fig. 9). However, in the current model of Konnert et al. (1982), these peaks show improved agreement (Fig. 10). The tridymite model of Konnert et al. (1982) includes five- and six-membered rings with approximately one five-membered ring for each 2.6 six-membered rings. However, the exact ratio has not been established. Generally, the deviations of the bond distances from the mean are similar to those of tridymite. Thus tridymite-like rings dominate in the model; however, others also are important.

\section{Models based on a combination of $\mathrm{SiO}_{2}$ polymorphs}

Some investigators have suggested that the $\mathrm{Si}-\mathrm{O}-\mathrm{Si}$ angle has a bimodal distribution, implying that there is more than one ordered structure within $v-\mathrm{SiO}_{2}(c f$. Henderson et al. 1984). This has led some to believe that the structure of silica glass can be modeled by considering both cristobalite and tridymite structures. Cartz (1964) considered the structure of glass to be a random three-dimensional network of tetrahedra linked together at corners in a manner similar to the pattern in tridymite and cristobalite. However, unlike cristobalite and tridymite, which contain only six-membered rings, his model contained five-, six-, and seven-membered rings. Cartz (1964) felt that the presence of sevenmembered rings is important to the glass structure because the larger rings are more easily incorporated into the random network. On the other hand, five- and six-membered rings have a smaller number of possible configurations and are more constrained.

Henderson et al. (1984) considered the structure of $\mathrm{SiO}_{2}$ glass to consist predominantly of distorted sixmembered rings, although three-, four-, seven-, and eight-membered rings were also considered important. Approximately two-thirds of the rings were considered ditrigonal tridymite-like rings, whereas the other onethird are oval cristobalite-like rings.

Marians \& Burdett (1990) proposed a model in which ordered regions of tridymite- and cristobalite-like layers are joined by interfacial material. The ordered domains consist of six-membered rings, and range from 15 to $100 \AA$ across. However, these domains are not crystalline. The atom positions in the domains are not periodic because they are curved in Euclidean space. The interfacial material is disordered and contains many sizes of rings. Some rings are smaller than six, but most are eight-membered rings or larger. The interfacial layer can be quite thin, as thin as one eight-membered ring. The ratio of the ordered domains to the disordered interfaces is not known, as the boundaries are not discrete.

The strained mixed-cluster model of Goodman $(1975,1985)$ includes various crystalline polymorphs of silica. Cristobalite, tridymite and quartz are more abundant than other silica polymorphs because they are the most stable. In his model, he assumed that the glass is formed from a melt, and so the polymorphs that are stable at the highest temperatures form the largest clusters. Cristobalite would therefore be the most abundant, followed by tridymite, then quartz. Other polymorphs such as keatite, coesite, and stishovite
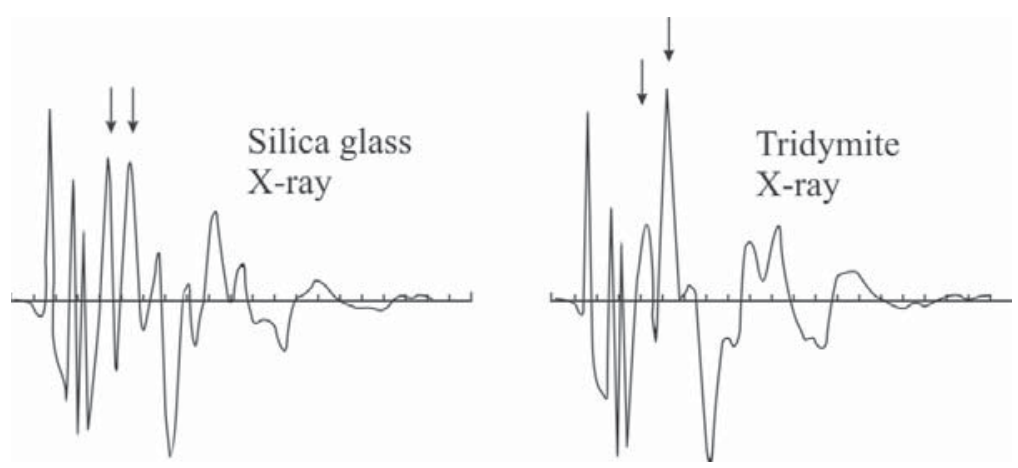

FIG. 9. Radial distribution functions (RDFs) derived from powder-diffraction profiles of $\mathrm{SiO}_{2}$ glass and tridymite (after Konnert \& Karle 1973). 


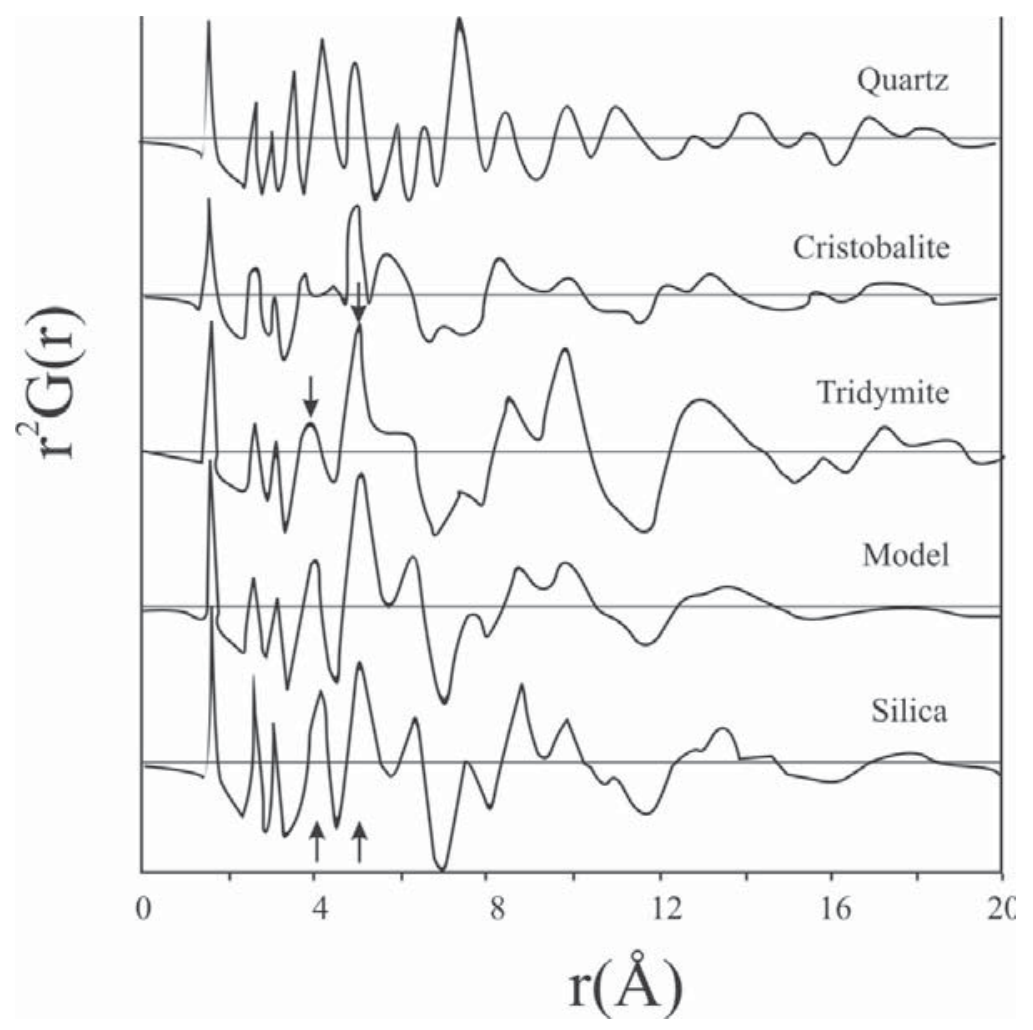

FIG. 10. Experimental RDFs for a number of crystalline model compounds, a hand-built ball-and-stick model, and $\mathrm{SiO}_{2}$ glass (after Konnert et al. 1982).

would be present in small quantities. Goodman (1986) noted that silica glasses formed close to $\mathrm{T}_{\mathrm{g}}$ would form larger clusters of tridymite because it is stable at that temperature. The centers of each cluster are mostly crystalline, and the intercluster boundaries are strained regions. The degree of strain depends on factors such as the relative orientation of the adjacent clusters and the length of the boundary. One problem with this model, as pointed out by Wright (1994), is that the size of the clusters can reach 60-80 A. However, experimental data do not show the presence of order beyond $\sim 10-20$ $\AA$ ( (cf. Fig. 9).

First sharp diffraction-peak, polyamorphic phasetransitions and high-pressure behavior

In the past decade, there have been relatively few studies of $\mathrm{SiO}_{2}$ glass using direct structural methods such as neutron and X-ray scattering ( $c f$. Nakamura et al. 2001, 2003, Ohno et al. 2001, Bruning \& Cottrell 2003, Pilla et al. 2003, Inamura et al. 2004). Those that have been performed have tended to investigate the structure as a function of temperature (Bruning
\& Cottrell 2003) or pressure (Inamura et al. 2004). Furthermore, those authors are interested in probing the median-range structure of the glass through analysis of the first sharp diffraction-peak (FSDP) in the experimental interference-function or total structure-factor (Fig. 11) [cf. Henderson (2002) for a detailed discussion of the FSDP in glass-structure analysis). The FSDP has been taken as a signature of median-range order ( $c f$. Elliott 1991). The position of the FSDP in $k$ space is related to real space distances by $d \approx 2 \pi / k$, and the width of the peak is related to the damping in amplitude of the real space correlations. The real space distances in the RDF thus occur at 3-6 $\AA$ for a FSDP in the range of 1.0-1.7 $\AA$ and appear as a damped oscillation in $T(\mathrm{r})$ (Swenson \& Börjesson 1998).

However, the origin of the FSDP remains controversial. It has been assigned to quasicrystalline layerstructures in chalcogenide glasses (Cervinka 1988), to correlations between clusters within oxide glasses (Price et al. 1988), to interstitial void space (Lee \& Elliott 1994), to possible interference-effects between partial structure-factors (Hajdu 2000), and to the presence of pseudo- or quasi-Bragg planes in the glass (Gaskell 
\& Wallis 1996) with an interlayer separation of $\sim 4 \AA$ (Uchino et al. 2005).

Regardless of its origins, however, it remains an area of intense interest, because the FSDP does undergo changes with increases in temperature, pressure and with changes in glass composition. For example, with increasing pressure, the FSDP of vitreous $\mathrm{SiO}_{2}$ undergoes a number of changes indicative of changes in the medium-range structure (Meade et al. 1992). Up to 8 $\mathrm{GPa}$, there is no change in the intensity of the FSDP, but it does shift to higher $\mathrm{k}$ values. Above $8 \mathrm{GPa}$, the FSDP decreases in intensity, and at $28 \mathrm{GPa}$, a new peak occurs at a slightly shorter length-scale, indicating a significant change in the median-range structure beyond this pressure. Inamura et al. (2004) concluded that vitreous $\mathrm{SiO}_{2}$ undergoes a phase transformation to a stable highpressure form of glass. Furthermore, Huang \& Kieffer (2004a) have shown that such phase transformations may be reversible or irreversible depending upon the combination of temperature and pressure at which the transitions takes place. In addition, Huang \& Kieffer (2004a, b) also showed that the nature of the transition resembles that of the $\alpha-\beta$ transition in cristobalite, and the stable high-pressure form is characterized by larger sizes of rings. The ring behavior and ring statistics appears to be important contributors to the behavior of $\mathrm{SiO}_{2}$ glass at high pressure. Davila et al. (2003) noted that ring-size distributions are important in shock-wave amorphization of $\mathrm{SiO}_{2}$, and that the formation of small three-membered rings are important, particularly with respect to network connectivity and rigidity. They observed that the transition between elastic (floppy) and rigid behavior is correlated with changes in ring size. The link between high-pressure behavior and rigidity percolation has been further explored by Trachenko et al. (2004), who also showed that the temperatureinduced densification of $\mathrm{SiO}_{2}$ under pressure is related

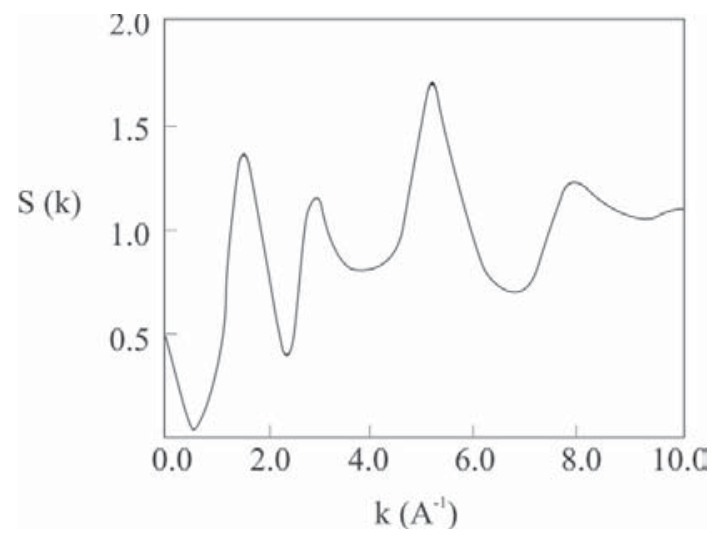

FIG. 11. The Total Structure-Factor $[S(k)]$ for silica glass. Note the sharp peak at low $k\left(\sim 1.6 \AA^{-1}\right)$, which is the FSDP (after Lee \& Elliott 1994). to this behavior. Clearly, the mean field-constraint hypothesis and rigidity percolation have application to an understanding of the structural response of oxide network glasses, such as silicate glasses, to high pressures and temperatures.

\section{The Role of Network Modifiers: Sodium Silicate Glasses}

The structure of glasses containing network modifiers such as alkalis has been the focus of numerous geological studies, as these glasses provide a more realistic picture, albeit a simplified one, of naturally occurring silicate melts (e.g., Furukawa \& White 1980, Greaves et al. 1981, Mysen et al. 1982, Matson et al. 1983, Dupree et al. 1986, Schneider et al. 1987, Stebbins 1987, 1998, Maekawa et al. 1991, Hannon et al. 1992, Smith et al. 1995, Vessal et al. 1996, Uchino \& Yoko 1999). These glasses are composed of network formers and network modifiers, in contrast to $\mathrm{SiO}_{2}$ glass, which consists of only a network former. Network formers are elements such as silicon and germanium that form tetrahedra and make up the bulk of the structure through corner-sharing BO atoms. Network modifiers, such as alkali and alkaline-earth ions, modify the continuous silicate network by breaking the BOs to form negatively charged $\mathrm{Si}-\mathrm{O}^{-} \mathrm{NBO}$ and $\mathrm{Q}^{\mathrm{n}}$ species (where $n$ is the number of bridging oxygen atoms per silicon tetrahedron and has values from 0 to 4 ). Of the alkali-containing silicate glass systems, sodium silicate glasses have been the most extensively studied.

Warren \& Biscoe (1938) conducted the earliest structural study of sodium silicate glass. The diffraction profiles showed a continuous change in appearance with increasing sodium content. Warren \& Biscoe (1938) concluded that the structure of sodium silicate glass does not exist as simple discrete $\mathrm{SiO}_{2}, \mathrm{Na}_{2} \mathrm{O}$, $\mathrm{Na}_{2} \mathrm{Si}_{2} \mathrm{O}_{5}$ or $\mathrm{Na}_{2} \mathrm{SiO}_{3}$ molecules. Instead, the structure was interpreted to consist of tetrahedrally coordinated silicon atoms surrounded by four oxygen atoms, with a bond distance of $1.62 \AA$. Some of the oxygen atoms are bonded to two silicon atoms (BO) and some bonded to only one silicon atom (NBO). The sodium ions are surrounded by six oxygen atoms with an average bond-length of $2.35 \AA$ and arranged in random holes throughout the silicon-oxygen network. It was also observed that as the sodium content increased, the number of non-bridging oxygen atoms also increased. Warren \& Biscoe (1938) concluded that even though the structure is quite definite, it does not repeat periodically and is therefore non-crystalline.

In describing the sodium silicate structure, Warren \& Biscoe (1938) employed the CRN (see above) to fit the observed data. The random network model accounts for the replacement of a BO with two NBOs upon the addition of each network-modifier unit, $M_{2} \mathrm{O}(M=\mathrm{Li}, \mathrm{Na}$, $\mathrm{K}, \mathrm{Rb}, \mathrm{Cs}$ ). The negative charge of the NBO is therefore 
balanced by the positively charged alkali cation in order to maintain charge neutrality.

Neutron-scattering techniques have also been used to probe the structure of alkali-containing glasses. Misawa et al. (1980) studied the short-range structure of lithium and sodium disilicate glasses and determined silicon to be tetrahedrally coordinated to four oxygen atoms in these glasses. Misawa et al. (1980) also reported the first observed lengthening of the alkali silicate $\mathrm{Si}-\mathrm{O}$ bond in comparison to pure vitreous silica; $\mathrm{Si}-\mathrm{O}$ bond lengths were reported to be 1.63 and $1.62 \AA$ for the sodium and lithium silicates, respectively. This increase in $\mathrm{Si}-\mathrm{O}$ bond length with the addition of a network modifier was later confirmed through other studies ( $c f$. Henderson 1995). Misawa et al. (1980) also reported an observed $\mathrm{Si}-\mathrm{O}$ bond weakening and the presence of non-bridging oxygen atoms with an average of one nonbridging and three bridging oxygen atoms per silicon atom, as observed by Warren \& Biscoe (1938).

Greaves et al. (1981) and Greaves (1985) conducted an analysis using extended X-ray absorption fine structure (EXAFS) to study the local structure of sodium silicate glasses with varying molar compositions. The $\mathrm{Si}$ EXAFS data revealed that the structures of sodium silicate glasses remain relatively similar. Minor differences were observed in the EXAFS data and were attributed to the addition of network modifiers and the distribution of $\mathrm{Q}^{\mathrm{n}}$ species. The Na EXAFS spectra showed a higher frequency of oscillations than the Si EXAFS, indicating that the $\mathrm{Na}-\mathrm{O}$ bond is longer than the $\mathrm{Si}-\mathrm{O}$ bond and that different bonding interactions are taking place.

Another Si EXAFS study of sodium silicates was performed by Henderson (1995) for silicate glasses containing $15-40 \mathrm{~mol} . \% \mathrm{Na}_{2} \mathrm{O}$. In addition to EXAFS, $\mathrm{X}$-ray absorption near-edge spectroscopy (XANES) data were also collected. In agreement with previous studies, Henderson (1995) reported that sodium silicates were locally structured, with tetrahedrally coordinated silicon environments. However, Henderson observed that with the addition of $\mathrm{Na}_{2} \mathrm{O}$, the $\mathrm{Si}-\mathrm{Si}$ bond distributions decreased, and the contribution from multiple scattering beyond the second coordination sphere increased. These results suggested that a degree of intermediate-range ordering was taking place with the addition of sodium. The EXAFS data revealed an increase in $\mathrm{Si}-\mathrm{O}$ bond distance with the addition of sodium, from $1.61 \pm 0.02$ $\AA$ for amorphous silica to $1.66 \pm 0.02 \AA$ for $30 \mathrm{~mol} . \%$ $\mathrm{Na}_{2} \mathrm{O}$. This change in bond distance indicated that the network depolymerization effect on the $\mathrm{Si}-\mathrm{O}$ bond dominated over increased numbers of non-bridging oxygen atoms. However, $\mathrm{Si}-\mathrm{O}$ bond distances decreased for sodium concentrations greater than $30 \mathrm{~mol} \%$ owing to the dominating NBO distribution. This relationship suggested that the microsegregation of network modifiers from network formers is significant for sodium concentrations greater than $30 \mathrm{~mol} \%$.

In order to aid in the interpretation of the results of direct structural studies such as X-ray and neutron scat- tering, molecular dynamic (MD) simulations have been extensively performed to compare whether MD-derived structures are in agreement with experimental observations and results. Although very useful to interpret experimental results, it must be kept in mind that MD simulations are theoretical, may not have any basis in reality, and can be highly dependent on input parameters and assumptions (see later).

MD simulations by Huang \& Cormack (1990, 1991), Smith et al. (1995) and Vessal et al. (1996) have all been performed on sodium silicate glasses. The MD simulation of sodium disilicate glass obtained by Smith et al. (1995) indicated that the structure is inhomogeneous, with the segregation of sodium ions and their clustering around NBO atoms. Such a representation agrees with experimental evidence that segregation exists within sodium silicate glasses, thus further supporting the modified random-network (MRN) model. Furthermore, Huang \& Cormack (1991) studied silicate glass with a range of sodium content. Their simulated sodium silicate structures showed sodium atoms to exist as clusters around NBOs with both sodium-rich and silicate-rich regions. With increasing amounts of sodium, the sodium-rich and silicate-rich regions extend threedimensionally to form sodium- and NBO-rich channels, with silica-rich regions. The observed structure differs from the earlier model of Zachariasen \& Warren, in which the cations are continuously distributed throughout the network but are consistent with the MRN model of Greaves (1985).

Vedishcheva et al. (1995) compared thermodynamic and MD simulations with neutron-diffraction data in order to study the distribution of tetrahedral $\mathrm{Q}^{\mathrm{n}}$ species and the network-modifying cation environment of sodium silicate glasses. They found that the cation arrangement within the network is non-uniform, and exists as clusters of negatively charged non-bridging oxygen atoms attracting the positively charged networkmodifying cations, and vice versa. In the opinion of Vedishcheva et al. (1995), not only do the sodium ions tend to cluster, but the tetrahedral $\mathrm{Q}^{4}$ species also tend to accumulate in silica-rich regions. However, in contrast to earlier studies by Warren \& Biscoe (1938), and Greaves et al. (1981), who reported that 4-6 oxygen atoms surround a sodium atom, Vedishcheva et al. (1995) calculated the $\mathrm{Na}(\mathrm{O})$ coordination number to be $3.0 \pm 0.5$, indicating that each sodium ion is in contact with only three oxygen neighbors. Vedishcheva et al. (1995) also reported that the shortest $\mathrm{Na}-\mathrm{O}$ bond would arise from the non-bridging oxygen atoms. On the basis of these findings, Vedishcheva et al. (1995) suggested that the percolation channels within the modified-network model would not be sufficiently regular for the sodium ions to be at an ideal distance from every oxygen atom. The sodium ions would consequently adopt an optimum configuration with respect to the negatively charged $\mathrm{NBO}$ atoms, rather than with the $\mathrm{BO}$ atoms, which carry a smaller effective charge associated 
with heteropolar covalent bonding. Vessal et al. (1996) reported similar results based on the interpretation of neutron-diffraction data using MD techniques. In agreement with the modified random-network model, they, like Vedishcheva et al. (1995), concluded that sodium ions adopt a non-uniform distribution, with the network being microsegregated into sodium-rich and silica-rich zones. However, it should be remembered that these glasses can undergo phase separation and may not be homogeneous (see below).

\section{The structure of other alkali silicate glasses}

The inferred structure of sodium silicate glasses has been summarized above. However, the structures of alkali-containing glasses in general exhibit a dependence upon the type of alkali present in the glass. Different alkali cations in a silicate glass have been shown to have a number of effects on the physical properties of the glass, such as changes in activation energy of viscous flow, molar volume and thermal expansion ( $c f$. Stebbins et al. 1995). The network structure will depend on the type of network former added to the glass.

In addition to sodium silicate glass, Greaves (1985) also investigated potassium silicate glass and found a $\mathrm{K}-\mathrm{O}$ bond length of $2.8 \pm 0.1 \AA$ and a coordination number between 5 and 7 for potassium. Such values were later challenged; Hannon et al. (1992) considered them to be too large. Just like Misawa et al. (1980), Hannon et al. (1992) investigated the local structure of lithium and potassium silicate glasses and presented data consistent with the MRN model. The $\mathrm{Li}-\mathrm{O}$ bond distance was observed to be consistent with the average Li-O distance of $1.94 \AA$ for crystalline lithium silicates. The lithium thus should be tetrahedrally coordinated to four oxygen atoms; however, Hannon et al. (1992) determined a coordination of approximately two. Following this, Hannon et al. (1992) interpreted the lithium silicate glass structure to consist of a pairing of lithium ions that are immediately surrounded by two non-bridging oxygen atoms, thus satisfying charge neutrality. However, Zhao et al. (1998) determined a higher coordination of $\mathrm{Li}$ for glasses of $\mathrm{Li}_{2} \mathrm{Si}_{2} \mathrm{O}_{5}$ composition with lithium in four-fold coordination with oxygen. Hannon et al. (1992) also concluded that in comparison to potassium, lithium occupies a distinctly different position in the alkali silicates. In a MD study of potassium silicates, Huang \& Cormack (1991) found that potassium cations cluster around NBO atoms. With an increase in potassium ion concentration, the potassium and NBO clusters are observed to extend three-dimensionally, thus fitting with the MRN model. However, even though Huang \& Cormack (1991) noted this clustering arrangement for both sodium and potassium silicates, they found that the percentage of silicon atoms with more than one NBO is reflected in the distribution of the alkali and NBO clusters. Therefore, there will be, on average, one NBO per silicon at the disilicate composition. However, whether this occurs depends on whether or not the structure is homogeneous. The simulations performed by Huang \& Cormack (1991) indicate that the distribution of alkali and NBO clusters is more uniform for potassium than for sodium silicate glasses. They further extended this observation to include the other alkali silicate glasses, in which the NBO per silicon distribution decreases in the order $\mathrm{Li}>\mathrm{Na}>\mathrm{K}$.

De Jong et al. (1981) investigated silica-rich alkali silicate glasses using NMR. They reported that both lithium and sodium cations tend to have a bimodal distribution throughout the silicate network and form alkali clusters. In contrast to this, potassium, rubidium and cesium cations were observed to exhibit a more uniform distribution. De Jong et al. (1981) determined that lithium silicates are more stable with a $\mathrm{Q}^{4}-\mathrm{Q}^{2}$ distribution rather than a $\mathrm{Q}^{3}-\mathrm{Q}^{3}$ arrangement, resulting in the clustering of lithium pairs around the $\mathrm{SiO}_{4}$ tetrahedra. These conclusions were supported by Matson et al. (1983). They obtained Raman spectra for $x M_{2} \mathrm{O} \bullet(100-x) \mathrm{SiO}_{2}$ glasses $(M=\mathrm{Li}, \mathrm{Na}, \mathrm{K}, \mathrm{Rb}, \mathrm{Cs}$ and $x=0,5,10,15,20,25,30)$. In comparison with pure silica and glasses containing similar amounts of silica but different cations, significant changes in the Raman spectra were observed, even for the addition of small amounts of alkali oxides. The intensity of high-frequency spectral features of high-silica binary alkali silicate glasses were useful in interpreting the distribution of $\mathrm{Q}^{\mathrm{n}}$ species. The data indicated the presence of a three-dimensional network of $\mathrm{Q}^{4}$ species as well as $\mathrm{Q}^{3}$ and $\mathrm{Q}^{2}$ species. They also observed that at high silica content, the glasses (with the exception of lithium silicates) contain two structurally distinct NBO sites, $\mathrm{Q}^{3}$ and $\mathrm{Q}^{31}$, owing to the presence of two Raman bands in the $1050-1200 \mathrm{~cm}^{-1}$ region. However, with increasing alkali content, the $\mathrm{Q}^{31} \mathrm{NBO}$ become less apparent, either disappearing or blending in with the $\mathrm{Q}^{3}$ band. Matson et al. (1983) accounted for the presence of these two sites by using the model of Bockris et al. (1956). This model suggests that alkali silicate systems exist as cages of $\mathrm{Si}-\mathrm{O}-\mathrm{Si}$ bonds surrounding single or multiple cations. The degree of cation crowding within each cage would subsequently affect the Si-NBO bond distance, thus giving rise to different $\mathrm{Q}^{3}$ species. However, lithium cations are small enough that the presence of more than one lithium cation does not cause a crowding effect. Matson et al. (1983) also recognized that lithium-containing glasses are distinctly different from the other alkali silicates because smaller cations, such as lithium, have a greater tendency to cluster in pairs around $\mathrm{SiO}_{4}$ tetrahedra to form $\mathrm{Q}^{2}$ species. Recent work by Soltay \& Henderson (2005) has confirmed that $\mathrm{Li}$ behaves differently than other alkali cations once incorporated into the glass network.

Phillips (1985) analyzed the Raman spectra of Matson et al. (1983) and suggested that the CRN model is incompatible with the interpretation of Matson et al. 
(1983) and suggested that a model similar to the MRN model should be adopted in its place. Phillips (1985) concluded that lithium silicate glasses behave differently with increasing lithium content than other alkali silicate glasses ( $c f$. Fig. 12) and are more prone to undergo phase separation. It is evident from Figure 12 that the trend of increasing alkali content should place the Raman frequency of lithium above sodium. However, it remains pinned at $490 \mathrm{~cm}^{-1}$ for up to $20 \mathrm{~mol} \% \mathrm{Li}_{2} \mathrm{O}$, at which point it disappears. To explain this observation, Phillips (1985) suggested that lithium silicate glasses with greater than $20 \mathrm{~mol} \% \mathrm{Li}_{2} \mathrm{O}$ precipitate lithium disilicate and metasilicate microphases. However, if such microphases do exist, one would expect smallangle X-ray scattering (SAXS) data to confirm their formation, and this has not been the case.

\section{Nuclear magnetic resonance}

Nuclear magnetic resonance (NMR) spectroscopy has been widely employed to investigate the structure of glasses, particularly with respect to the identification and quantification of Q species. Detailed reviews of the hypothesis of NMR spectroscopy and the application of the different NMR techniques to melt and glass structure studies have been given by Kirkpatrick (1988), and Stebbins (1988, 1995). Nuclei with odd mass numbers and non-integer spin quantum numbers (e.g., $\left.{ }^{29} \mathrm{Si},{ }^{17} \mathrm{O}\right)$ are of most interest in solid-state NMR studies of glasses. With appropriate NMR techniques, the structure around these nuclei may be probed, and different structural environments identified. ${ }^{29} \mathrm{Si} \mathrm{NMR}$ studies of silicate glasses are able to determine the distribution of Q species, as well as $\mathrm{Si}-\mathrm{O}-\mathrm{Si}$ angles.

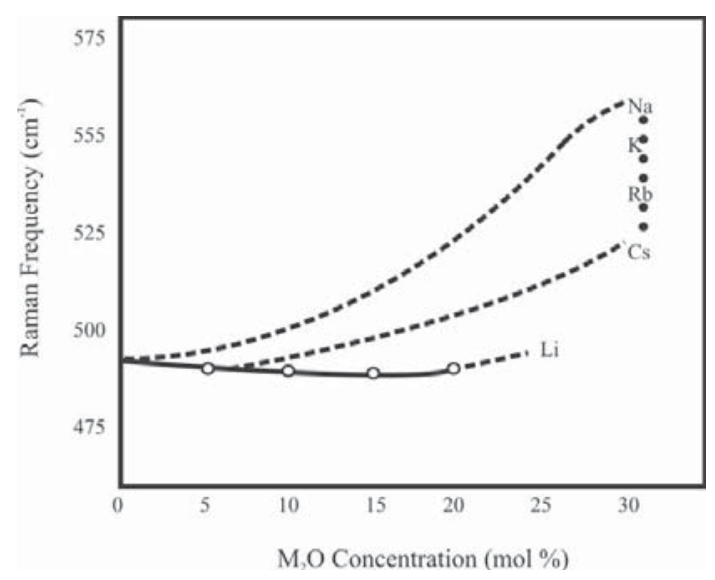

FIG. 12. Peak frequencies of the $490 \mathrm{~cm}^{-1}$ peak in $\mathrm{SiO}_{2}$ glass as $x$ increases for various alkali metals $\mathrm{M}=\mathrm{Li}, \ldots, \mathrm{Cs}$. Note the regular progression for $\mathrm{M}=\mathrm{Na}$ to $\mathrm{Cs}$ depending on mass, and the anomalous behavior of Li (after Phillips 1985).
Different Q species can be identified because the NMR spectrum is dependent upon the degree of shielding of the nucleus by its electrons. Silicon-oxygen tetrahedra with different numbers of NBOs and BOs will experience different degrees of shielding, and will consequently exhibit slightly different NMR spectra. The NMR spectrum itself is usually given as a plot of intensity versus energy $(\delta)$. The latter is given in terms of frequency relative to a standard and is reported as parts per million (ppm) where

$$
\delta=10^{6}\left(v_{\text {sample }}-v_{\text {standard }}\right) / v_{\text {sample }}
$$

and may range from a few to thousands of ppm, depending upon the nucleus being investigated, and is commonly termed the chemical shift.

For solids, a number of phenomena act to broaden the NMR spectrum. These include chemical shift anisotropy, dipole-dipole and quadrupolar interactions (Emerson \& Bray 1994, Stebbins 1995). This peak broadening is further enhanced in disordered systems, owing to the inherent nature of glasses, where an individual type of atom may have many slightly different environments within the glass network. Fortunately, a number of experimental techniques have been developed in the past decade, such as magic angle spinning NMR (MAS-NMR), which reduce or minimize peak broadening ( $c f$. Stebbins 1995).

In glass NMR spectra, the $\mathrm{Q}$ species have characteristic ranges of frequency; for the $\mathrm{Na}_{2} \mathrm{O}-\mathrm{SiO}_{2}$ glasses (Maekawa et al. 1991), the ranges are: $\mathrm{Q}^{4}(99.0-105.6$ ppm), $\mathrm{Q}^{3}$ (85.0-92.2), $\mathrm{Q}^{2}$ (75.5-78 ppm) and $\mathrm{Q}^{1}$ (66.7$68.0 \mathrm{ppm})$. The different $\mathrm{Q}$ species may be well resolved into individual peaks within the NMR spectrum of the glass, or they may appear as shoulders on a complex peak (Fig. 13). If the latter occurs, the distribution of $\mathrm{Q}$ species can be easily obtained by curve-fitting the spectral envelope of the complex peak (Fig. 14). This has the added advantage of being able to provide quantitative information on distributions of $\mathrm{Q}$ species since NMR peak areas are proportional to the concentration of the Q species generating the signal. Whereas ${ }^{29} \mathrm{Si}$ has been the principal NMR nucleus of interest in silicate glasses for the last decade, interest in ${ }^{17} \mathrm{O}$ has now become an exciting new area of research ( $c f$. Clark \& Grandinetti 2003, Clark et al. 2001, 2004), particularly with the application of multinuclear NMR techniques such as two-dimensional dynamic angle spinning NMR (cf. Florian et al. 1996, Clark et al. 2004), and multiquantum NMR (Frydman \& Harwood 1995).

\section{Distribution of $Q$ species}

Dupree et al. (1986) examined the local effect of alkalis on silicate glass structure using magic angle spinning nuclear magnetic resonance (MAS-NMR) spectroscopy. They included compositions up to $\sim 50$ mol.\% $M_{2} \mathrm{O}$. Figure 13 shows an example of the ${ }^{29} \mathrm{Si}$ 


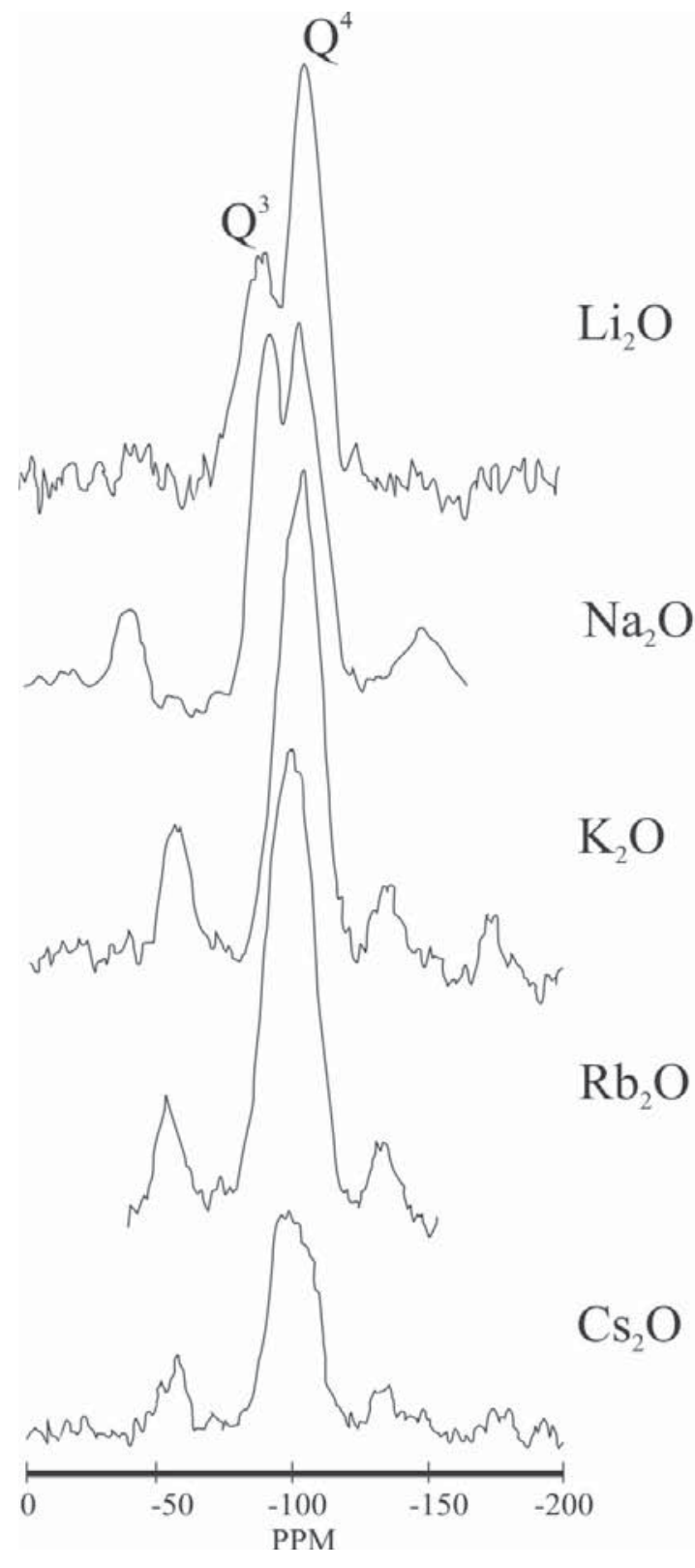

FIG. 13. ${ }^{29} \mathrm{Si}$ spectra for alkali silicate glasses containing approximately $20 \mathrm{~mol} \%$ alkali oxide (after Dupree et al. 1986)

spectra for a series of glasses obtained by Dupree $e t$ al. (1986) containing approximately $20 \mathrm{~mol} \% \mathrm{M}_{2} \mathrm{O}$. Both lithium and sodium silicate glasses have two clearly resolved peaks, corresponding to the presence of $\mathrm{Q}^{3}$ and
$\mathrm{Q}^{4}$ silicate species. $\mathrm{K}, \mathrm{Rb}$ and $\mathrm{Cs}$ peaks were also shown similarly to contain mixtures of $\mathrm{Q}^{3}$ and $\mathrm{Q}^{4}$ species.

In agreement with the original observation of Warren \& Biscoe (1938), Dupree et al. (1986) reported that for sodium silicate glass, the addition of each alkali ion results in the formation of a NBO that is uniformly distributed amongst the $\mathrm{SiO}_{4}$ tetrahedra. This results in the formation of one or two $\mathrm{Q}^{\mathrm{n}}$ and $\mathrm{Q}^{\mathrm{n}-1}$ species, with the relative amounts corresponding to the concentration of $\mathrm{M}_{2} \mathrm{O}$. Dupree et al. (1986) observed that for low-content cesium and rubidium silicate glasses, the NMR intensities followed the same pattern as observed for sodium silicate glass, in which there is a sequential replacement of $\mathrm{Q}^{4}$ by $\mathrm{Q}^{3}$ species up to $33.3 \mathrm{~mol} \% \mathrm{M}_{2} \mathrm{O}$. For concentrations greater then $33.3 \mathrm{~mol} \% \mathrm{M}_{2} \mathrm{O}$, a replacement of $\mathrm{Q}^{3}$ by $\mathrm{Q}^{2}$ species was observed. However, as the $\mathrm{M}_{2} \mathrm{O}$ concentrations reached $45-50 \mathrm{~mol} \%$, the rubidium and cesium silicate spectra were observed to fit three narrow peaks (Fig. 14), indicating the presence of $Q^{3}$, $\mathrm{Q}^{2}$ and $\mathrm{Q}^{1}$ species. The $\mathrm{Q}^{1}$ species was proposed to arise from the partial disproportionation; $2 \mathrm{Q}^{2} \rightarrow \mathrm{Q}^{1}+\mathrm{Q}^{3}$. Dupree et al. (1986) proposed that even though sodium silicate $\mathrm{Q}^{2}$ species are stable within their composition range below $50 \mathrm{~mol} \%$, cesium and rubidium silicate $\mathrm{Q}^{2}$ species are destabilized with respect to $\mathrm{Q}^{3}$ and $\mathrm{Q}^{1}$ species for concentrations greater than $\sim 45 \mathrm{~mol} . \%$ $\mathrm{M}_{2} \mathrm{O}$. This could possibly be the result of the formation of crystalline phases at $\sim 50 \mathrm{~mol} \%$, even though no indication of phase separation or crystallization was observed. Dupree et al. (1986) explained this observation by suggesting that the structure of silicate glass containing primarily $\mathrm{Q}^{2}$ species exists as chains and rings of silicate tetrahedra, despite a lack of structural evidence, with the modifying cations positioned close to the non-bridging oxygen atoms. Larger cations, such as rubidium and cesium, would therefore tend to push these silicate chains further apart due to the increased steric crowding and coulombic repulsions associated with larger cations. Such an interaction would result in the silicate matrix accommodating this with the formation of a mixture of $\mathrm{Q}^{3}, \mathrm{Q}^{2}$ and $\mathrm{Q}^{1}$ species, to create more local free volume for the larger cations.

In conclusion, Dupree et al. (1986) stated that the structure of alkali silicate glasses depends on the type and concentration of alkali cation. Clustering of $\mathrm{Q}^{3}$ and $\mathrm{Q}^{4}$ species were observed for small alkali cations, whereas a uniform $\mathrm{Q}^{3}$ distribution was observed for larger alkali cations at low concentrations (i.e., <30 mol.\%). However, Dupree et al. (1986) reported that the reverse is observed for high alkali concentrations (i.e., $>40 \mathrm{~mol} . \%$ ), where more than one cation is associated with each silica tetrahedron. They also concluded that the NBO repulsion in lithium and sodium silicates resulted in a uniform distribution of $\mathrm{Q}^{3}$ and $\mathrm{Q}^{2}$. However, the larger electrostatic forces of cesium and rubidium cations resulted in a non-uniform distribution of alkali cation with the formation of a mixture of $\mathrm{Q}^{3}$, $\mathrm{Q}^{2}$ and $\mathrm{Q}^{1}$ species and a narrowing of the distribution of 


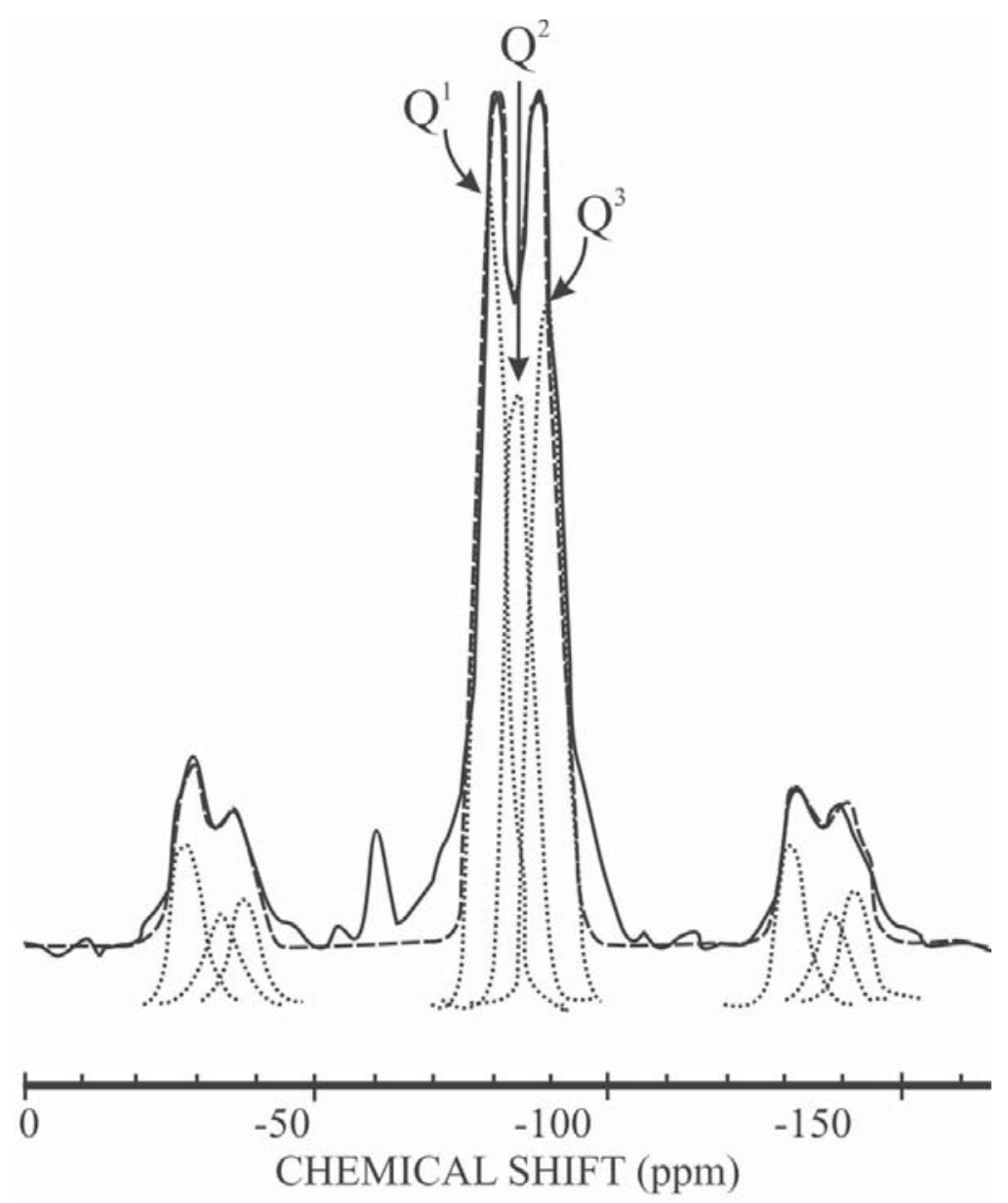

FIG. 14. Example of a ${ }^{29} \mathrm{Si}$ MAS-NMR spectrum from compositions of $\mathrm{R}_{2} \mathrm{O}>45 \mathrm{~mol} \%$. The spectrum is for $51.1 \mathrm{~mol} \% \mathrm{Cs}_{2} \mathrm{O}$ glass (after Dupree et al. 1986).

Si-O-Si bond angles. A similar study was performed by Schneider et al. (1987) on binary sodium and potassium silicates of non-integer mean $\mathrm{Q}^{\mathrm{n}}$ number. Double peaks were observed in the ${ }^{29} \mathrm{Si} \mathrm{NMR}$ spectra similar to the results of Dupree et al. (1986). Schneider et al. (1987) asserted that the glasses are homogeneous and single phased and that the peaks arose from the presence of only two distinct silicate species with different numbers of non-bridging oxygen atoms $\left(\mathrm{Q}^{3}\right.$ and $\mathrm{Q}^{4}$ species $)$.

Maekawa et al. (1991) performed a ${ }^{29} \mathrm{Si}$ MAS-NMR study on alkali silicate glasses but focused on the smaller alkali cations, lithium, sodium and potassium, with 20-56 mol. $\% M_{2} \mathrm{O}$. The observed peaks were correspondingly assigned to the $\mathrm{Q}^{3}, \mathrm{Q}^{2}, \mathrm{Q}^{1}$ and some $\mathrm{Q}^{0}$ species. Maekawa et al. (1991) reported that the distribution of the structural $\mathrm{Q}^{\mathrm{n}}$ species in disilicate glass is governed by the equilibrium as proposed by Stebbins et al. (1985):

$$
2 \mathrm{Q}^{\mathrm{n}} \leftrightarrow \mathrm{Q}^{\mathrm{n}-1}+\mathrm{Q}^{\mathrm{n}+1}(\mathrm{n}=3,2,1)
$$

However, unlike the binary model and the discrete bonding model (see below), where the number of different $\mathrm{Q}^{\mathrm{n}}$ species is limited to a maximum of two for each alkali silicate composition, Maekawa et al. (1991) observed a wider $\mathrm{Q}^{\mathrm{n}}$ distribution. Figure 15 illustrates the $\mathrm{Q}^{\mathrm{n}}$ distribution for potassium, sodium and lithium silicate glasses as a function of alkali content, as calculated from the equilibrium constants for equation 6 . From Figure 15, it is evident that the network-modifying cations affect the $\mathrm{Q}^{\mathrm{n}}$ distributions and with increasing $\mathrm{Z} / \mathrm{r}\left(\mathrm{Li}^{+}>\mathrm{Na}^{+}>\mathrm{K}^{+}\right)$ratios, equation 5 shifts to the right. 


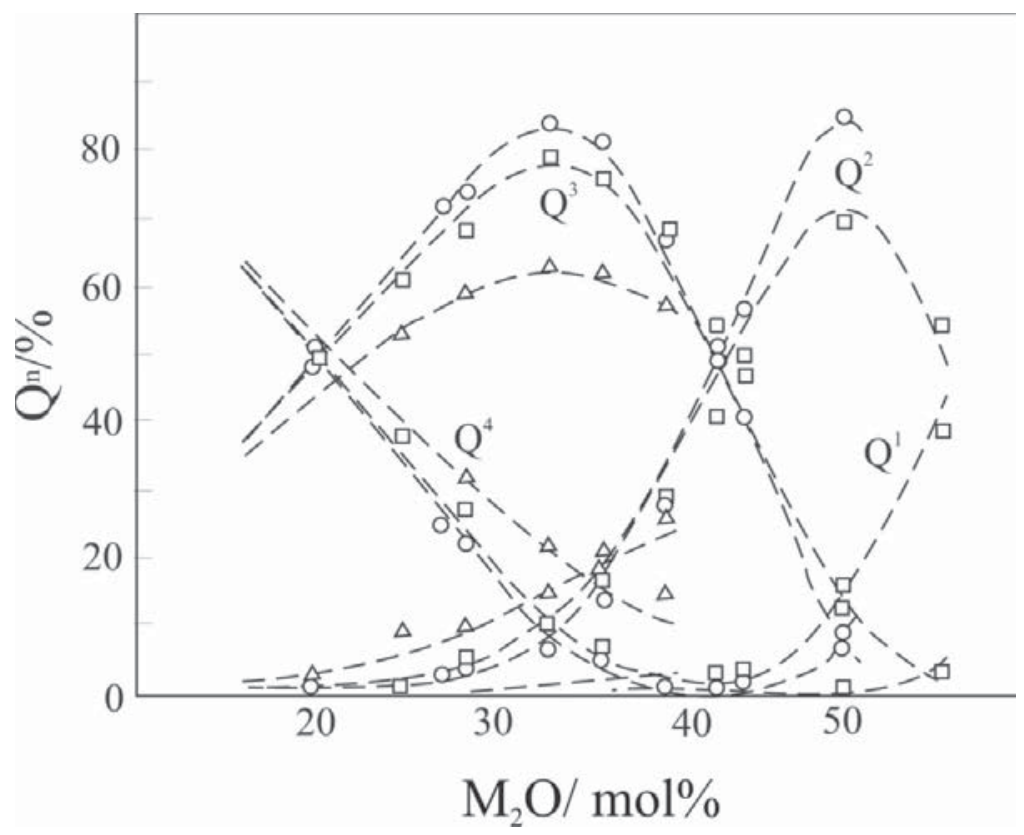

FIG. 15. Experimentally determined $\mathrm{Q}^{\mathrm{n}}$ distribution in lithium $(\Delta)$, sodium $(\square)$ and potassium $(\bigcirc)$ silicate glasses as a function of mol.\% alkali oxide.

This trend agrees with results from Raman spectroscopy (Mysen et al. 1980) and NMR studies (Emerson et al. 1989, Murdoch et al. 1985) of disilicate and metasilicate composition glasses.

Maekawa et al. (1991) also noted that the MASNMR spectra for potassium silicate glasses with greater than $40 \mathrm{~mol} . \% \mathrm{~K}_{2} \mathrm{O}$ have at least four different peaks. These peaks were proposed to arise from either the $\mathrm{Q}^{0}$, $\mathrm{Q}^{1}, \mathrm{Q}^{2}$ and $\mathrm{Q}^{3}$ set of species, or the $\mathrm{Q}^{1}, \mathrm{Q}^{2}, \mathrm{Q}^{3}, \mathrm{Q}^{4}$ set of species, resulting in 2.44 or 1.44 NBOs per silicon atom, respectively, rather than the expected stoichiometric value of 2. To account for this difference, the existence of two different $\mathrm{Q}^{2}$ species was proposed. The presence of two $\mathrm{Q}^{2}$ species would result in the correct stoichiometric value, but direct evidence of two $\mathrm{Q}^{2}$ species in potassium silicate glasses has not subsequently been demonstrated.

Figure 16 shows that an increase in the numbers of non-bridging oxygen atoms per silicon atom correlates with an increase in metal oxide concentration. Maekawa et al. (1991) noted that the [NBO]/[Si] value for potassium and sodium silicate glasses are in good agreement with the expected values assuming that no free alkali oxides remain in the glass. However, the experimental $[\mathrm{NBO}] /[\mathrm{Si}]$ value for the lithium silicate glasses is lower than calculated. In agreement with other studies, Maekawa et al. (1991) accounted for this by suggesting that phase separation may be taking place for silicate glasses with less than 30 mol. $\% \mathrm{Li}_{2} \mathrm{O}$.

In another study, Yasui et al. (1994) examined the distribution of $\mathrm{Si}-\mathrm{O}-\mathrm{Si}$ bond angles for alkali metasilicates through the comparison of neutron and X-ray scattering data with molecular dynamics calculations. They found that sodium metasilicates have the narrowest distribution of bond angles (Fig. 17), with a $\mathrm{Si}-\mathrm{O}-\mathrm{Si}$ angle centered around $140^{\circ}$. Lithium, potassium and cesium metasilicates have a bimodal distribution of bond angles. In addition, cesium metasilicate glasses also have a distinct subpeak at a $\mathrm{Si}-\mathrm{O}-\mathrm{Si}$ angle of $96^{\circ}$. From this observation, Yasui et al. (1994) deduced that there is an optimal size, represented by $\mathrm{Na}$, for cations to be incorporated, with minimal deformation, into the glass network. Lithium ions were considered to be too small, resulting in less controlled inward bending of $\mathrm{Si}-\mathrm{O}-\mathrm{Si}$ angles. However, for larger cations, the $\mathrm{Si}-\mathrm{O}-\mathrm{Si}$ bond angles increase to accommodate the cation. Yasui et al. (1994) attributed the small Si-O-Si angle for cesium metasilicate glass, $96^{\circ}$, to edge-sharing of $\mathrm{SiO}_{4}$ tetrahedra, thus violating the Zachariasen's (1932) corner-sharing model. However, there has been no spectroscopic evidence to support the existence of such edge-sharing in cesium metasilicate glasses. In addition to this, Yasui et al. (1994) indicated that ring statistics for the structure of cesium metasilicate glass 


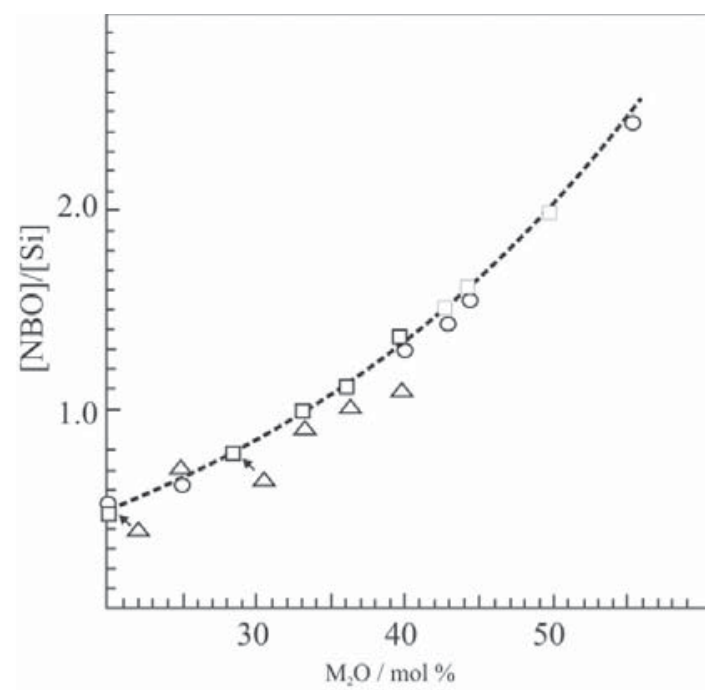

FIG. 16. Number of non-bridging oxygen per Si tetrahedron as a function of composition where $\Delta, \square$ and $\bigcirc$ represent lithium, sodium and potassium silicate glasses, respectively. The dashed line is the NBO/Si ratio expected from stoichiometry.

revealed the presence of several 2- and 3-membered rings. Yasui et al. (1994), therefore, suggested that for large cation modifiers, the glass structure is modified to form smaller rings.

Yasui et al. (1994) proposed a structural hypothesis for metasilicates in which the basic silicate structure is composed of one-dimensional $\mathrm{Si}-\mathrm{O}$ chains with alkali ions filling the free space (pockets) formed in the chain or between the chains. One should note, however, that the existence of chain structures within a silicate glass network has yet to be proven or observed through spectroscopic data. The model predicts that modifiers of optimum size, such as sodium, would therefore coordinate with three or four atoms of oxygen in the chain and two atoms of oxygen from another chain. Lithium is considered to be less than optimum in size; therefore, this cation coordinates with oxygen atoms from different chains. Stretching of silicate chains results from increasing bond-angles and allows larger modifying cations, such as potassium, to be accommodated. However, for cesium, Yasui et al. (1994) proposed that the cation is too large to be accommodated within the chain, and therefore some of the chains are extended, and some form small rings, thus accounting for the small bond-angles.

Uchino \&Yokko (1999) performed a study of sodium and lithium silicate glasses by $a b$ initio molecular orbital calculations. They reported that the $\mathrm{Si}-\mathrm{O}(\mathrm{BO})$ and the $\mathrm{Si}-\mathrm{O}$ (NBO) bonds for sodium silicate glass were longer and shorter, respectively, than the corresponding lithium silicate bond-distances. In addition to this, the difference in radii of sodium and lithium resulted in a larger coordination-number for sodium than for lithium in silicate glass. Uchino \& Yoko (1999) also noted that the local cation-environment is influenced by the electronegativities of the alkali cations. $\mathrm{Li}-\mathrm{O}$ bonds were calculated to have a greater bond-overlap and greater covalent interactions than $\mathrm{Na}-\mathrm{O}$ bonds. These results indicate that from lithium to sodium, the covalent interactions decrease, and the tendency of the alkali cations to interact with bridging and non-bridging atoms of oxygen rises, thus increasing the total coordination-number. Therefore, Uchino \& Yoko (1999) concluded that the coordination environment of alkali cations in silicate glasses is determined by both the size and molecular orbital interactions between alkali cations and the surrounding atoms of oxygen.

Meneau et al. (2001) studied the medium-range structure of potassium silicate glasses (5-35 mol.\% $\mathrm{K}_{2} \mathrm{O}$ ) using wide-angle X-ray scattering (WAXS) and ${ }^{29} \mathrm{Si}$ NMR. The FSDP in the WAXS data was interpreted as being indicative of correlations between voids in the glass network, which are formed by the repulsion of pairs of non-bonding electrons localized at the network atoms. Evidence for this was reflected as a decrease in the line width for the first diffraction-peak Their data indicate that the average void distance decreases with increasing $\mathrm{K}_{2} \mathrm{O}$ content. The addition of $\mathrm{K}_{2} \mathrm{O}$ results in the introduction of more lone electron pairs into the structure, thus creating more voids. With continued addition of $\mathrm{K}_{2} \mathrm{O}$, more NBOs are formed, and the network structure expands. To reduce the strain, the larger voids relax to form smaller ones, resulting in a more ordered overall structure. However, for compositions below $20 \mathrm{~mol} . \% \mathrm{~K}_{2} \mathrm{O}$, the first sharp diffractionpeak was observed to broaden, and this was interpreted as indicating phase separation.

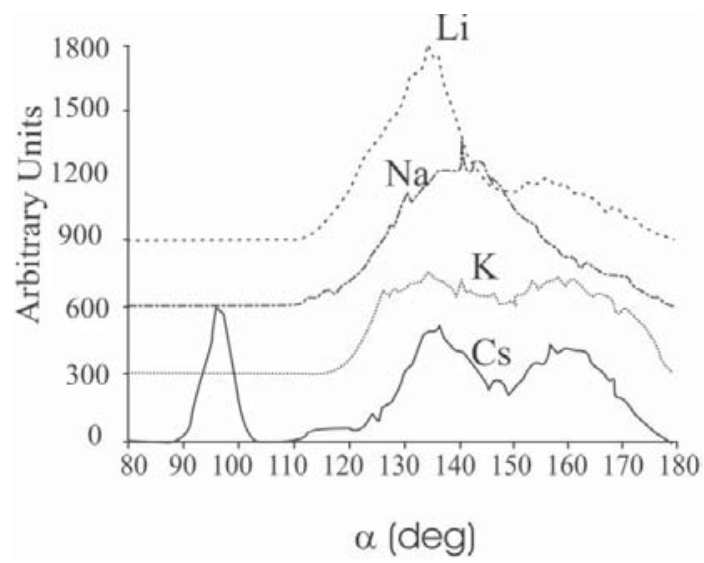

FIG. 17. Bond-angle distribution of Si-O-Si in four types of metasilicate glass. 
Olivier et al. (2001) compared double quantum (DQ) MAS NMR to MD simulations of binary alkali silicate glasses. As in previous studies, Olivier et al. (2001) observed a decrease in $\mathrm{Q}^{4}$ and increase in $\mathrm{Q}^{3}$ species with increasing sodium content. $\mathrm{Q}^{2}$ species also increased but were present only in relatively small amounts. Olivier et al. (2001) also observed $\mathrm{Q}^{4}$ species to be connected to other $\mathrm{Q}^{4}$ and $\mathrm{Q}^{3}$ species, thus suggesting that the DQ NMR results support the presence of silica-rich regions, in agreement with the MRN data.

Sen \& Youngman (2003) investigated, using ${ }^{29} \mathrm{Si}$ and ${ }^{17} \mathrm{O} N M R$, the $\mathrm{Q}^{\mathrm{n}}$ distribution and connectivity of potassium silicate glasses with silica contents ranging from 76.0 to $97.6 \mathrm{~mol} \%$. Their spectra provided evidence that $\mathrm{Q}^{3}$ species along with two different $\mathrm{Q}^{4}$ species exist in potassium silicate glasses with greater than $83.5 \mathrm{~mol} . \%$ $\mathrm{SiO}_{2}$. The ${ }^{17} \mathrm{O}$ MAS data indicate that the different $\mathrm{Q}^{4}$ species correspond to $\mathrm{Q}^{4}$ species connected to one or more $\mathrm{Q}^{3}$ nearest neighbors and $\mathrm{Q}^{4}$ species with only $\mathrm{Q}^{4}$ neighbors, denoted by $\mathrm{Q}^{4-3}$ and $\mathrm{Q}^{4-4}$, respectively. The concentration of $\mathrm{Q}^{4-3}$ species in the glasses was shown to agree well with predicted concentrations based on the statistically random distribution of $\mathrm{Q}^{3}$ and $\mathrm{Q}^{4}$ species. However, Sen \& Youngman (2003) proposed that the random distribution of $\mathrm{Q}^{\mathrm{n}}$ species leads to the formation of nanoclusters of $\mathrm{Q}^{3}$-rich regions in a $\mathrm{Q}^{4}$-rich matrix, with percolating $\mathrm{Q}^{3}$-rich clusters forming at $7.5 \mathrm{~mol} . \%$ $\mathrm{K}_{2} \mathrm{O}$ composition (see earlier comment on the term "clusters"). The formation of nanoclusters of $\mathrm{Q}^{3}$ species may consequently have an impact on the transport properties of the alkali silicate glasses by forming pathways for alkali diffusion and ionic conductivity.

X-ray photoelectron spectroscopy (XPS) has also been used to investigate the structure of silicate glasses even though it is primarily a surface technique. Highresolution XPS can distinguish between bridging and non-bridging oxygen atoms. Sprenger et al. (1993) presented XPS, Raman and NMR measurements of sodium silicate glasses. On the basis of these data, they developed the discrete bond model (DBM) to link the chemical shift of the BO and NBOs of the sodium silicate glasses with the structural changes in the glass network and change in alkali concentration. Figure 18 shows the O 1s XPS spectra of Sprenger et al. (1993) for a series of sodium silicate glasses of different compositions. The two clearly resolved signals correspond to the NBO and $\mathrm{BO}$ binding energies. In agreement with other alkali silicate studies, the NBO signal becomes more prominent with an increase in $\mathrm{Na}_{2} \mathrm{O}$ concentration. Figure 18 also shows that the binding energy of the NBOs and BOs shift to lower energies with increasing $\mathrm{Na}_{2} \mathrm{O}$ concentration. Sprenger et al. (1993) related the shift in binding energy to changes in the electronic structure of oxygen induced by the addition of cations with strong ionic character donating partial charges to both the $\mathrm{NBO}$ and $\mathrm{BO}$ atoms. In the discrete bond model, one assumes that the NBO and BOs of each Q species may have several different next-nearest neighbors. For example, a NBO will form a bond with $\mathrm{Na}$, but the NBO itself could be bound to a $\mathrm{Q}^{0}, \mathrm{Q}^{1}, \mathrm{Q}^{2}$ or $\mathrm{Q}^{3}$ species, and the energy associated with the NBO bond will be dependent upon which Q species it is attached to. The model can then be used to calculate oxygen distributions associated with the different possible configurations of Q species next-nearest neighbors and then to predict the energies of those configurations. Figure 19a illustrates the NBO distributions of Sprenger et al. (1993) calculated by the DBM, whereas Figures $19 \mathrm{~b}$ and $\mathrm{c}$ are for BO atoms. Two distributions are given depending upon whether or not the BOs are associated with a phase-separated region. The O 1s XPS measurements indicate that the distributions of oxygen bonds are different for phase-separated and non-phase-separated compositions. However, experimental evidence has shown that not all possible bridging oxygen bonds are energetically favored, and the DBM has not received wide acceptance.

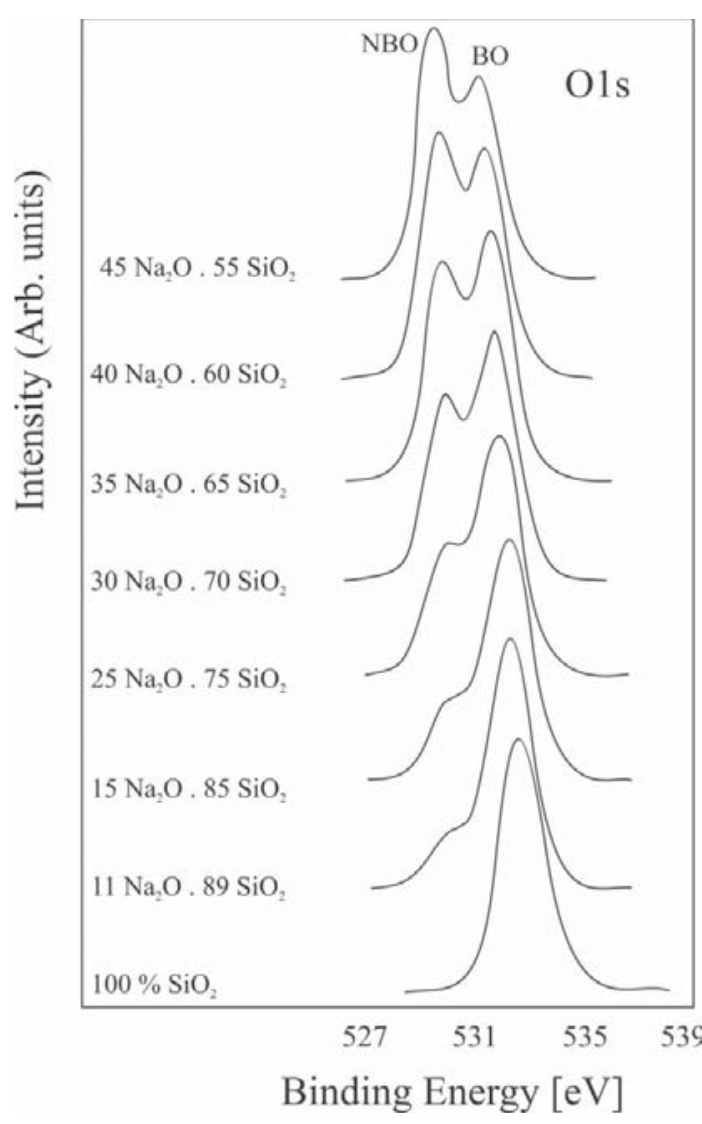

FIG. 18. O 1s XPS spectra of sodium silicate glasses of different compositions (after Sprenger et al. 1993). 
Mixed alkali silicate glasses

Mixed alkali silicate glasses are also useful models for understanding the dynamics of basaltic magmas and mantle melts. The rate at which different alkali ions diffuse and interact, together with varying proportions of ions, play crucial roles in melt behavior. The substitution of one alkali oxide for another leads to significant non-linear changes in a number of physical properties of glasses, such as electrical resistivity and expansion coefficients (Isard 1969). This effect is known as the mixed-alkali effect (MAE). However, despite many experimental and computational studies, the physical origin of the mixed alkali effect remains poorly understood.

Explanations of the MAE hypotheses have been dynamic in nature, involving either transport of alkalis through microdomains in phase-separated glasses

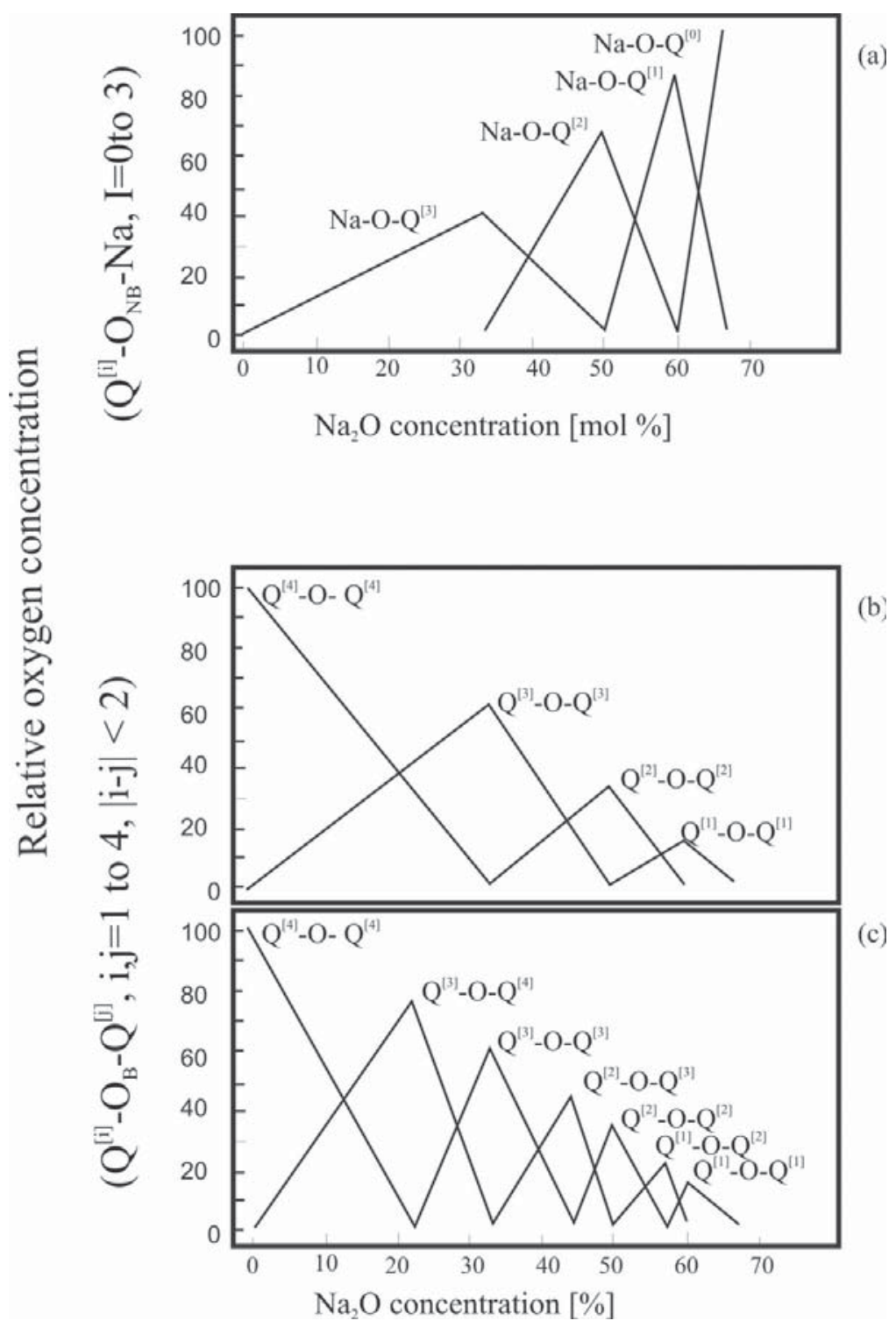

FIG. 19. Oxygen concentration (mol.\%) relative to the total oxygen content as calculated from the discrete bonding model for a) NBO bonds, b) phase-separated $\mathrm{BO}$, and c) non-phase-separated BO bonds (after Sprenger et al. 1993). 
or "blocking" of cation sites as alkalis migrate in an otherwise homogeneous network. For example, in the cluster bypass model, Ingram (1989) described MAE glass as a network of microdomains connected by a "tissue" of different composition, whereas in the mixed alkali-defect model, LaCourse (1987) proposed the existence of specific cation sites that can be occupied by foreign cations.

Most recently, MAE models have tended to favor the blocking of alkali sites as mobile ions migrate through the glass network. Swenson et al. (2001) proposed the random ion-distribution model. In this model, the alkalis are distributed randomly and maintain their respective local structural environments. The alkalis will effectively only occupy matching sites in the glass and will move or "jump" some distance to achieve this. The MAE effect arises from the large mismatch in energy for ionic jumps to dissimilar alkali sites. This results in blocking of alkali-migration pathways. A model that does not involve site blocking is that of Kircheim (2001).

Alternatively, Bunde et al. (2004) suggested the dynamic structure model (DSM) (cf. Bunde et al. 1991, Maass et al. 1992) as a more likely explanation. This model is similar to the random ion-distribution model, but involves modification of the environment of the mobile ions and the formation of empty alkali sites. For example, regular 'A' sites have a geometry that is optimized with respect to the space and energy requirements of the occupying cation. The ' $\mathrm{B}$ ' sites are sites that have previously been occupied by the second cation, and therefore have dimensions that are mismatched to the requirements of the first type of cation. 'B' sites consequently change into ' $A$ ' sites upon structural relaxation of the surrounding glass network after a corresponding change in occupying cations. For sodium-lithium glasses, there are matched $\mathrm{Na}_{\mathrm{Na}}$ sites and $\mathrm{Li}_{\mathrm{Li}}$ sites, as well as mismatched $\mathrm{Na}_{\mathrm{Li}}$ and $\mathrm{Li}_{\mathrm{Na}}$ sites. In a mixed Li-Na silicate glass, the $\mathrm{Li}$ cations will seek to occupy previously occupied Li sites rather than $\mathrm{Na}$ sites, and will move into those preferred sites more rapidly than they would into a Na site (Ingram \& Roling 2003). This may be accompanied by relaxation of the site when the alkali enters.

Regardless of the preferred model, one question common to all the models is: "What is the role of the glass network?". NMR spectroscopy has been widely used to investigate the structural environment of the alkalis, as well as the elements making up the glass network. However, owing to spectroscopic resolution, instead of observing separate NMR peaks corresponding to the different alkali sites above, changes in the center of gravity of the peaks are observed. These changes are represented by an average chemical shift value, arising from the contributions of both types of sites.

Bray et al. (1991) studied mixed lithium-potassium silicate glasses using ${ }^{29} \mathrm{Si},{ }^{7} \mathrm{Li}$ and ${ }^{6} \mathrm{Li}$ NMR. They showed that the NMR linewidths broaden and do not exhibit a linear dependence on alkali concentration. They concluded that the increased dipolar broadening and non-linear dependence results from pairing of likealkali cations (i.e., $\mathrm{Li}-\mathrm{Li}$ ) and not mixed alkali cation pairs $(\mathrm{Li}-\mathrm{K})$, as one might have expected. However, their ${ }^{29} \mathrm{Si}$ results indicate that the $\mathrm{Q}^{\mathrm{n}}$ distribution in mixed-alkali silicate glasses fit the trends one would expect by simply extrapolating from alkali silicates. They also reported that even though the mixed lithiumpotassium silicate glasses do not show any evidence of phase separation, the presence of the alkali pairing may indicate microscopic phase-separation.

Emerson \& Bray (1994) extended the work of Bray et al. (1991) by using transmission electron microscopy (TEM) to determine if the MAE is caused by phase separation. The TEM study indicated the presence of phase separation in the mixed $\mathrm{Li}-\mathrm{K}$ silicate glasses, with increased phase-separation at low $\mathrm{K}_{2} \mathrm{O}$ contents. However, they also concluded that although the NMR data indicate that $\mathrm{Li}-\mathrm{Li}$ pairing occurs in these glasses, the pairing is not confined to the phase-separated regions, and consequently, the observed MAE for these glasses is not related to phase separation.

Yap \& Elliott (1995) studied a series of lithiumsodium disilicate glasses by ${ }^{7} \mathrm{Li}$ NMR and by computer simulation. In agreement with the previous NMR studies reviewed above, they concluded that preferential clustering of like-alkali cations occurs. In addition, Yap \& Elliott (1995) suggested that there is a changeover in the preferred type of like-cation clustering near the $\mathrm{Li}-\mathrm{Na}$ equimolar ratio, indicating that it is the minority species that tends to cluster.

As an alternative, Gee et al. (1997) studied mixed Li-Na silicate glasses. They found the NMR chemical shifts to move in the same direction as an increase in the compositional parameter $\mathrm{Na} /(\mathrm{Na}+\mathrm{Li})$, thus providing evidence in support of the two-site hypothesis; the $\mathrm{Na}_{\mathrm{Na}}$ site probability will increase with increasing $\mathrm{Na} /(\mathrm{Na}$ $+\mathrm{Li}$ ), and the $\mathrm{Li}_{\mathrm{Na}}$ site probability also will increase with increasing $\mathrm{Na} /(\mathrm{Na}+\mathrm{Li})$. Their NMR data also indicate that the oxygen environments of the sodium sites undergo substantial changes as neighboring sites are filled by lithium. Furthermore, they concluded that monotonic compositional dependences of alkali NMR chemical shifts suggest an intimate mixing of lithium and sodium species, statistically mixed within an overall homogeneous spatial distribution, in agreement with the earlier results of Ali et al. (1995). However, these findings contradict the evidence for like-cation association discussed above. Similar results to those of Gee et al. (1997) have been made for sodium-cesium (Dupree et al. 1986) and sodium-rubidium (Hater et al. 1989) silicate glasses.

Florian et al. (1996) used NMR to probe the structure of sodium and potassium mixed-alkali glasses of varying composition. The NMR data revealed that each non-bridging oxygen atom is randomly coordinated with a combination of four alkali cations. A similar 
conclusion was made by Greaves et al. (1991), who found that the coordination number of the NBOs does not change with increasing addition of potassium and reduction in sodium.

Greaves (1998) studied the microstructure, alkali environment and hopping mechanisms of mixed-alkali silicates using small-angle X-ray scattering (SAXS), XAFS and MD simulations. He reported that the alkali environment in single and mixed-alkali glasses of composition $\left(\mathrm{K}_{x} \mathrm{Cs}_{(1-x) 2} \mathrm{Si}_{2} \mathrm{O}_{5}\right)$ has an oxygen coordination number between 5 and 6 for both $\mathrm{K}$ and Cs. However, by analyzing Debye-Waller factors for potassium-cesium glasses, an improvement in local order was indicated by XAFS as the concentration of each alkali falls below $50 \%$. Consequently, a change in glass composition would change the configuration of neighboring alkalis.

Stebbins (1998) reported correlations between recent NMR data and site size and bond distances of mixed-alkali silicate glasses. Stebbins (1998) noted that oxide glasses containing only sodium or lithium as the single network modifier trend toward higher values of the NMR chemical shifts with increasing ratio of non-bridging oxygen atoms to tetrahedral network-forming cations (NBO/T). He also noted that the cation environments are influenced by the size of the alkali cations. Stebbins (1998) concluded that for mixed alkali silicate glasses, the average size of the sites occupied by a given cation, along with the coordination number, increases with substitution by a smaller cation, and decrease with substitution by a larger cation. The competition for NBOs greatly influences this observed trend because NBO sites are the sites with the greatest concentration of negative charge in silicates. Therefore, at a given NBO/T value, a certain amount of NBO will be distributed around the modifying alkali cations according to their field strength. Small or more highly charged cations have relatively small coordinationshells, and therefore contain a higher number of NBO atoms than cations with larger sizes and lower charges. The larger, lower-charge cations contain a smaller proportion of NBOs and a higher proportion of BOs, thus corresponding to longer mean bond-distances. This was observed as a decrease in ${ }^{23} \mathrm{Na}$ chemical shift for $\mathrm{Na}-\mathrm{Li}$ silicate glasses. Stebbins (1998) generalized the effect of unlike cations on the coordination environment. He proposed that if the coordination number of one cation type decreases, then there is likely to be an increase in the coordination of the other cation. In addition to this, the overall mean size of the alkali site decreases with the replacement of smaller cations for larger cations. More recently, Lee \& Stebbins (2003) have investigated cation mixing in $\mathrm{Na}-\mathrm{Ca}$ silicate melts. They found evidence for $\mathrm{Na}-\mathrm{Ca}$ pairs and of interactions between network-modifying pairs and the bridging and non-bridging atoms of oxygen.

To date, although there is some movement toward agreement on the dynamic cause of the MAE, the underlying structural mechanism remains unresolved. For mixed-alkali systems, like-cation pairing appears to occur, whereas for alkali - alkaline-earth pairing, nonlike-cation pairing seems indicated. Furthermore, there is obviously some influence of the alkali cations on the $\mathrm{NBO}$ and $\mathrm{BO}$ distribution, and subsequently on the silicate network as a whole. However, much more work is required before a full understanding is achieved.

\section{INTERMEDIATE OXIDES (Al, Ti, Fe)}

Intermediate oxides such as aluminum $(\mathrm{Al})$, iron (Fe) and titanium (Ti) may act as network formers or network modifiers, depending upon whether they are 4-fold coordinated or 6-fold coordinated, respectively. If incorporated into the glass structure as tetrahedra, they will act as network formers; if, however, they change coordination and form octahedra, then they will act as network modifiers, disrupting the glass network. Naturally these cations are very important in silicate melt studies, as they are commonly found in natural melts, and there have been many studies on melts and glasses incorporating one or more of these elements (Fe: Jayasuriya et al. 2004, Magnien et al. 2004, Ti: Henderson et al. 2003, Roskosz et al. 2004, Al: Lee et al. 2004, Neuville et al. 2004a). However, many of these authors have utilized compositions that are inherently complex structurally. Here, I review, from a glass-structure perspective, what is known about the structural role of these intermediate oxides, but only for simple compositions; in particular, I explore the effect of adding one of these oxides to $\mathrm{SiO}_{2}$ glass, and then the case of adding a single network modifier, such as Na.

\section{Aluminum $\left(A l^{3+}\right)$}

According to Zachariasen's rules, $\mathrm{Al}^{3+}$ will act as a network former if in tetrahedral coordination and as a network modifier if it has a higher coordination. Consequently, the structural environment of $\mathrm{Al}^{3+}$ within the glass network is important for understanding the behavior of aluminosilicate glasses. However, this environment is somewhat complicated by the need for $\mathrm{Al}^{3+}$ to be charge-compensated by another cation, where $\mathrm{Al}^{3+}$ substitutes for $\mathrm{Si}^{4+}$.

Direct structural studies of $\mathrm{Al}_{2} \mathrm{O}_{3}-\mathrm{SiO}_{2}$ melts and glasses have been carried out (cf. Morikawa et al. 1982, Brown et al. 1995 and references therein, Stebbins 1995, McMillan \& Wolf 1995). Morikawa et al. (1982) carried out an X-ray-scattering study of a number of compositions along the join $\mathrm{Al}_{2} \mathrm{O}_{3}-\mathrm{SiO}_{2}$. They noted that these glasses are phase-separated into a $\mathrm{SiO}_{2}$-rich and an $\mathrm{Al}_{2} \mathrm{O}_{3}$-rich phase. Their results showed that the $\mathrm{Al}$ environment in the $\mathrm{Al}_{2} \mathrm{O}_{3}$-rich phase resembles that found in mullite, and they suggested that $\mathrm{Al}$ is probably in both octahedral and tetrahedral coordination as triclusters (see below). However, as glasses quenched from compositions along this join are indeed 
phase-separated (Takei et al. 2001), any conclusions concerning the structural role of $\mathrm{Al}^{3+}$ must be carefully evaluated.

More recently, NMR studies indicate that $\mathrm{Al}$ in these glasses is 4- or 6-fold coordinated (Schmucker et al. 1997), with a third Al environment present. The third $\mathrm{Al}$ environment indicated by the NMR data has been assigned to either 5-fold Al (Risbud et al. 1987) or Al triclusters (Schmucker et al. 1997). However, MD simulations of glasses along this compositional join ( $c f$. Winkler et al. 2004) indicate that $\mathrm{Al}^{3+}$ is mostly 4-foldcoordinated by oxygen atoms with the $\mathrm{AlO}_{4}$ tetrahedra forming small rings and triclusters. More specifically, Winkler et al. (2004) found that a typical configuration is two-membered $\mathrm{AlO}_{4}$ rings where the shared $\mathrm{O}$ atoms form a tricluster with either $\mathrm{Si}$ or Al.

Alkali-containing Al-silicate glasses have also been investigated using X-ray scattering. Glasses of $\mathrm{NaAlSi}_{3} \mathrm{O}_{8}$ and $\mathrm{KAlSi}_{3} \mathrm{O}_{8}$ composition were investigated by Taylor \& Brown (1979a, b). With a RDF analysis and quasi-crystalline model, they found that these glasses have a ring topology consistent with sixmembered rings similar to those found in tridymite. This was not the same as that found in glasses of composition $\mathrm{CaAl}_{2} \mathrm{Si}_{2} \mathrm{O}_{8}$, where the ring topology is more consistent with four-membered $\mathrm{SiO}_{4}$ rings similar to those found in feldspars.

Raman and NMR studies of alkali- and alkalineearth-containing $\mathrm{Al}$-silicate glasses indicate that $\mathrm{Al}^{3+}$ is in tetrahedral coordination ( $c f$. Stebbins 1995).

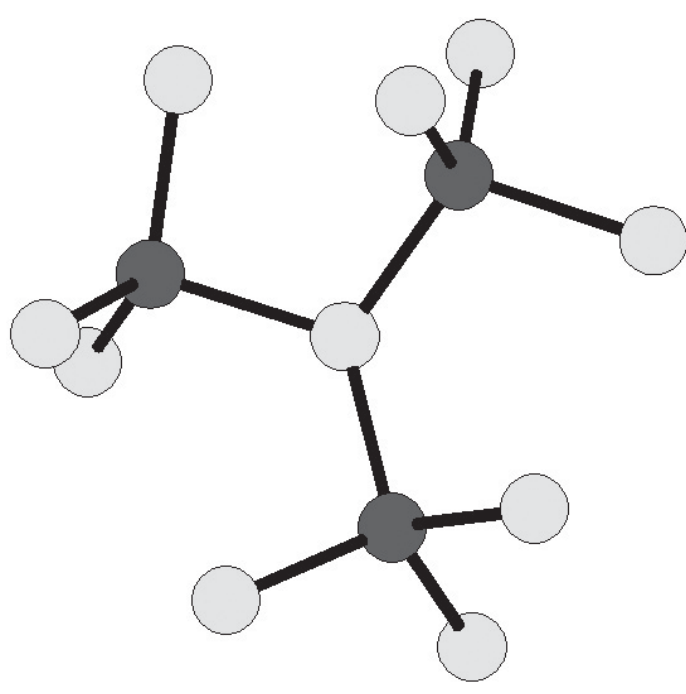

FIG. 20. Oxygen tricluster similar to that found in $\mathrm{CaAl}_{4} \mathrm{O}_{7}$ (Goodwin \& Lindop 1970). An oxygen atom (light gray) is shared between three $\mathrm{AlO}_{4}$ tetrahedra. If triclusters form in a glass, $\mathrm{Al}^{3+}$ does not need to be charge-compensated by a nearby network modifier.
However, in alkali- or alkaline-earth-containing glasses in which the ratio of charge-compensating network modifiers (such as alkalis or alkaline earths) to $\mathrm{Al}_{2} \mathrm{O}_{3}$ is $<1, \mathrm{Al}$ is in excess of the network modifiers required for charge balance. As a consequence of this, these glasses exhibit anomalous behavior of physical properties ( $c f$. Toplis et al. 1997) such as viscosity, which has been traditionally explained by the formation of six-fold Al. As these glass compositions are peraluminous, there is a deficiency in the cations required to charge-compensate the $\mathrm{Al}^{3+}$, and consequently one would expect $\mathrm{Al}$ to exist in higher coordinations. However, little six-fold $\mathrm{Al}$ is observed in these glasses. The current explanation for this behavior is that $\mathrm{Al}$ forms oxygen triclusters (Fig. 20), as first proposed by Lacy (1963). These triclusters have, however, not been conclusively demonstrated by structural techniques such as ${ }^{17} \mathrm{O}$ NMR $(c f$. Schmucker et al. 1997, Stebbins et al. 2001), but are formed in MD simulations ( $c f$. Cormier et al. 2003, Winkler et al. 2004). Furthermore, recent NMR data do indicate the presence of significant proportions of 5-fold $\mathrm{Al}$ in these glasses (Neuville et al. 2004a), which may indicate that oxygen tri-clusters, if present, are not as important as previously thought (Neuville et al. 2004a). Observation of such triclusters and their relative importance in glass behavior is an ongoing area of interest.

In Ca-containing aluminosilicate glasses, at high silica or $\mathrm{Al}_{2} \mathrm{O}_{3}$ contents, $\mathrm{Al}$ is found to enter the network as $\mathrm{Q}^{4} \mathrm{AlO}_{4}$ tetrahedra and acts as a pure network former. However, at lower $\mathrm{SiO}_{2}$ or $\mathrm{Al}_{2} \mathrm{O}_{3}$ contents, $\mathrm{Al}$ will form $\mathrm{Q}^{2}, \mathrm{Q}^{3}$ and $\mathrm{Q}^{4}$ tetrahedra (cf. Neuville et al. 2004a, b) and exhibits a preference for forming tetrahedra with NBOs while retaining tetrahedral coordination. In addition, $\mathrm{MD}$ simulations of $\mathrm{CaO}-\mathrm{Al}_{2} \mathrm{O}_{3}-\mathrm{SiO}_{2}$ glasses indicate that $\mathrm{Al}$ is in tetrahedral coordination, with only $1-2 \%$ of $\mathrm{Al}$ atoms in five-fold geometry. Furthermore, Al triclusters are in greater abundance in the more polymerized compositions (Cormier et al. 2003).

Iron $\left(F e^{2+} / F e^{3+}\right)$

Studies of Fe-containing glasses are complicated by the fact that $\mathrm{Fe}$ can exist in two oxidation states $\left(\mathrm{Fe}^{2+}\right.$ and $\mathrm{Fe}^{3+}$ ), each oxidation state may occur in different polyhedral configurations $\left({ }^{[4]} \mathrm{Fe},{ }^{[5]} \mathrm{Fe}\right.$ or ${ }^{[6]} \mathrm{Fe}$ ), and some $\mathrm{Fe}^{2+}$ is usually produced in small quantities when an $\mathrm{Fe}^{3+}$-containing silicate liquid is quenched to a glass. Nevertheless, several investigators have probed the nature of $\mathrm{Fe}$ in $\mathrm{SiO}_{2}$, and alkali- and alkaline-earthcontaining silicate glasses. An excellent review of theses studies is given by Brown et al. (1995).

Early studies of $\mathrm{FeO}-\mathrm{SiO}_{2}$ and $\mathrm{FeO}-\mathrm{Fe}_{2} \mathrm{O}_{3}-\mathrm{SiO}_{2}$ melts (cf. Brown et al. 1995) indicated that $\mathrm{Fe}^{2+}$ is in octahedral coordination in FeO-rich liquids, but tetrahedral configurations become predominant as $\mathrm{SiO}_{2}$ is added. However, Jackson et al. (1993) later showed that $\mathrm{Fe}^{2+}$ is tetrahedral in a melt of fayalite composition. These studies were performed on melts and not glasses, 
as quenching these liquids results in the formation of crystalline $\mathrm{Fe}_{2} \mathrm{SiO}_{4}$ and cristobalite (Nanri et al. 1996). Consequently, the majority of studies on $\mathrm{Fe}$ in glasses have involved alkali- or alkaline-earth-containing silicate glasses. By and large, early studies of Fe-containing alkali silicate glasses suggested that $\mathrm{Fe}^{3+}$ occurs as both ${ }^{[4]} \mathrm{Fe}$ and ${ }^{[6]} \mathrm{Fe}$, and $\mathrm{Fe}^{2+}$, as ${ }^{[6]} \mathrm{Fe}$ in alkali-silicate glass networks [ $c f$. Fleet et al. (1984), and Henderson et al. (1984) for a discussion of the early literature, and Brown et al. (1995)]. This debate has continued in recent years, but is further complicated by the observation of ${ }^{[5]} \mathrm{Fe}$ in many $\mathrm{Fe}$-containing glasses ( $c f$. Brown et al. 1995, Rossano et al. 2000a, b). In a series of relatively oxidized Li-, $\mathrm{Na}$ - and $\mathrm{Ca}$-containing $\mathrm{Fe}$-silicate glasses, Burkhard (2000) used Mössbauer spectroscopy to show that $\mathrm{Fe}^{3+}$ is in four-fold coordination in the Na glasses, in a mixture of four- and six-fold coordination in the Ca-containing glasses, and in six-fold coordination in the Li-containing glasses. Nagata \& Hayashi (2001) found, in similar Ca-containing Fe-silicate glasses, $\mathrm{Fe}^{2+}$ in tetrahedral coordination and $\mathrm{Fe}^{3+}$ in both fourand six-fold coordination. Alternatively, Rossano et al. (2000a, b) found, using EXAFS and MD simulations, that $\mathrm{Fe}^{2+}$ was present as a mix of four- and five-fold coordinations in reduced Ca-containing Fe-silicate glasses. Magnien et al. (2004) investigated the kinetics of iron oxidation in Fe-bearing glasses of pyroxene composition and obtained $\mathrm{Fe}^{3+}$ in four-fold coordination and $\mathrm{Fe}^{2+}$ in six-fold coordination, again based on curve fitting of the Fe $K$-edge XANES pre-edge peak. They also noted that the respective coordination-environments were retained when reduced glasses containing predominantly $\mathrm{Fe}^{2+}$ are oxidized.

Recent work utilizing the EXAFS-XANES and MD simulations on glasses of geological interest suggests that the coordination of $\mathrm{Fe}^{2+}$ is close to five, whereas $\mathrm{Fe}^{3+}$ may vary from four- to six-fold coordination, depending on composition (Farges et al. 2004, 2005). However, these results are somewhat variable depending upon whether the Fe coordination has been determined using XANES-EXAFS or Mössbauer spectroscopy. In addition, the ability to distinguish true five-fold $\mathrm{Fe}\left({ }^{[5]} \mathrm{Fe}\right)$ using the pre-edge features as opposed to a mixture of four- and six-fold Fe remains difficult (Wilke et al. 2004). EXAFS-XANES data generally involve fitting of a pre-edge peak in the $\mathrm{Fe}$ $K$-edge XANES (Galoisy et al. 2001, Petit et al. 2001, Berry et al. 2003, Wilke et al. 2004, Farges et al. 2004) or modeling of the XANES spectrum itself (Farges et al. 2004), whereas the Mössbauer spectra are fit using different procedures depending upon whether (or not) the characteristic line-broadening observed in glasses due to variations in site distributions has been accounted for (Rossano et al. 1999). Furthermore, there has been a tendency in the recent literature to overemphasize the MD results. One should be cautious in utilizing MD results. It must be remembered that these calculations, although extremely helpful in interpreting experimental data, remain theoretical, and their results should not be accepted in preference to experimental data ( $c f$. Rossano et al. 2000b).

Finally, direct structural studies of Fe-containing glasses using $\mathrm{X}$-ray or neutron scattering remain relatively uncommon. Henderson et al. (1984) investigated the structure of $\mathrm{NaFeSi}_{3} \mathrm{O}_{8}$ and $\mathrm{KFeSi}_{3} \mathrm{O}_{8}$ by $\mathrm{X}$-ray scattering. They were unable to resolve individual $\mathrm{Fe}-\mathrm{O}$ distances owing to the poor resolution of their data, but they did model the glass RDFs using crystalline analogues. The albite composition RDF most closely resembled a calculated RDF based on a structure involving six- and four-membered $\mathrm{SiO}_{4}$ rings, whereas the orthoclase composition was predominantly composed of six-membered rings. Holland et al. (1999) recently used neutron scattering to investigate a series of $\mathrm{Na}-\mathrm{Fe}$-silicate glasses. Their data suggest that $\mathrm{Fe}$, regardless of its oxidation state, is four-fold-coordinated $\left({ }^{[4]} \mathrm{Fe}\right)$ with oxygen, consistent with earlier studies, and that it is possibly in a square planar configuration. Similar results were obtained by Johnson et al. (1999) on another series of Na-containing Fe-silicate glasses with $\mathrm{Fe}-\mathrm{O}$ distances measured around $1.90 \AA$, and decreasing as more $\mathrm{Fe}_{2} \mathrm{O}_{3}$ is added.

To date there appears to be some consensus in that $\mathrm{Fe}^{3+}$ in $\mathrm{Na}$ - and $\mathrm{K}$-containing silicate glasses is in four-fold coordination. Lithium-containing Fe-silicate glasses appear to have $\mathrm{Fe}^{3+}$ in higher coordination (five or six), whereas alkaline-earth-containing glasses have $\mathrm{Fe}^{3+}$ with more variable coordinations $\left({ }^{[4]} \mathrm{Fe},{ }^{[5]} \mathrm{Fe}\right)$. Ferrous iron appears to have a coordination of either four $\left({ }^{[4]} \mathrm{Fe}\right)$ or five $\left({ }^{[5]} \mathrm{Fe}\right)$ in alkali- and alkaline-earthcontaining silicate glasses.

\section{Titanium $\left(\mathrm{Ti}^{4+}\right)$}

The structural role of $\mathrm{Ti}$ in glasses has been extensively studied owing to its influence on the physical and chemical behavior of silicate glasses, e.g., ultralow thermal expansion properties ( $c f$. Henderson \& Fleet 1995). For glasses along the $\mathrm{TiO}_{2}-\mathrm{SiO}_{2}$ join, it has been found that $\mathrm{Ti}$ is incorporated into the glass network exclusively in four-fold coordination $\left({ }^{[4]} \mathrm{Ti}\right.$ ) and essentially acts as a network former replacing $\mathrm{Si}$ ( $c f$. Henderson \& Fleet 1995, 1997, Henderson et al. 2003). An exception to this finding occurs where a network modifier is present (see below) or at very low $\mathrm{TiO}_{2}$ contents. Greegor et al. (1983) inferred the occurrence of ${ }^{[6]} \mathrm{Ti}$ in compositions along the $\mathrm{TiO}_{2}-\mathrm{SiO}_{2}$ join with very low $\mathrm{TiO}_{2}$ contents, whereas Henderson et al. (2002) found no evidence for this coordination, but suggested instead ${ }^{[5]} \mathrm{Ti}$ as the predominant coordination below $3.6 \mathrm{wt} \% \mathrm{TiO}_{2}$. The reason for the presence of a more highly coordinated Ti species such as ${ }^{[5]} \mathrm{Ti}$ at low $\mathrm{TiO}_{2}$ contents is unclear. Greegor et al. (1983) suggested that the higher Ti coordination is due to the formation of octahedral holes within the glass network that are 
generated by breaking bridging atoms of oxygen bonds as the $\mathrm{TiO}_{2}$ is incorporated into the network.

Henderson \& Fleet (1995) noted that some NBO vibrations are apparent in the Raman spectra of the $\mathrm{TiO}_{2}-\mathrm{SiO}_{2}$ glasses. The formation of these NBOs is consistent with the generation of ${ }^{[5]} \mathrm{Ti}$ in a square pyramidal configuration (Farges 1996, Farges et al. 1996) with four Ti-O bonds and one titanyl bond $(\mathrm{Ti}=\mathrm{O})$. The titanyl bond is a NBO bond (Farges 1997). One explanation for the formation of ${ }^{[5]} \mathrm{Ti}$ may be that it is a result of the method of preparation. Greegor et al. (1983) prepared their glasses using a flame hydrolysis method, whereas the glasses of Henderson \& Fleet (1995) and Henderson et al. (2002) were prepared using sol-gel techniques. In the latter method, the precursor gel is a complex mixture of micelle-like regions, which have high surface-areas. Consequently, during annealing at higher temperatures, a large number of NBOs may be present, which may preferentially result in the formation of ${ }^{[5]} \mathrm{Ti}$ in the initial stages of glass formation. This would be consistent with the fact that Henderson et al. (2002) obtained the more highly coordinated Ti over a broader compositional range than did Greegor et al. (1983), whose method of preparation would not produce a large number of NBOs.

Upon the addition of a network modifier, the coordination of Ti changes, with higher-coordination Ti polyhedra being formed. By and large, early investigators suggested that the more highly coordinated Ti species is ${ }^{[6]} \mathrm{Ti}$, and that the glasses contain a mixture of ${ }^{[4]} \mathrm{Ti}$ and ${ }^{[6]}$ Ti (e.g., Rao 1963, Hanada \& Soga 1980, Wright et al. 1987, Sandstrom et al. 1980, Greegor et al. 1983, Emili et al. 1985). Rao (1963) suggested that Ti acts

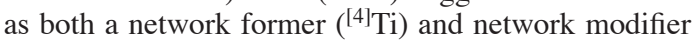
$\left({ }^{[6]} \mathrm{Ti}\right)$ in $\mathrm{K}_{2} \mathrm{O}$-containing Ti-silicate glasses. Mysen et al. (1980) found only ${ }^{[4]} \mathrm{Ti}$ in both alkali- and alkaline-earth-containing glasses. Hanada \& Soga (1980) suggested the presence of ${ }^{[6]} \mathrm{Ti}$ at low $\mathrm{TiO}_{2}$ content and ${ }^{[4]} \mathrm{Ti}$ at high $\mathrm{TiO}_{2}$ contents in $\mathrm{Na}_{2} \mathrm{O}$-containing Ti-silicate glasses. Dickinson \& Hess (1985) have suggested similar results for $\mathrm{Ti}$ in both $\mathrm{K}_{2} \mathrm{O}-\mathrm{Al}_{2} \mathrm{O}_{3}-\mathrm{SiO}_{2}$ and $\mathrm{CaO}-\mathrm{Al}_{2} \mathrm{O}_{3}-\mathrm{SiO}_{2}$ glasses. Hidaka et al. (1985) proposed the presence of ${ }^{[4]} \mathrm{Ti}$ in $\mathrm{Na}_{2} \mathrm{O}$-containing glasses, whereas Kusabiraki (1987) suggested the presence of both ${ }^{[4]} \mathrm{Ti}$ and ${ }^{[6]} \mathrm{Ti}$ in glasses of similar composition. Mysen \& Neuville (1995) suggested the presence of ${ }^{[4]} \mathrm{Ti}$ only in $\mathrm{Na}_{2} \mathrm{Si}_{2} \mathrm{O}_{5}-\mathrm{Na}_{2} \mathrm{Ti}_{2} \mathrm{O}_{5}$ glasses. Density and partial molar volume measurements performed on $\mathrm{Na}_{2} \mathrm{SiO}_{3}-\mathrm{TiO}_{2}$ and $\mathrm{CaSiO}_{3}-\mathrm{TiO}_{2}$ melts (Dingwell 1992a, b) implied that Ti must be four-fold coordinated in alkali-containing silicate melts, but six-fold coordinated in alkaline-earth-containing silicate melts. As an alternative, Yarker et al. (1986) suggested that Ti occurs as ${ }^{[5]} \mathrm{Ti}$ in $\mathrm{K}_{2} \mathrm{O}$-containing glasses, whereas Paris et al. (1994) suggested the presence of ${ }^{[5]} \mathrm{Ti}$ in low-pressure $\mathrm{K}_{2} \mathrm{O}$-containing Ti-silicate glasses, with a change to ${ }^{[6]} \mathrm{Ti}$ at high pressure. Similarly, Dingwell (1992a, b) and Dingwell et al. (1994) have suggested that ${ }^{[5]} \mathrm{Ti}$ (or ${ }^{[4]} \mathrm{Ti}$ ) may occur in alkali Ti-silicate glasses, and ${ }^{[6]} \mathrm{Ti}$ in alkaline-earth Ti-silicate glasses. Ponader et al. (1996) have suggested that $\mathrm{Ti}$ is mainly ${ }^{[6]} \mathrm{Ti}$ in sodium titanium silicate glasses, but increasing amounts of ${ }^{[5]} \mathrm{Ti}$ are found as the silica content decreases. Henderson \& Fleet (1995) found ${ }^{[4]} \mathrm{Ti}$ at low $\mathrm{TiO}_{2}$ contents in alkalicontaining Ti-silicate glasses, but ${ }^{[5]} \mathrm{Ti}$ predominant at high $\mathrm{TiO}_{2}$ contents. They noted a predominance of ${ }^{[4]} \mathrm{Ti}$ with some ${ }^{[5]} \mathrm{Ti}$ at low $\mathrm{TiO}_{2}$ contents, but a mixture of coordinations with increasing $\mathrm{TiO}_{2}$ content. At high $\mathrm{TiO}_{2}$ contents in alkali-containing Ti-silicate glasses, the coordination of $\mathrm{Ti}$ appears to be almost exclusively ${ }^{[5]} \mathrm{Ti}$ (Yarker et al. 1986, Cormier et al. 1998, 2001, Farges 1999).

In alkaline-earth glasses, Henderson et al. (2002) found ${ }^{[4]} \mathrm{Ti}$ to be again present at low $\mathrm{TiO}_{2}$ contents and ${ }^{[5]} \mathrm{Ti}$ at high $\mathrm{TiO}_{2}$ contents. However, unlike the alkali Ti-silicate glasses, ${ }^{[4]} \mathrm{Ti}$ was also found to be important in the alkaline-earth glasses at high $\mathrm{TiO}_{2}$ contents; the alkaline-earth glasses contain more of a mixture of ${ }^{[4]} \mathrm{Ti}$ and ${ }^{[5]}$ Ti. However, Henderson et al. (2003) noted that alkaline-earth-containing Ti-silicate glasses have ${ }^{[4]} \mathrm{Ti}$ almost exclusively at the highest $\mathrm{TiO}_{2}$ contents. This is not consistent with the finding that $\mathrm{Ca}$-containing Ti-silicate glasses should have $\mathrm{Ti}$ in higher coordination than equivalent alkali-containing compositions, as suggested by Dingwell et al. (1994) or Farges et al. (1996), but it is consistent with other work by Dingwell et al. (1994), who noted that compositions of the larger modifiers appear to favor the formation of the lower

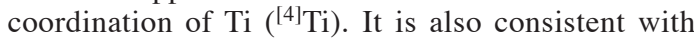
the findings of Dingwell (1992b), who observed that shear viscosities of alkaline-earth-containing Ti-silicate glasses are higher than for alkali-containing glasses, and with the viscosity data of Webb \& Dingwell (1994). In the latter study, and in order to explain high viscosities for Ca-containing Ti-silicate glasses, Webb \& Dingwell had suggested that a decrease in the average coordination number of Ti results in an increase in melt viscosity due to stiffening of the structure. A two-site model for Ti in Ti-silicate glasses, as suggested by previous studies, appears to be correct; however, the Ti environment consists of ${ }^{[4]} \mathrm{Ti}$ and ${ }^{[5]} \mathrm{Ti}$ rather than ${ }^{[4]} \mathrm{Ti}$ and ${ }^{[6]} \mathrm{Ti}$.

\section{SUMMARY}

Clearly, the structure of even compositionally simple glasses is complex. For a glass such as $\mathrm{SiO}_{2}$, the $\mathrm{SiO}_{4}$ tetrahedron is identified as the basic building block, and the extended three-dimensional structure can be described as a network of corner-sharing $\mathrm{SiO}_{4}$ tetrahedra with bridging atoms of oxygen shared between adjacent $\mathrm{Si}$ atoms. This extended structure appears to consist of rings of tetrahedra, with many of these rings being similar to those found in one or more of the crystalline $\mathrm{SiO}_{2}$ polymorphs. With the addition of network modifiers such as alkali cations, the continuous $\mathrm{SiO}_{4}$ network is modified by the breaking of $\mathrm{Si}-\mathrm{O}-\mathrm{Si}$ 
bridging bonds to form non-bridging oxygen atoms and $\mathrm{Q}^{\mathrm{n}}$ species. The structural complexity also is increased. There are variations in $\mathrm{Si}-\mathrm{O}$ bond lengths, as well as changes in the $\mathrm{Si}-\mathrm{O}-\mathrm{Si}$ bond angle as network modifiers are added to the glass. The number and types of $\mathrm{Q}^{\mathrm{n}}$ species are dependent upon the type of network modifier that is added. In addition, where two different alkali cations are incorporated into a glass, the structural response of the network is not a simple combination of the structural changes expected from addition of each alkali alone. Numerous experimental and theoretical studies have resulted in a variety of models of the glass structure, such as the continuous and modified random-network models. Despite the complexities and limitations in dealing with these materials, current knowledge and understanding of their structure have substantially progressed from the early studies, and this has been in large part due to continued interest in the physical and chemical behavior of silicate melts by geological investigators.

\section{ACKNOWLEDGEMENTS}

This work was funded by NSERC in the form of a Discovery grant to GSH. Mike Fleet and Laurent Cormier are thanked for their detailed reviews and constructive comments. Graduate students L. Soltay and $\mathrm{H}$. Wang are thanked for help with compiling figures and references. F. Farges provided preprints of his work, whereas M. Micoulaut ensured that my explanation of the mean field-constraint hypothesis is coherent.

\section{REFERENCES}

Ali, F., Chadwick, A.V., Greaves, G.N., Jermy, M.C., Ngai, K.L. \& Sмітн, M.E. (1995): Examination of the mixed alkali-effect in (Li,Na) disilicate glasses by nuclear magnetic resonance and conductivity experiments. Solid State Nucl. Mag. Res. 5, 133-143.

BELL, R.J. \& DEAN, P. (1972): The structure of vitreous silica: validity of the random network theory. Phil. Mag. 25, 1381-1398.

Berry, A.J., O'Neill, H.S.C., Jayasuriya, K.D., CAmpbell, S.J. \& ForAN, G.J. (2003): XANES calibrations for the oxidation state of iron in silicate glass. Am. Mineral. 88, 976-977.

Bockis, J.O., Tomlinson, J.W. \& White, J.L. (1956): The structure of liquid silicates. Partial molar volumes and expansivities. Trans. Farad. Soc. 52, 299-310.

Boolchand, P., FenG, X. \& Bresser, W.J. (2001b): Rigidity transitions in binary Ge-Se glasses and the intermediate phase. J. Non-Cryst. Solids 293-295, 348-356.

Georgiev, D.G. \& Goodman, B. (2001a): Discovery of the intermediate phase in chalcogenide glasses. $J$. Opt. Adv. Mater. 3, 703-720.
Bray, P.J., EMERSon, J.F., DonghoON, L., Feller, S.A., BAIN, D.L. \& FeIL, D.A. (1991): NMR and NQR studies of glass structure. J. Non-Cryst. Solids 129, 240-248.

Brown, G.E., JR., FARGES, F. \& CALAS, G. (1995): X-ray scattering and X-ray spectroscopy studies of silicate melts. In Structure, Dynamics, and Properties of Silicate Melts (J.F. Stebbins, P.F. McMillan \& D.B. Dingwell, eds.). Rev. Mineral. 32, 317-409.

BRuning, R. \& CotTrell, D. (2003): X-ray and neutron scattering observations of structural relaxation of vitreous silica. J. Non-Cryst. Solids 325, 6-15.

Bunde, A., Ingram, M.D., Maass, P. \& NGai, K.L. (1991): Mixed alkali effects in ionic conductor: a new model and computer simulations. J. Non-Cryst. Solids 131-133, 1109-1112.

\& Russ, S. (2004): A new interpretation of the dynamic structure model of ion transport in molten and solid glasses. Phys. Chem., Chem. Phys. 6, 3663-3668.

BURKHARD, D.J.M. (2000): Iron-bearing silicate glasses at ambient temperatures. J. Non-Cryst. Solids 275, 175-188.

CARTZ, L. (1964): An X-ray diffraction study of the structure of silica glass. Z. Kristallogr. 120, 241-260.

Cervinka, L. (1988): Medium range order in amorphous materials. J. Non-Cryst. Solids 106, 291-300.

Clark, T.M. \& GrandinetTi, P.J. (2003): Dependence of bridging oxygen ${ }^{17} \mathrm{O}$ quadrupolar coupling parameters on $\mathrm{Si}-\mathrm{O}$ and Si-O-Si angle. J. Phys. Condens. Matter 15, S2387-S2395.

, FloRian, P. \& STEBbins, J.F. (2001): An ${ }^{17} \mathrm{O} N \mathrm{NR}$ investigation of crystalline metasilicate: implications for the determination of local structure in alkali silicates. J. Phys. Chem. B105, 12257-12265.

$$
\&
$$
(2004): Correlated structural distributions in silica glass. Phys. Rev B70, 064202 .

CoOmbs, P.G., De Natale, J.F., Hood, P.J., McElfresh, D.K., WORTMAN, R.S. \& SHACKELFORD, J.F. (1985): The nature of the $\mathrm{Si}-\mathrm{O}-\mathrm{Si}$ bond angle distribution in vitreous silica. Phil. Mag. B51, L39-L42.

Cormier, L., Calas, G., Neuville, D.R. \& Bellissent, R. (2001): A high temperature neutron diffraction study of a titanosilicate glass. J. Non-Cryst. Solids 293-295, 510516.

Gaskell, P.H., Calas, G. \& Soper, A.K. (1998): Medium-range order around titanium in a silicate glass studied by neutron diffraction with isotopic substitution. Phys. Rev. B58, 11322-11330.

Ghaleb, D., Neuville, D.R., Delaye, J.-M. \& CALAS, G. (2003): Chemical dependence of network topol- 
ogy of calcium aluminosilicate glasses: a computer simulation study. J. Non-Cryst. Solids 332, 255-270.

Davila, L.P., Catula, M.-J., Kubota, A., Sadigh, B., Diaz de la Rubia, T.D., Shackelford, J.F., Risbud, S.H. \& GAROFILINI, S.H. (2003): Transformations in the medium range order of fused silica under pressure. Phys. Rev. Lett. 91, 205501

Da Silva, J.R.G.D., Pinatti, D.G., Anderson, C.E. \& Rudee, M.L. (1975): A refinement of the structure of vitreous silica. Phil. Mag. 31, 713-717.

De Jong, B.W.H.S., KeEFER, K.D., Brown, G.E., JR. \& TAYLOR, C.M. (1981): Polymerization of silicate and aluminate tetrahedra in glasses, melts, and aqueous-solutions. 3. Local silicon environments and internal nucleation in silicate glasses. Geochim. Cosmochim. Acta 45, 1291-1308.

DiCKINSON, J.E. \& HeSS, P.C. (1985): Rutile solubility and titanium coordination in silicate melts. Geochim. Cosmochim. Acta 49, 2289-2296.

Dingwell, D.B. (1992a): Density of some titanium-bearing silicate liquids and the compositional dependence of the partial molar volume of $\mathrm{TiO}_{2}$. Geochim. Cosmochim. Acta 56, 3403-3407.

(1992b): Shear viscosity of alkali and alkaline-earth titanium silicate liquids. Am. Mineral. 77, 270-274.

, Paris, E., Seifert, F., Mottana, A. \& Romano, C. (1994): X-ray absorption study of Ti-bearing silicate glasses. Phys. Chem. Minerals 21, 501-509.

Dupree, E., Holland, D. \& Williams, D.S. (1986): The structure of binary alkali silicate glasses. J. Non-Cryst. Solids 81, 185-200.

\& PetTifer, R.F. (1984): Determination of the $\mathrm{Si}-\mathrm{O}-\mathrm{Si}$ angle distribution in vitreous silica by magic angle spinning NMR. Nature 308, 523-525.

ELLIOTT, S.R. (1991): Medium-range structural order in covalent amorphous solids. Nature 354, 445-452.

EMERSON, J.F. \& BRAY, P.J. (1994): Nuclear magnetic resonance and transmission electron microscopy studies of mixed-alkali silicate glasses. J. Non-Cryst. Solids $\mathbf{1 6 9}$, 87-95.

, Stallworth, P.E. \& BRay, P.J. (1989): High-field ${ }^{29} \mathrm{Si}$ NMR studies of alkali silicate glasses. J. Non-Cryst. Solids 113, 253-259.

Emili, M., Incoccia, I., Mobilio, S., Fagherazzi, G. \& GugLIELMI, M. (1985): Structural investigations of $\mathrm{TiO}_{2}-\mathrm{SiO}_{2}$ glassy and glass-ceramic materials prepared by the sol-gel method. J. Non-Cryst. Solids 74, 129-146.

Evstropyev, K.S. \& Porai-Koshits, E.A. (1972): Discussion on the modern state of the crystalline hypothesis of glass structure. J. Non-Cryst. Solids 11, 170-172.
FABER, T.E. \& ZiMAN, J.M. (1965): A theory of binary metal alloys. Phil. Mag. 11, 153-173.

FARGES, F. (1996): Coordination of Ti in crystalline and glassy fresnoites: a high resolution XANES spectroscopy study at the Ti $K$-edge. J. Non-Cryst. Solids 204, 53-64.

(1997): Coordination of $\mathrm{Ti}^{4+}$ in silicate glasses: a high resolution XANES spectroscopy study at the Ti $K$ edge. Am. Mineral. 82, 36-43.

(1999): A Ti K-edge EXAFS study of the medium range environment around $\mathrm{Ti}$ in oxide glasses. J. NonCryst. Solids 244, 25-33.

Brown, G.E., NAVRotsky, A., Gan, H. \& Rehr, J.J. (1996): Coordination chemistry of Ti(IV) in silicate glasses and melts. II. Glasses at ambient temperature and pressure. Geochem. Cosmochim. Acta 60, 3039-3053.

Lefrere, Y., Rossano, S., Berthereau, A., Calas, G. \& BRown, G.E., JR. (2004): The effect of redox state on the local structural environment of iron in silicate glasses: a combined XAFS spectroscopy, molecular dynamics, and bond valence study. J. Non-Cryst. Solids 344, 176-188.

Rossano, S., Lefrere, Y., Wilke, M. \& Brown, G.E., JR. (2005): Iron in silicate glasses: a systematic analysis of pre-edge, XANES and EXAFS features. Physica Scripta, in press.

Farnan, I., GrandinetTi, P.J., Baltisberger, J.H., Stebbins, J.F., Werner, U., Eastman, M.A. \& Pines, A. (1992): Quantification of the disorder in network modified silicate glasses. Nature 358, 31-35.

Feng, X., Bresser, W.J. \& Boolchand, P. (1997): Direct evidence for stiffness threshold in chalcogenide glasses. Phys. Rev. Lett. 78, 4422-4425.

Fleet, M.E., Herzberg, C.T., Henderson, G.S., Crozier, E.D., Osborne, M.D. \& SCARfe, C.M. (1984): Coordination of $\mathrm{Fe}, \mathrm{Ga}$ and $\mathrm{Ge}$ in high pressure glasses by Mössbauer, Raman and X-ray absorption spectroscopy, and geological implications. Geochim. Cosmochim. Acto 48, 1455-1466.

Florian, P., Vermillion, K.E., Grandinetti, P.J., Farnan, I. \& StEBBins, J.F. (1996): Cation distribution in mixed alkali disilicate glasses. J. Am. Chem. Soc. 118, 3493-3497.

FRYDMAN, L. \& HARWOOD, J.S. (1995): Isotropic spectra of half-integer quadrupolar spins from bidimensional magicangle spinning NMR. J. Am. Chem. Soc. 117, 5367-5368.

FurukaWA, T. \& White, W.B. (1980): Vibrational spectra and glass structure. J. Non-Cryst. Solids 38-39, 87-92.

GaleEner, F.L. (1982): Planar rings in glasses. Solid State Commun. 44, 1037-1040.

(1988): Current models for amorphous $\mathrm{SiO}_{2}$. In The Physics and Technology of Amorphous SiO* (R.A.B. Devine, ed.). Plenum Press, New York, N.Y. 
(1990): The structural and vibrational excitations of simple glasses. J. Non-Cryst. Solids 123, 182-196.

\& Wright, A.C. (1986): The J.C. Phillips model for vitreous $\mathrm{SiO}_{2}$ : a critical appraisal. Solid State Commun. 57, 677-682.

Galoisy, L., Calas, G. \& Arrio, M.A. (2001): High-resolution XANES spectra of iron in minerals and glasses: structural information from the pre-edge region. Chem. Geol. 174, 307-319.

GASKELl, P.H. (1975): Construction of a model for amorphous tetrahedral materials using ordered units. Phil. Mag. 32, 211-229.

(1995): Structure, glass formation and properties. $J$. Non-Cryst. Solids 192-193, 9-22.

, Eckersley, M.C., Barnes, A.C. \& Chieux, P. (1991): Medium-range order in the cation distribution of a calcium silicate glass. Nature 350, 675-677.

\& TARRANT, I.D. (1980): Refinement of a random network model for vitreous silicon dioxide. Phil. Mag. B42, 265-286

\& Wallis, D.J. (1996) Medium-range order in silica, the canonical network glass. Phys. Rev. Lett. 76, 66-69.

Gee, B., Janseen, M. \& Eckert, H. (1997): Local cation environments in mixed alkali silicate glasses studied by multinuclear single and double resonance magic-angle spinning NMR. J. Non-Cryst. Solids 215, 41-50.

Gerber, T. \& Himmel, B. (1986): The structure of silica glass. J. Non-Cryst. Solids 83, 324-334.

GladDEN, L.F. (1990a): Computer modelling studies of 4-2 coordinated glasses. J. Non-Cryst. Solids 123, 22-25.

(1990b): Medium-range order in $\mathrm{v}^{-\mathrm{SiO}_{2}}$. J. NonCryst. Solids 119, 318-330.

Goodman, C.H.L. (1975): Strained mixed cluster model for glass structure. Nature 257, 370-372.

(1985): The structure and properties of glass and the strained mixed cluster model. Phys. Chem. Glasses 26, 1-10.

(1986): The structure of silica glass and its surface. Phys. Chem. Glasses 27, 27-31.

Goodwin, D.W. \& Lindop, A.J. (1970): The crystal structure of $\mathrm{CaO} \cdot 2 \mathrm{Al}_{2} \mathrm{O}_{3}$. Acta Crystallogr. B26, 1230-1235.

GREAVES, G.N. (1985): EXAFS and the structure of glass. $J$. Non-Cryst. Solids 71, 203-217.

(1998): Structural studies of the mixed alkali effect in disilicate glasses. J. Non-Cryst. Solids 71, 203-217.
Fontaine, A., Lagarde, P., RaOux, D. \& Gurman, S.J. (1981): Local structure of silicate glasses. Nature $\mathbf{2 9 3}$, 611-616.

Gurman, S.J., Catlow, C.R.A., Chadwick, A.V., Houdewalter, S., Henderson, C.M.B. \& Dobson, B.R. (1991): A structural basis for ionic-diffusion in oxide glasses. Phil. Mag. A64, 1059-1072.

Greegor, R.B., Lytle, W.B., SAndstrom, D.R., Wong, J. \& Schultz, P. (1983): Investigation of $\mathrm{TiO}_{2}-\mathrm{SiO}_{2}$ glasses by X-ray absorption spectroscopy. J. Non-Cryst. Solids 55, 27-43.

GutTMAn, L. (1990): Ring structure of the crystalline and amorphous forms of silicon dioxide. J. Non-Cryst. Solids 116, 154-147.

HAJDU, F. (2000): Tracing the origin of the first sharp diffraction peak (FSDP) of sodium metaphosphate glass and melt. J. Non-Cryst. Solids 277, 15-21.

Hanada, T. \& Soga, N. (1980): Co-ordination of titanium in sodium titanium silicate glasses, J. Non-Cryst. Solids 38-39, 105-110.

Hannon, A.C., Vessal, B. \& Parker, J.M. (1992): The structure of alkali silicate glasses. J. Non-Cryst. Solids 150, 97-102.

Hater, W., Muller-Warmuth, W., Meier, M. \& Fischat, G.H. (1989): High resolution solid state NMR studies of mixed-alkali silicate glasses. J. Non-Cryst. Solids 113, 210-212.

HawthoRne, F.C. (1992): Structure of glasses of geological interest: applying spectroscopic techniques. Mater. Res. Soc. Bull. 17, 53-59.

Henderson, G.S. (1995): A Si K-edge EXAFS/XANES study of sodium silicate glasses. J. Non-Cryst. Solids 183, 4350.

(2002): The application of synchrotron radiation to amorphous materials. In Synchrotron Radiation: Earth, Environmental, and Materials Sciences Applications (G.S Henderson \& D.R. Baker, eds.). Mineral. Assoc. Can., Short-Course Ser. 30, 159-178.

\& FLEET, M.E. (1995): The structure of Ti silicate glasses by micro-Raman spectroscopy. Can. Mineral. $\mathbf{3 3}$ 399-408.

\& ______ (1997): The structure of titanium silicate glasses investigated by $\mathrm{Si} K$-edge X-ray absorption spectroscopy. J. Non-Cryst. Solids 211, 214-221.

\& BANCROFT, G.M. (1984): An X-ray scattering study of vitreous $\mathrm{KFeSi}_{3} \mathrm{O}_{8}$ and $\mathrm{NaFeSi}_{3} \mathrm{O}_{8}$ and reinvestigation of vitreous $\mathrm{SiO}_{2}$ using quasi-crystalline modelling. J. Non-Cryst. Solids 68, 333-349. 
Liu, X. \& FleEt, M.E. (2002): A Ti L-edge absorption study of Ti silicate glasses. Phys. Chem. Minerals 29, 32-42.

$$
\&
$$
(2003): Titanium coordination in silicate glasses investigated using O K-edge X-ray absorption spectroscopy. Mineral. Mag. 67, 597-607.

\& WANG, H. (2002): Germanium coordination and the germanate anomaly. Eur. J. Mineral. 14, 733-744.

Henninger, E.H., Buschert, R.C. \& Heaton, L. (1967): Atomic structure and correlation in vitreous silica by x-ray and neutron diffraction. J. Phys. Chem. Solids 28, 423-432.

Herms, G. \& Steil, H. (1980): The pentagonal dodecahedral model of vitreous silica and its compatibility with diffraction experiments. Krist. Tech. - Cryst. Res. Tech. 15, 879-884.

Hicks, J.F.G. (1967): Structure of silica glass. Science $\mathbf{1 5 5}$, 459-461.

Hidaka, H., Imamoto, N., Umesaki, N., Fukunaga, T. \& SUZUKI, K. (1985): Structural analysis of sodium silicate glasses containing $\mathrm{TiO}_{2}$ by pulsed neutron scattering. $J$. Mater. Sci. 20, 2497-2502.

Holland, D., Mekki, A., Gee, I.A., McConville, C.F., Johnson, J.A., Johnson, C.E., Appleyard, P. \& Thomas, M. (1999): The structure of sodium iron silicate glass - a multitechnique approach. J. Non-Cryst. Solids 253, 192-202.

HuAng, L. \& CoRmack, A.N. (1990): The structure of sodium silicate glass. J. Chem. Phys. 93, 8180-8186.

\& (1991): Structural differences and phase separation in alkali silicate glasses. J. Chem. Phys. 95, 3634-3642.

\& KiefFeR, J. (2004a): Amorphous-amorphous transitions in silica glass. I. Reversible transitions and thermochemical anomalies. Phys. Rev. B69, 224203.

\&

(2004b): Amorphous-amorphous transitions in silica glass. II. Irreversible transitions and densification limit. Phys. Rev. B69, 224204.

Inamura, Y., Katayam, Y., Utsumi, W. \& Fuankoshi, K.-I. (2004): Transformations in the intermediate-range structure of $\mathrm{SiO}_{2}$ glass under high pressure and temperature. Phys. Rev. Lett. 93, 015501.

Ingram, M.D. (1987): Ionic-conductivity in glass. Phys. Chem. Glasses 28, 215.

(1989): Ionic conductivity and glass structure. Phil. Mag. B60, 729-740.

\& Roling, B. (2003): The concept of matrix-mediated coupling: a new interpretation of mixed cation effects in glass. J. Conden. Matter Phys. 15, S1595-S1605.
IsARD, J.O. (1969): The mixed alkali effect in glass. J. NonCryst. Solids 1, 235-261.

Jackson, W.E., Mustre De Leon, J., Brown, G.E., JR., WAYCHUNAS, G.A., CONRADSON, S.D. \& COMBES, J.-M. (1993): High temperature XAS study of $\mathrm{Fe}_{2} \mathrm{SiO}_{4}$ liquid: reduced coordination of ferrous iron. Science 262, 229-239.

Jayasuriya, K., O’Neill, H.St.C., Berry, A.J. \& Campbell, S.J. (2004): A Mössbauer study of the oxidation of $\mathrm{Fe}$ in silicate melts. Am. Mineral. 89, 1597-1609.

Johnson, J.A., Johnson, C.E., Holland, D., Mekri, A., ApPleyARD, P. \& ThOMAs, M.F. (1999): Transition metal ions in ternary sodium silicate glasses: a Mössbauer and neutron study. J. Non-Cryst. Solids 246, 104-114.

Johnson, P.A.V., Wright, A.C. \& SinclaiR, R.N. (1983): Neutron scattering from vitreous silica. II. Twin-axis diffraction experiments. J. Non-Cryst. Solids 58, 109-130.

KIRCHEIM, R. (2001): The mixed alkali effect as a consequence of network density and site energy distribution. J. NonCryst. Solids 272, 85-102.

KIRKPATRICK, R.J. (1988): MAS NMR spectroscopy in minerals and glasses. In Spectroscopic Methods in Mineralogy and Geology (F.C. Hawthorne, ed.). Rev. Mineral. 18 , 341-403.

Konnert, J.H., D’Antonio, P. \& Karle, J. (1982): Comparison of radial distribution function for silica glass with those for various bonding topologies: use of correlation function. J. Non-Cryst. Solids 53, 135-141.

Ferguson, G.A. \& KarLe, J. (1974): Structure of silica glass: rebuttal. Science 184, 93-93.

\& KARLE, J. (1972): Tridymite-like structure in silica glass. Nature Phys. Sci. 236, 92-94.

\& __ (1973a): Crystalline ordering in silica and germania glasses. Science 179,177-179.

\& (1973b), The computation of radial distribution functions for glassy materials. Acta Crystallogr. A29, 702-710.

KUSABIRAKI, K. (1987): Infrared and Raman spectra of vitreous silica and sodium silicates containing titanium. $J$. Non-Cryst. Solids 95-96, 411-418.

LACOuRSE, W.C. (1987): A defect model for the mixed alkali effect. J. Non-Cryst. Solids 95-96, 905-912.

LACY, E.D. (1963): Aluminium in glasses and melts. Phys. Chem. Glasses 4, 234-238.

LeBAIL, A. (1995): Modelling the silica glass structure by the Rietveld method. J. Non-Cryst. Solids 183, 39-42.

LEBEDEV, A.A. (1921): On the polymorphism and annealing of glass. Trudy Gos. Opt. Inst. 2, 1-20 (in Russ.). 
LEE, J.H. \& ElLiotT, S.R. (1994): Simulation of void-filled vitreous silica to interpret the origin of the first sharp diffraction peak. Phys. Rev. B50, 5981-5987.

LeE, S.K., Cody, G.D., FeI, Y. \& Mysen, B.O. (2004): Nature of polymerization and properties of silicate melts and glasses at high pressure. Geochim. Cosmochim. Acta $\mathbf{6 8}$, 4189-4200.

\& STEBbins, J.F. (2003): Nature of cation mixing and ordering in Na-Ca silicate glasses and melts. J. Phys. Chem. B107, 3141-3148.

LEKo, V. K. (1993): The structure of vitreous silica. Glass Phys. Chem. 19, 351-374.

MaAss, P., Bunde, A. \& Ingram, M.D. (1992): Ion transport anomalies in glasses. Phys. Rev. Lett. 68, 3064-3067.

Maekawa, H., Maekawa, T., Lawamura, K. \& Yokokawa, T. (1991): The structure groups of alkali silicate glasses determined from ${ }^{29}$ Si MAS-NMR. J. Non-Cryst. Solids 127, 53-64.

Magnien, V., Neuville, D.R., Cormier, L., Mysen, B.O., Briois, V., Belin, S., Pinet, O. \& Richet, P. (2004): Kinetics of iron oxidation in silicate melts: a preliminary XANES study. Chem. Geol. 213, 253-263.

Marians, C.S. \& BurdetT, J.K. (1990): Geometric constraints: a refined model for the structure of silica glass. $J$. Non-Cryst. Solids 124, 1-21.

\& HobBs, L.W. (1990): Local structure of silica glasses. J. Non-Cryst. Solids 119, 269-282.

Matson, D.W., Sharma, S.K. \& Philpotts, J.A. (1983): The structure of high-silica alkali-silicate glasses. A Raman spectroscopic investigation. J. Non-Cryst. Solids 58, 323-325.

Mauri, F., Pasquarello, A., Pfrommr, B.G., Yoon, Y.-G. \& LouIE, S.G. (2000): Si-O-Si bond-angle distribution in vitreous silica from first principles ${ }^{29} \mathrm{Si}$ NMR analysis. Phys. Rev. B62, R4786-R4789.

McMillan, P.F. \& Wolf, G.H. (1995): Vibrational spectroscopy of silicate liquids. In Structure, Dynamics, and Properties of Silicate Melts (J.F. Stebbins, P.F. McMillan \& D.B. Dingwell, eds.). Rev. Mineral. 32, 247-315.

Meade, C., Hemley, R.J. \& Mao, H.K. (1992): High pressure X-ray diffraction of $\mathrm{SiO}_{2}$ glass. Phys. Rev. Lett. 69, 1387-1390.

Meneau, F., Greaves, G.N., Winter, R. \& Vails, Y. (2001): WAXS and NMR studies of intermediate and short-range order in $\mathrm{K}_{2} \mathrm{O}-\mathrm{SiO}_{2}$ glasses. J. Non-Cryst. Solids 293-295, 693-699.

Micoulaut, M. \& Phillips, J.C. (2003): Rings and rigidity transitions in network glasses. Phys.l Rev. B67, 104204.
Misawa, M., Price, D.L. \& SuZuKi, K. (1980): The short-range structure of alkali disilicate glasses by pulsed neutron total scattering. J. Non-Cryst. Solids 37, 85-97.

Morikawa, H., Miwa, S.-I., Miyake, M., Marumo, F. \& Sata, T. (1982): Structural analysis of $\mathrm{SiO}_{2}-\mathrm{Al}_{2} \mathrm{O}_{3}$ glasses. $J$. Am. Ceram. Soc. 65, 78-81.

Moynihan, C.T. (1995): Structural relaxation and the glass transition. In Structure, Dynamics, and Properties of Silicate Melts (J.F. Stebbins, P.F. McMillan, \& D.B. Dingwell, eds.). Rev. Mineral. 32, 1-19.

Mozzi, R.L. \& WARREN, B.E. (1969): The structure of vitreous silica. J. Appl. Crystallogr. 2, 164-172.

Murdoch, J.B., Stebbins, J.F. \& CARMichael, I.S.E. (1985): High resolution ${ }^{29} \mathrm{Si}$ NMR study of silicate and aluminosilicate glasses: the effect of network-modifying cations. Am. Mineral. 70, 745-766.

Mysen, B.O. (2003): Physics and chemistry of silicate glasses and melts. Eur. J. Mineral. 15, 781-802.

\& NeuVILLE, D.R. (1995): Effect of temperature and $\mathrm{TiO}_{2}$ content on the structure of $\mathrm{Na}_{2} \mathrm{SiO}_{5}-\mathrm{Na}_{2} \mathrm{Ti}_{2} \mathrm{O}_{5}$ melts and glasses. Geochim. Cosmochim. Acta 59, 325-342.

SEIfERT, F. \& VIRGO, D. (1980): The influence of $\mathrm{TiO}_{2}$ on the structure and derivative properties of silicate melts. Am. Mineral. 65, 1150-1165.

VIRGO, D. \& SEIFERT, F.A. (1982): The structure of silicate melts: implications for chemical and physical properties of natural magma. Rev. Geophys. 20, 353-383.

NAGATA, K. \& HAyAshi, M. (2001): Structure relaxation of silicate melts containing iron oxide. J. Non-Cryst. Solids 282, 1-6.

Nakamura, M., Arai, M., Inamura, Y. \& Otomo, T. (2003): Dynamical properties of vitreous silica around the first sharp diffraction peak. Phys. Rev. B67, 064204.

, Otomo, T., InAmura, Y. \& BenNington, S.M. (2001): Dispersive excitation in different forms of $\mathrm{SiO}_{2}$. J. Non-Cryst. Solids 293-295, 377-382.

Nanri, H., TAKeuchi, N., Ishida, S., Watanabe, K. \& WaKaMATSU, M. (1996) Mineralizing action of iron in amorphous silica. J. Non-Cryst. Solids 203, 375-379.

NARTEN, A.H. (1972): Diffraction pattern and structure of non-crystalline $\mathrm{BeF}_{2}$ and $\mathrm{SiO}_{2}$ at $25^{\circ} \mathrm{C}$. J. Chem. Phys. 56, 1905-1909.

Neuville, D.R., Cormier, L. \& Massiot, D. (2004a): Al environment in tectosilicate and peraluminous glasses: a ${ }^{27} \mathrm{Al}$ MQ-MAS-NMR, Raman and XANES investigation. Geochim. Comsochim. Acta 68, 5071-5079.

$$
\text { \& }
$$

(2004b): Al speciation and $\mathrm{Ca}$ environment in calcium aluminosilicate glasses and 
crystals by $\mathrm{Al}$ and $\mathrm{Ca} \mathrm{K}$-edge $\mathrm{X}$-ray absorption spectroscopy. Chem. Geol. 213, 153-163.

Ohno, H., Kohara, S., Umesaki, N. \& Suzuya, K. (2001): High-energy X-ray diffraction studies of non-crystalline materials. J. Non-Cryst. Solids 293-295, 125-135.

Olivier, L., Yuan, X., Cormack, A.N. \& JäGer, C. (2001): Combined ${ }^{29} \mathrm{Si}$ double quantum NMR and MD simulation studies of network connectivities of binary $\mathrm{Na}_{2} \mathrm{O} \cdot \mathrm{SiO}_{2}$ glasses: new prospects and problems. J. Non-Cryst. Solids 293-295, 53-66.

Paris, E., Dingwell, D.B., Seifert, F.A., Mottana, A. \& Romano, C. (1994): Pressure-induced coordination change of Ti in silicate glass: a XANES study. Phys. Chem. Minerals 21, 510-515.

Petit, P.-E., Farges, F., Wilke, M. \& Sole, A. (2001): Determination of the iron oxidation state in Earth materials using XANES pre-edge information. J. Synchr. Rad. 8, 952-954.

PhILLIPS, J.C. (1979): Topology of covalent non-crystalline solids. I. Short-range order in chalcogenide alloys. J. NonCryst. Solids 34, 153-181.

(1982): Spectroscopic and morphological structure of tetrahedral oxide glasses. Solid State Phys. 37, 93-171.

(1985): Structure and selectively enhanced Raman spectra of high-silica alkali-silicate glasses. Phys. Rev. B32, 5350-5355.

Pilla, O., Fontana, A., Caponi, S., Rossi, F., Viliani, G., GonZalez, M.A., Fabiani, E. \& VARSAmis, C.P.E. (2003): Vibrational dynamic of 'strong' glasses: the case of $\mathrm{v}-\mathrm{SiO}_{2}$ and v-GeO ${ }_{2}$. J. Non-Cryst. Solids 322, 53-57.

Ponader, C.W., Boek, H. \& Dickinson, J.E., JR. (1996): $\mathrm{X}$-ray absorption study of the coordination of titanium in sodium-titanium-silicate glasses. J. Non-Cryst. Solids 201, 81-94.

PoraI-Koshits, E.A. (1958): The possibilities and results of $\mathrm{x}$-ray methods for investigation of glassy substances. In The Structure of Glass (A.A. Lebedev, ed.). Consultants Bureau, New York, N.Y. (25-35).

(1990): Genesis of concepts on structure of inorganic glasses. J. Non-Cryst. Solids 123, 1-13.

Price, D.L., Moss, S.C., ReiJers, R., SAboungi, M.L. \& SusMAN, S. (1988): Intermediate-range order in glasses and liquids. J. Phys. C21, L1069-L1072.

RANDALL, J.T., RoOKSBY, H.P. \& COOPER, B.S. (1930): X-ray diffraction and the structure of vitreous solids. Z. Kristal$\log$. 75, 196-214.

RAO, B.V.J. (1963): The dual role of titanium in the system $\mathrm{K}_{2} \mathrm{O} \cdot \mathrm{SiO}_{2} \cdot \mathrm{TiO}_{2}$. Phys. Chem. Glasses 4, 22-34.
Risbud, S.H., KiRKPATRICK, R.J.,TAglialaVoRe, A.P. \& MONTEZ, B. (1987): Solid state NMR evidence of 4-fold, 5-fold, and 6-fold aluminum sites in roller-quenched $\mathrm{SiO}_{2}-\mathrm{Al}_{2} \mathrm{O}_{3}$ glasses. J. Am. Ceram. Soc. 70, C10-C12.

RoBinson, H.A. (1965): On the structure of vitreous $\mathrm{SiO}_{2}$. I. A new pentagonal dodecahedral model. J. Phys. Chem. Solids 26, 209-222.

Roskosz, M., Toplis, M.J. \& RicheT, P. (2004): The structural role of Ti in aluminosilicate liquids in the glass transition range: insights from heat capacity and shear viscosity measurements. Geochim. Cosmochim. Acta 68, 591-606.

Rossano, S., Balan, E., Morin, G., Bauer, J.-P., Calas, G. \& BROUDER, C. (1999): ${ }^{57} \mathrm{Fe}$ Mössbauer spectroscopy of tektites. Phys. Chem. Minerals 26, 530-538.

Ramos, A.Y. \& Delaye, J.-M. (2000a): Environment of ferrous iron in $\mathrm{CaFeSi}_{2} \mathrm{O}_{6}$ glass; contributions of EXAFS and molecular dynamics. J. Non-Cryst. Solids 273, 48-52.

Creux, S., FilipPoni, A., Brouder, C.H. \& CALAS, G. (2000b): EXAFS and molecular dynamics combined study of $\mathrm{CaO}-\mathrm{FeO}-2 \mathrm{SiO}_{2}$ glass. New insight into site significance in silicate glasses. Europhys. Letters 49, 597-602.

Roy, R. (1974): Structure of silica glass. Science 184, 91-92.

Sandstrom, D.R., Lytle, F.W., Wei, P., Greegor, R.B., Wong, J. \& Schultz, P. (1980): Coordination of Ti in $\mathrm{TiO}_{2}-\mathrm{SiO}_{2}$ glasses by X-ray absorption spectroscopy. $J$. Non-Cryst. Solids 41, 201-207.

Schmucker, M., Mackenzie, K.J.D., Schneider, H. \& MEINHOLD, R. (1997): NMR studies on rapidly solidified $\mathrm{SiO}_{2}-\mathrm{Al}_{2} \mathrm{O}_{3}$ and $\mathrm{SiO}_{2}-\mathrm{Al}_{2} \mathrm{O}_{3}-\mathrm{Na}_{2} \mathrm{O}$ glasses. J. Non-Cryst. Solids 217, 99-105.

SChNeider, E., Stebbins, J.F. \& Pines, A. (1987): Speciation and local structure in alkali and alkaline earth silicate glasses: constraints from ${ }^{29} \mathrm{Si}$ NMR spectroscopy. J. NonCryst. Solids 89, 371-383.

Selvanathan, D., Bresser, W.J. \& Boolchand, P. (2000): Stiffness transitions in $\mathrm{Si}_{x}-\mathrm{Se}_{1-x}$ glasses from Raman scattering and temperature modulated differential scanning calorimetry. Phys. Rev. B61, 15061-15076.

Sen, P.N. \& Thorpe, M.F. (1977): Phonons in $\mathrm{AX}_{2}$ glasses - from molecular to band-like modes. Phys. Rev. B15, 4030-4038.

Sen, S. \& Youngman, R.E. (2003): NMR study of Q-speciation and connectivity in $\mathrm{K}_{2} \mathrm{O}-\mathrm{SiO}_{2}$ glasses with high silica content. J. Non-Cryst. Solids 331, 100-107.

Smith, J.V. \& Blackwell, C.S. (1983): Nuclear magnetic resonance of silica polymorphs. Nature 303, 223-225. 
Smith, W., Greaves, G.N. \& Gillan, M.J. (1995): The structure and dynamics of sodium disilicate glass by molecular simulation. J. Non-Cryst. Solids 192-193, 267-271.

Soltay, L.G. \& Henderson, G.S. (2005): Structural differences between lithium silicate and lithium germanate glasses by raman spectroscopy. Phys. Chem. Glasses, in press.

SoulEs, T.F. (1990): Computer-simulation of glass structures. J. Non-Cryst. Solids 123, 48-70.

Sprenger, D., BaCh, H., Meisel, W. \& Gütlich, P. (1993): Discrete bond model (DBM) of sodium silicate glasses derived from XPS, Raman and NMR measurements. $J$. Non-Cryst. Solids 159, 187-203.

Stebbins, J.F. (1987): Identification of multiple structural species in silicate glasses by ${ }^{29} \mathrm{Si}$ NMR. Nature 330, 465-467.

(1988): NMR spectroscopy and dynamic processes in mineralogy and geochemistry. In Spectroscopic Methods in Mineralogy and Geology (F.C. Hawthorne, ed.). Rev. Mineral. 18, 405- 429.

(1995): Dynamics and structure of silicate and oxide melts: nuclear magnetic resonance studies. In Structure, Dynamics, and Properties of Silicate Melts (J.F. Stebbins, P.F. McMillan \& D.B. Dingwell, eds.). Rev. Mineral. 32, 141-245.

(1998): Cation sites in mixed-alkali oxide glasses: correlations of NMR chemical shift data with site size and bond distance. Solid State Ionics 112, 137-141.

McMillan, P.F. \& Dingwell, D.B., eds. (1995): Structure, Dynamics and Properties of Silicate Melts. Rev. Mineral. 32, 1-616.

Murdoch, J.B., Schneider, E., CARMichael, I.S.E. \& PINES, A. (1985): A high-temperature high-resolution NMR study of NA-23, Al-27 and Si-29 in molten silicates. Nature 314, 250-252.

Zhao, P., LeE, S.K. \& Oglesby, J.V. (2001): Direct observation of multiple oxygen sites in oxide glasses: recent advances from triple quantum, magic angle spinning nuclear magnetic resonance. J. Non-Cryst. Solids 293-295, 67-73.

Stevenson, R.J., Dingwell, D.B., Webb, S.L. \& BagdassaROV, N.S. (1995): The equivalence of enthalpy and shear stress relaxation in rhyolitic obsidians and quantification of the liquid-glass transition in volcanic processes. J. Volcan. Geotherm. Res. 68, 297-306.

Sunyer, E., Jund, P. \& Jullien, R. (2002): Characterization of channel diffusion in a sodium tetrasilicate glass via molecular-dynamics simulations. Phys. Rev. B65, 214203.

Swenson, J. \& BÖRJESSON, L. (1998): Intermediate range ordering in a network glass. J. Non-Cryst. Solids 223, 223-229.
, Matic, A., Karlsson, C., Börjesson, L. Meneghini, C. \& Howells, W.S. (2001): Random ion model: a structural approach to the mixed alkali effect in glasses. Phys. Rev. B63, 132202.

TAKei, T., Kameshima, Y., Yasumori, A., OKada, K., Kumada, N. \& Kinomura, N. (2001): SAX analysis of textures formed by phase separation and crystallization of $\mathrm{Al}_{2} \mathrm{O}_{3}-\mathrm{SiO}_{2}$ glasses. J. Non-Cryst. Solids 282, 265-277.

TAYlor, M. \& BROWN, G.E., JR. (1979a): Structure of mineral glasses. I. The feldspar glasses $\mathrm{NaAlSi}_{3} \mathrm{O}_{8}, \mathrm{KAlSi}_{3} \mathrm{O}_{8}$, $\mathrm{CaAl}_{2} \mathrm{Si}_{2} \mathrm{O}_{8}$. Geochim. Cosmochim. Acta 43, 61-75. (1979b): Structure of mineral glasses. II. The $\mathrm{SiO}_{2}-\mathrm{NaAlSiO}_{4}$ join. Geochim. Cosmochim. Acta 43, 1467-1473

Thorpe, M.F. (1983): Continuous deformations in random networks. J. Non-Cryst. Solids 57, 355-370.

\& De Leeuw, S.W. (1986): Coulomb effects in disordered solids. Phys. Rev. B33, 8490-8505.

JaCobs, D.J., Chubynsky, M.V. \& Phillips, J.C. (2000): Self-organization in network glasses. J. Non-Cryst. Solids 266-269, 859-166.

Toplis, M.J., Dingwell, D.M. \& Lenci, T. (1997): Peraluminous viscosity maxima in $\mathrm{Na}_{2} \mathrm{O}-\mathrm{Al}_{2} \mathrm{O}_{3}-\mathrm{SiO}_{2}$ liquids: the role of oxygen triclusters in silicate melts. Geochim. Cosmochim. Acta 61, 2605-2612.

Tranchenko, K., Dove, M.T., Brazhinin, V. \& El'Kin, F.S (2004): Network rigidity and properties of $\mathrm{SiO}_{2}$ and $\mathrm{GeO}_{2}$ glasses under pressure. Phys. Rev. Lett. 93, 135502.

Tucker, M.G., Keen, D.A., Dove, M.T. \& Trachenko, K. (2005): Refinement of the Si-O-Si angle distribution in vitreous silica. J. Phys. Condens. Matter 17, S67-S75.

Uchino, T., Harrop, J.D., TARaskin, S.N. \& Elliott, S.R. (2005): Real and reciprocal space structural correlations contributing to the first sharp diffraction peak in silica glass. Phys. Rev. B71, 014202.

\& YoKo, T. (1999): Sodium and lithium environments in single- and mixed-alkali silicate glasses. An ab Initio molecular orbital study. J. Phys. Chem. B103, 1854-1858.

Vaills, Y., Qu, T., Micoulaut, M., Chaimbault, F. \& BoolCHAND, P. (2005): Direct evidence of rigidity loss and selforganization in silicate glasses. Europhys. Lett., in press.

Vedishcheva, N.M., Shakhmatkin, B.A., Shultz, M.M., VesSal, B., Wright, A.C., Bachra, B., Clare, A.G., Hannon, A.C. \& SinclaIR, R.N. (1995): A thermodynamic, molecular dynamics and neutron diffraction investigation of the distribution of tetrahedral $\left\{\mathrm{Si}^{(\mathrm{n})}\right\}$ species and the network of modifying cation environment in alkali silicate glasses. J. Non-Cryst. Solids 192-193, 292-297. 
Vessal, B., Greaves, G.N., Marten, P.T., Chadwick, A.V., Mole, R. \& Houde-Walter, S. (1992): Cation microsegregation and ionic mobility in mixed alkali glasses. Nature 356, 504-506.

Wright, A.C. \& Hannon, A.C. (1996): Alkali silicate glasses: interpreting neutron diffraction results using the molecular simulation technique. J. Non-Cryst. Solids 196, 233-238.

Vogel, W. (1971): Structure and Crystallization of Glasses. Pergamon Press, New York, N.Y.

Wang, Y., Boolchand, P. \& Micoulaut, M. (2000): Glass structure, rigidity transitions and the intermediate phase in the Ge-As-Se ternary. Europhys. Lett. 52, 633-639.

WARREN, B.E. (1934): The diffraction of X-rays in glass. Phys. Rev. 45, 657-661.

\& Biscoe, J. (1938): Fourier analysis of X-ray patterns of soda-silica glass. J. Am. Ceram. Soc. 21, 259-265.

WebB, S.L. \& Dingwell, D.B. (1994): Compressibility of titanosilicate melts. Contrib. Mineral. Petrol. 118, 157168.

Wilke, M., Partzsch, G.M., Bernhardt, R. \& Lattard, D. (2004): Determination of the iron oxidation state in basaltic glasses using XANES at the $K$-edge. Chem. Geol. 213, 71-87.

Winkler, A., Horbach, J., Kob, W. \& Binder, K. (2004): Structure and diffusion in amorphous aluminum silicate: a molecular dynamics computer simulation. J. Chem. Phys. 120, 384-393.

Wong, J. \& ANGELl, C.A. (1976): Glass Structure by Spectroscopy. Marcel Dekker, New York, N.Y.

WRIGHT, A.C. (1990): Diffraction studies of glass structure. $J$. Non-Cryst. Solids 123, 129-148.

(1994): Neutron scattering from vitreous silica. $\mathrm{V}$. The structure of vitreous silica: what have we learned from 60 years of diffraction studies? J. Non-Cryst. Solids 179, 84-115.
Clare, A.G., Bachra, B., Sinclair, R.N., HanNON, A.C. \& VeSSAL, B. (1991b): Neutron diffraction studies of silicate glasses. Trans. Am. Crystallogr. Soc. 27, 239-254.

Etherington, G., Desa, J.A.E., Sinclair, R.N., CONNELl, G.A.N. \& MikKelSEN, J.C., JR. (1982): Neutron amorphography. J. Non-Cryst. Solids 49, 63-102.

Hulme, R.A., Grimley, D.I., Sinclair, R.N., Martin, S.W., Price, D.L. \& Galeener, F.L. (1991a): The structure of some simple amorphous network solids revisited. J. Non-Cryst. Solids 129, 213-232.

YARKER, C.A., JoHnSON, P.A.V. \& WedGWOOD, F.A. (1987): Neutron scattering techniques for structural studies of amorphous solids. In Non-Crystalline Solids (G.H. Fischat, ed.). Trans. Tech. Alfred University, Alfred, N.Y. (118-123).

YAP, A.T.-W. \& ELLIOTT, S.R. (1995): A study of the mixedalkali effect in disilicate glasses using ${ }^{7} \mathrm{Li}$ nuclear magnetic resonance. J. Non-Cryst. Solids 192-193, 207-211.

Yarker, C.A., Johnson, P.A.V., Wright, A.C., Wong, J., GreEgoR, R.B., Lytle, F.W. \& Sinclair, R.N. (1986): Neutron diffraction and EXAFS evidence for $\mathrm{TiO}_{5}$ units in vitreous $\mathrm{K}_{2} \mathrm{O} \bullet \mathrm{TiO}_{2} \bullet 2 \mathrm{SiO}_{2}$. J. Non-Cryst. Solids $\mathbf{7 9}$, 117-136.

Yasui, I., AKasaKa, Y. \& Inoue, H. (1994): Re-examination of detailed structure of alkali silicate glasses based on two types of diffraction data. J. Non-Cryst. Solids 177, 91-96.

ZACHARIASEN, W.H. (1932): The atomic arrangement in glass. J. Am. Chem. Soc. 54, 3841-3850.

ZARZYCKI, J. (1982): Glass structure. J. Non-Cryst. Solids 52, 31-43.

Zhao, J., Gaskell, P.H., Cluckie, M.M. \& Soper, A.K. (1998): A neutron diffraction, isotopic substitution study of the structure of $\mathrm{Li}_{2} \mathrm{O} \cdot 2 \mathrm{SiO}_{2}$ glass. J. Non-Cryst. Solids 232-234, 721-727.

Received February 25, 2005, revised manuscript accepted July 15, 2005. 